Illinois State University

ISU ReD: Research and eData

Theses and Dissertations

$6-11-2018$

\title{
Supporting Intermediate Teachers' Implementation of the NGSS Through a Collaboration Based on Mutuality
}

\author{
Elisha Nichole Swanson \\ Illinois State University, enswans@ilstu.edu
}

Follow this and additional works at: https://ir.library.illinoisstate.edu/etd

Part of the Science and Mathematics Education Commons

\section{Recommended Citation}

Swanson, Elisha Nichole, "Supporting Intermediate Teachers' Implementation of the NGSS Through a Collaboration Based on Mutuality" (2018). Theses and Dissertations. 944.

https://ir.library.illinoisstate.edu/etd/944

This Dissertation is brought to you for free and open access by ISU ReD: Research and eData. It has been accepted for inclusion in Theses and Dissertations by an authorized administrator of ISU ReD: Research and eData. For more information, please contact ISUReD@ilstu.edu. 


\title{
SUPPORTING INTERMEDIATE TEACHERS' IMPLEMENTATION OF THE NGSS THROUGH A COLLABORATION BASED ON MUTUALITY
}

\author{
Elisha Nichole Swanson
}

190 Pages

The Next Generation Science Standards (NGSS) are based on a wealth of research on science education and student learning and written by a range of experts from relevant fields. This study is significant and timely, given the recent release of these standards which are designed to build a scientifically literate and productive society. The potential impact on K-12 students rests on the shoulders of educational professionals in the schools. The elementary level presents a unique set of challenges for quality science instruction, implicating a need for classroom support to address limiting factors. The scope of the study is narrow; a case study approach focused this exploration on a single unit of study- the implementation of an NGSSaligned unit of instruction at one intermediate school. The proposed research questions set the stage to explore how coaching as a delivery of on-going, embedded teacher support can facilitate the transfer of the NGSS from paper to practice; these questions also explored how reform-based initiatives in science can impact teacher perspectives and practices and student learning outcomes. Findings suggest that coaching in science for intermediate teachers that is based on a collaborative partnership supports teachers' shift toward reform-based science teaching which influenced student outcomes. Having a team of educational professionals join forces with a common goal effectively addressed limiting factors present in the research setting. While the coaching approach to professional development (PD) reflected most of the features indicative of 
high-quality PD, within the school district of the research setting, this collaboration was an isolated case of PD in science. In order for changes in teacher practice and student learning to be sustainable and proliferate, support for practitioners must extend beyond one unit of instruction and two teachers.

KEYWORDS: NGSS; Coaching; Professional Development; Science Education 
SUPPORTING INTERMEDIATE TEACHERS' IMPLEMENTATION OF THE NGSS

THROUGH A COLLABORATION BASED ON MUTUALITY

ELISHA NICHOLE SWANSON

A Dissertation Submitted in Partial

Fulfillment of the Requirements for the Degree of

DOCTOR OF EDUCATION

School of Teaching and Learning

ILLINOIS STATE UNIVERSITY 
Copyright 2018 Elisha Nichole Swanson 
SUPPORTING INTERMEDIATE TEACHERS' IMPLEMENTATION OF THE NGSS

THROUGH A COLLABORATION BASED ON MUTUALITY

ELISHA NICHOLE SWANSON

COMMITTEE MEMBERS:

Anthony Lorsbach, Chair

Allison Antink-Meyer

William Hunter 


\section{ACKNOWLEDGMENTS}

The journey to complete this doctoral degree was a long one, and this accomplishment would not have been possible without the support I received from my family and committee members along the way. My faith in God has also provided a source of strength and solace.

My parents always believed in me, pushed me to be my best, and loved me unconditionally through my failures and successes in life. I truly do not know the meaning of sibling rivalry as my older brother and sister have expressed nothing but genuine pride and happiness for me at each milestone. My husband Eric supports my passion for learning and encouraged me to stay the course to obtain my undergraduate and graduate degrees. Ethan, Elahson, Emilia, and Eli are the loves of my life and inspire me to set a good example each day.

It may have taken eight years to complete this particular degree, but this pace meant I did not have to sacrifice precious time with my family. Thank you, Tony, for reminding me of this when I got discouraged at the duration of this academic marathon. Thank you also for always lending a listening ear and offering sound advice at my moments of concern, doubt, and naivety about the research process. To Allison, thank you for pushing me to be a better researcher and writer in the most collegiate and positive way. Willy, I have had the privilege of receiving guidance, mentorship, and an opening of doors from you since I set foot on the ISU campus fifteen years ago. I am honored to have the three of you on my dissertation committee and beyond grateful for the time, effort, and support you have bestowed upon me over the years.

Elizabeth and Ruth, I can never repay you for the opportunity you so graciously gave me to explore these research questions in your classrooms. I was in awe of your ability to care for and shape these young minds and enjoyed our partnership from beginning to end.

E. N.S. 


\section{CONTENTS}

Page

ACKNOWLEDGMENTS

$\begin{array}{ll}\text { CONTENTS ii } & \text { ii }\end{array}$

TABLES vii

FIGURES viii

CHAPTER I: INTRODUCTION 1

Statement of the Problem $\quad 1$

Purpose Statement and Research Questions $\quad 2$

Significance of the Study $\quad 3$

Science Education for an Informed Citizenry 4

Science Education for Equitable Learning Opportunities 4

Science Education: Success Depends Upon Support $\quad 5$

CHAPTER II: REVIEW OF THE LITERATURE

$\begin{array}{ll}\text { The Next Generation Science Standards (NGSS): A Closer Look } & 7\end{array}$

Core Disciplinary Ideas, CDIs $\quad 7$

$\begin{array}{ll}\text { Crosscutting Concepts, CCs } & 7\end{array}$

Science and Engineering Practices $\quad 8$

The Nature of Science $\quad 9$

An Emphasis on STEM and Literacy

Performance Expectations, PEs $\quad 10$

$\begin{array}{ll}\text { Three-Dimensional Learning } & 11\end{array}$

All Standards, All Students 13

$\begin{array}{ll}\text { Implementing the NGSS- Theory to Practice } & 15\end{array}$

The BSCS 5E Instructional Model $\quad 17$

Project-Based Science 17

Subject-Based Learning Versus Project-Based Learning 18

$\begin{array}{ll}\text { Implementing PBS } & 19\end{array}$

$\begin{array}{ll}\text { Challenges at the Elementary Level } & 21\end{array}$

$\begin{array}{ll}\text { Teacher Characteristics } & 22\end{array}$ 
The Call for Professional Development 24

The Goals of Professional Development 27

Features of Effective Professional Development 29

Professional Development with Coaching for Elementary Level Science Teaching 31

Gap in the Literature $\quad 32$

$\begin{array}{ll}\text { CHAPTER III: METHODOLOGY } & 34\end{array}$

Qualitative Methods $\quad 34$

A Case Study Approach $\quad 35$

Research Setting and Participants $\quad 37$

Theoretical Frameworks $\quad 37$

Features of High-Quality PD 38

A Coaching Model for NGSS Implementation $\quad 39$

Changes in Teacher Perspectives and Practices 40

Exploring Student Outcomes $\quad 40$

A Synthesis of Frameworks $\quad 42$

Researcher and Participant Roles $\quad 42$

Data Collection $\quad 44$

Participant Journals $\quad 44$

Semi-Structured Interviews $\quad 44$

Unstructured Interviews

Observations $\quad 45$

Documents 46

$\begin{array}{ll}\text { Data Analysis } & 46\end{array}$

$\begin{array}{ll}\text { Open Coding } & 47\end{array}$

Axial Coding $\quad 47$

$\begin{array}{ll}\text { Constructing Categories } & 47\end{array}$

$\begin{array}{ll}\text { Addressing Validity } & 48\end{array}$

Researcher Bias $\quad 49$

Reactivity $\quad 50$

Reflexivity $\quad 50$

Peer Review $\quad 51$

Respondent Validation or Member Checking 51

Rich Data $\quad 52$

Triangulation $\quad 52$ 
Human Subjects Protocol

Organization of Findings

CHAPTER IV: THE INSTRUCTIONAL UNIT

The Topic- Nature of Science $\quad 55$

Instructional Activities $\quad 55$

Engage $\quad 56$

$\begin{array}{ll}\text { Explore } & 57\end{array}$

Explain $\quad 58$

$\begin{array}{ll}\text { Elaborate } & 60\end{array}$

$\begin{array}{ll}\text { Evaluate } & 60\end{array}$

CHAPTER V: A COACHING MODEL FOR EFFECTIVE PD 64

Effective Features of Professional Development 64

Content is Situated in Practice $\quad 65$

Content is Focused on Student Learning $\quad 67$

The Process Includes a Modeling of Instructional Strategies 67

The Process Situates Teachers as Active Learners $\quad 69$

PD Builds Learning Communities and Supports Collaboration 70

PD is Grounded in School Practice and Integrated with Applicable Reform Efforts 72

PD Activities are On-going and Sustainable $\quad 74$

CHAPTER VI: THE COACHING PROCESS- EVOLUTIONARY CHANGES 83

$\begin{array}{ll}\text { Teacher Characteristics } & 83\end{array}$

The Teachers Were Comfortable with Collaboration $\quad 83$

The Teachers Were Willing to Take Risks $\quad 84$

The Teachers Care Deeply About Student Needs $\quad 87$

The Teachers Were Eager to Identify Misconceptions and Develop PCK 87

The Teachers Were Willing to Learn Alongside Students 90

$\begin{array}{ll}\text { Teacher Needs } & 91\end{array}$

Time $\quad 91$

$\begin{array}{ll}\text { Resources } & 93\end{array}$

$\begin{array}{ll}\text { Support } & 94\end{array}$

Teacher Expectations for Science Coaching 96

Coaching Activities as a Function of Time 99

$\begin{array}{ll}\text { A Starting Point } & 99\end{array}$ 
In the Thick of It

Trust and Dependability

Validation and Appreciation for Equal but Unique Contributions

Teacher Understandings

Relationship Building

NOS Understandings

Use of Science and Engineering Practices

Integration of Skills

Assessment-Centered Outcomes

Formative Assessment for Student Growth

Collaboration 
Coaching as High-Quality PD

The Coaching Process

Limitations of the Study 


\section{TABLES}

Table

Page

1. An Alignment of Research Goals with Qualitative Procedures and Qualities 36

2. How People Learn (HPL) Framework-Perspectives of an Effective Learning 41 Environment

3. A Comparison of Data Sources for the "Coach-Teacher Relationship" Theme 54

4. Alignment of Unit Activities with the Five Phases of the 5E BSCS Instructional Model

5. An Alignment of the NGSS NOS Understandings with the True/False Pre-Quiz Statements and the Six Explore Station Activities

6. An Alignment of the Engineering Project with Project-based Learning Features and NGSS Engineering Principles

7. Alignment of Coaching Approach with Effective Features of PD

8. An Alignment Between the Instructional Activities and the NGSS Science and Engineering Practices

9. Evaluation and Organization of Student Outcomes from the NGSS-Aligned Unit with the HPL Framework.

10. Student Outcomes Commonly Reported Across Multiple Data Sources 


\section{FIGURES}

Figure $\quad$ Page

1. Coaching as Professional Development for NGSS Implementation- Analysis Model 43

2. Data Analysis Example- Using Data to Describe the Coaching Process 48

3. Factors Influencing Expectations for Science Coaching 98

4. An Illustration of Coaching Activities and Participant Contributions over Time 105

5. Components of Mutuality 110

6. Progression of Student Knowledge and Skill over the 5E Phases of Instruction 142 


\section{CHAPTER I: INTRODUCTION}

John Dewey compared a subject-based approach to teaching science with providing students with a map. Although a map is useful and can be used to navigate, receiving it as an end product is not a substitute for the experience and knowledge obtained by the creator in exploring the land first-hand. He wrote, "Let me use the analogy of the difference between an explorer blazing a trail in a new country and the finished map that is constructed after the country has been thoroughly explored. Well, we may first tell what the map is not. The map is not a substitute for personal experience" (as cited by Archambault, 1965, p. 350.) With a strong emphasis on science and engineering practices, core disciplinary ideas (CDIs), and crosscutting concepts (CCs), the Next Generation Science Standards (NGSS) privilege exploration, integration, and application of content knowledge over a coverage of topics (NGSS Lead States, 2013). These dimensions are at the heart of the NGSS and work together to establish expectations for student performance. Applying the NGSS situates students as the trailblazers, with the teacher guiding and facilitating students' journey like a compass along the way.

\section{Statement of the Problem}

A review of the literature on science teaching in elementary schools depicts a set of challenges specific to this learning environment (Appleton, 2007 \& Roth, 2014). Elementary teachers cite a climate of standardized testing in language arts and mathematics, lack of teacher preparation in science and science methods courses, and lack of professional development opportunities in science as obstacles impacting both the quantity and quality of science learning activities they incorporate in their teaching. Yet the demands for teaching in a manner consistent with the NGSS require more instructional time, growth in teachers' pedagogical content knowledge, and professional development to support changes in teacher perceptions and 
practice. The NGSS call for major shifts in instruction and consequently a shift in the roles teachers and students assume in the classroom. Students will collaborate with each other and work with materials to construct knowledge, and teachers will create these engaging, interactive spaces. Passmore (2015) writes, "This is a time when teachers need to know they can stretch themselves to rise to new challenges. They need to be encouraged and supported in taking risks and trying new things with the knowledge that they won't be judged on their first attempts but be given time and space to reflect and improve" (p. 27). The factors limiting the quantity and quality of science instruction at the elementary level are well documented in the literature (McMurrer, 2008). Elementary educators need to build partnerships with faculty who have the expertise and time to focus on developing curricula that adhere to the spirit and intent of the NGSS while also considering the limiting factors present in the learning context.

\section{Purpose Statement and Research Questions}

The goal of this study is to explore how coaching as a mechanism for professional development can support elementary educators' implementation of an NGSS-aligned unit of instruction in the classroom. Coaching provides more teacher autonomy than the processes of evaluating, supervising, and mentoring (Barkley, 2010) and represents a "relationship between two equals committed to an idea of personal and professional improvement" (p. 6). This study is significant and timely, given the recent release of these standards which are designed to build a scientifically literate and productive society. The elementary level presents a unique set of challenges for quality science instruction, implicating a need for classroom support to address limiting factors. The scope of the study is narrow; a case study approach focuses this exploration on a single unit of study- the implementation of an NGSS-aligned unit of instruction at one intermediate school. The overarching research goal is not to generalize findings but to apply a 
magnifying glass on the unit of study and provide rich, detailed descriptions that other elementary educators may find relevant to their own practice. The proposed research questions set the stage to explore how coaching as a delivery of on-going, embedded teacher support can facilitate the transfer of the NGSS from paper to practice.

1. How can a coaching approach to teacher collaboration be used to offer high quality professional development for NGSS implementation at the elementary level?

2. Based on the characteristics and needs of the teacher-participants, how does the coaching model develop throughout the implementation of the NGSS unit?

3. How can a coaching model as PD for NGSS implementation be used to catalyze changes in elementary teachers' science teaching practice?

4. How can coaching as a model for professional development for NGSS implementation impact student outcomes?

\section{Significance of the Study}

"Science — and therefore science education—is central to the lives of all Americans" (NGSS Lead States, 2013, para 3). Scientific advancements are at the backbone of society, providing humans with the innovations necessary to adapt and thrive across all terrains on earth. A walk through history shows a parallel between scientific progress and the advancement of society (Le Couteur \& Burreson, 2004). For example, the scientific discipline is charged with addressing climate change, meeting an increasing demand for energy, protecting endangered species, informing technology development, and discovering treatments for diseases. Continuing on this trajectory, if the children of today are to thrive in the society of tomorrow, science education must be a top priority in K-12 curricula. The NGSS were built from the Framework for K-12 Science Education: Practices, Crosscutting Concepts, and Core Ideas; this document was 
rooted in research on how children develop and learn. They identify the scientific knowledge and skills practicing scientists, science educators, and science education faculty deem as critical for America's children. (National Research Council, 2012). According to the NGSS writing team, the release of the NGSS is timely given the "reduction in the US economic competitive edge, lagging achievement of US students, essential preparation for careers and modern workforce, and the scientific and technological literacy for an educated society" (NGSS Lead States, 2013, para 1)

\section{Science Education for an Informed Citizenry}

The National Research Council has defined scientific literacy as "the knowledge and understanding of scientific concepts and processes required for personal decision making, participation in civic and cultural affairs, and economic productivity" (National Research

Council, 1996, p. 2). To address these concerns and promote scientific literacy, classroom experiences must ignite a passion for learning science and maintain those interests by situating science learning in meaningful and relevant contexts. We are born into this world as curious and questioning beings. It is a travesty that through formal science education, children lose their propensity to ask and explore science-oriented questions (Kovalik \& Olsen, 2010). The literature speaks of the many obstacles facing elementary educators in teaching science, but the wonderment and curiosity of children is an encouraging factor to build upon in the elementary classroom.

\section{Science Education for Equitable Learning Opportunities}

The NGSS also have the potential to bring issues of equity to the forefront in reform efforts. The underrepresentation of women, minorities, and persons with disabilities is welldocumented. For example, a survey conducted by the National Science Foundation (2013) 
discloses the discrepancy between the percent of these populations in the total population and the percentage of these populations represented as groups of science and engineering undergraduate degrees earned and employed as scientists and engineers. According to Rodriguez and Berryman (2002) as cited in Appendix D of the NGSS:

Engineering has potential to be inclusive of students who have traditionally been marginalized in the science classroom and do not see science as being relevant to their lives or future. By solving problems through engineering in local contexts (e.g., gardening, improving air quality, cleaning water pollution in the community), students gain knowledge of science content, view science as relevant to their lives and future, and engage in science in socially relevant and transformative ways. (p. 4-5)

The elementary setting can be a place that breaks down the stereotype of who can be a scientist or engineer by providing opportunities for student-driven investigations and problem solving.

\section{Science Education: Success Depends Upon Support}

Designing a cohesive curriculum that progresses in content and skill development, integrates science content with other academic subjects, and engages students in science and engineering practices through relevant and meaningful experiences is a tall order and a challenge that classroom teachers should not have to face alone. As Whitworth and Chiu (2015) conclude, "Providing teachers with individualized feedback, tailored to their needs and classrooms, can support teachers to make substantial changes to their existing practice" (p. 123). As the researcher considered the possibility of exploring a coaching model with elementary teachers, she approached this work with the understanding of how difficult change is and how frustrating it can be for practitioners to have an outsider evaluate and judge their teaching. Coaching offers support on a level playing field; it is based on reciprocal feedback that is specific to the needs of 
a partnership. The shifts in instruction called for by the NGSS will be difficult and situate teachers outside of their comfort zone. However, there can be exhilaration and rejuvenation in new opportunities, and having someone to take that leap with makes the transition less daunting. 


\section{CHAPTER II: REVIEW OF THE LITERATURE}

\section{The Next Generation Science Standards (NGSS): A Closer Look}

Practicing scientists, cognitive scientists, science education researchers, and science education standards and policy experts wrote the National Research Council's Frameworkfor K12 Science Education based on the most current research on science and science learning. Achieve, Inc. used this framework as its foundation to construct the NGSS.

\section{Core Disciplinary Ideas, CDIs}

The work to identify the CDIs was based on the premise that depth of understanding is superior to a breadth of surface knowledge. Content presented in the NGSS framework is reserved for key concepts that can be developed over time, have real-world applicability, and are significant across multiple disciplines (Bybee, 2013). The CDIs are grouped according to four domains: physical sciences, earth and spaces sciences, life sciences, and engineering, technology and application of science. For example, the CDIs articulated for the physical sciences include the following: Matter and its interactions, Forces and interactions, Energy, and Waves and their applications in technologies for information transfer.

\section{Crosscutting Concepts, CCs}

Crosscutting concepts are concepts that form a common thread among all fields of science, bridging the life, physical, earth, and space sciences. Duschl (2012) cites A Framework for K-12 Science Education in emphasizing the role these concepts play in students' development of a "cumulative, coherent, and usable understanding of science and engineering" (p. 7). These concepts or themes span across scientific disciplines and represent science as a way of knowing. The CCs are reminiscent of the "unifying concepts" from the National Science Education Standards (NRC, 1996) and the "common themes" presented in Science for All 
Americans (AAAS, 1989). In the NGSS framework, they are articulated specifically as (1) patterns; (2) cause and effect; (3) scale, proportion, and quantity; (4) systems and system models; (5) energy and matter; (6) structure and function; and (7) stability and change.

\section{Science and Engineering Practices}

According to the NSES, classroom inquiry "engages learners by asking scientifically oriented questions, prompts students to form explanations to scientific phenomena based on evidence, and develops students' ability to evaluate, communicate, and support explanations" (NRC, 2000, p.25). Scientific inquiry has been a part of science education standards since the 1990s, and in the NGSS, it is included as a form of scientific practice. The NGSS describe the teaching and learning of science in terms of practices; these practices involve "doing something and learning something in such a way that the doing and learning cannot really be separated" (Michaels, Shouse, \& Schweingruber, 2008, p. 34). It is the link between content and practice that leads to proficiencies in science, just as a knowledge of music and active practice allow a musician to be proficient at playing an instrument. (Duschl, Schweingruber, \& Shouse, 2007). The NGSS focus on students' engagement with the practices scientists and engineers use to describe the nature of scientific knowledge, conduct scientific inquiries, explain natural phenomena, engage in scientific discourse, and propose solutions to real-world problems. There are eight practices included in the standards: (1) asking questions and defining problems, (2) developing and using models, (3) planning and carrying out investigations, (4) analyzing and interpreting data, (5) using mathematics and computational thinking, (6) constructing explanations and designing solutions, (7) engaging in argument from evidence, and (8) obtaining, evaluating, and communicating information. 


\section{The Nature of Science}

In addition to engaging students in the practices of scientists to explore natural phenomena, the NGSS also advocate for the explicit teaching of the nature of science (NOS). Through this teaching, students may gain an understanding of how the scientific discipline accumulates and articulates scientific knowledge over time. As referenced in Appendix $\mathrm{H}$ of the NGSS, the NRC (2012), states, "Epistemic knowledge is knowledge of the constructs and values that are intrinsic to science. Students need to understand what is meant by an observation, a hypothesis, an inference, a model, a theory, or a claim and be able to distinguish among them (p. 79). Accordingly, Appendix H of NGSS proposes the instruction of eight basic understandings about the nature of science: (1) scientific investigations use a variety of methods; (2) scientific knowledge is based on empirical evidence; (3) scientific knowledge is open to revision in light of new evidence; (4) scientific models, laws, mechanisms, and theories explain natural phenomena; (5) science is a way of knowing; (6) scientific knowledge assumes an order and consistency in natural systems; (7) science is a human endeavor; and (8) science addresses questions about the natural and material world.

\section{An Emphasis on STEM and Literacy}

During the period from 1990 through 2000, national education standards (Benchmarks for Science Literacy, National Science Education Standards, and Standards for Technology Literacy) articulated standards for technology and engineering. In recent years STEM (Science Technology Engineering \& Mathematics) education initiatives have emerged (Bybee, 2011). Scientists propose questions about natural phenomena and form explanations based on empirical evidence, and engineers address real-world problems, offering solutions based on scientific knowledge that meet certain criteria and constraints. Applied science can lead to the 
development of technology, and technology can be used to advance scientific knowledge.

Mathematics can be used to describe relationships between variables, computational methods can be used to describe natural phenomena, and statistical techniques are central to characterizing trends and correlations in data sets. There is a significant overlap among these STEM disciplines, and the science and engineering practices presented in the NGSS reflect the relationship between the STEM fields. Engaging in these practices also prompts students to develop literacy skills. Students expand their vocabulary and use of syntax specific to the scientific discipline. They construct evidence-based arguments and employ the discourse of science to communicate findings.

\section{Performance Expectations, PEs}

In addition to the three dimensions, the NGSS provide a list of Performance Expectations (PEs) for each core disciplinary idea. These PEs are "assessable statements of what students should know and be able to do" (Achieve, 2013, p. 1). The PEs incorporate all three dimensions within the framework, connect to the nature of science and other STEM disciplines, and are aligned with the Common Core State Standards in Mathematics and English Language Arts. The PEs, like the CDIs, grow in sophistication with increasing level of student thinking; PEs are articulated at early elementary, mid-elementary, middle, and high school levels. For example, consider the performance expectation articulated for grades 3-5: "develop a model to describe that matter is made of particles too small to be seen" (Achieve, 2013). This PE incorporates all three dimensions: (1) the science practice - developing and using models to explain phenomena, (2) the CDI- structure and properties of matter, and (3) the CC- scale, proportion, and quantity. The PEs also connect to the NOS understandings. For example, this PE could relate to the following NOS understanding: Scientific models, laws, mechanisms, and theories explain natural 
phenomena. It is also linked to CDIs across grade levels and to specific Common Core standards articulated for literacy and quantitative reasoning skills.

The PEs describe expectations for student performance and can be used to guide educational professionals' decisions regarding instruction and assessment. However, while the PEs indicate what students should achieve, it is up to the school administrators and practitioners to determine how students achieve the PEs. For example, students could investigate the differences between deflated and inflated basketballs (including measuring and quantifying variables) and develop particle models to explain the observable properties of each. A similar activity could be conducted with different concentrations of sugar water. There is flexibility in how teachers orchestrate these exploratory opportunities for students, but without quality, exemplary instructional tasks to model, some teachers may feel unprepared and overwhelmed when creating or modifying lessons that adhere to the PEs set forth by the NGSS.

\section{Three-Dimensional Learning}

Familiarity with the three dimensions and the performance expectations outlined in the $N G S S$ framework is a helpful starting point for practicing teachers. The $N G S S$ also call for the dimensions to be integrated. Three-dimensional learning (NRC, 2014) posits that these dimensions work together in science lessons to help students develop the knowledge and skills to meet the performance expectations. Teaching concepts through the use of practices gives students a first-hand experience with the epistemological nature of scientific knowledge. In contrast, teaching students content and then using practices to verify the content situates the dimensions in isolation of one another. In her editorial piece for Science and Children, Mariel Milano (2013), also a member of the NGSS writing team, emphasized the integration of the standards' dimensions, "One of the instructional shifts in the NGSS is the use of all practices, 
with all content, all year long. This represents a marked shift from the many curriculum tools that present the scientific method or scientific processes as a separate unit and leave their implied use up to chance throughout the year" (p. 15). These standards advocate for the teaching of science to be authentic to the discipline, to be meaningful to students' lives, and to progress as students grow and develop throughout their K-12 education.

The NGSS consist of expectations for student performance that incorporate the core disciplinary ideas, crosscutting concepts, and practices; these performance expectations serve as standards for evaluating student learning and can guide practitioners' decisions regarding instruction and assessment. What is both exciting and daunting about the NGSS is the freedom they bestow on teachers to design and implement curricula that adhere to the spirit and intent of the framework. The NGSS advocate for both teacher and student autonomy simultaneously, and with this freedom comes great responsibility. Joseph (2011) conceptualizes curriculum not as an object or explicitly prescribed plan but an opportunity for an in-depth examination and transformation of goals for education from all aspects, including the well-being of all students, classroom practices that promote understanding, and the moral and democratic obligations for an equitable society. The NGSS reflect a "constructing understanding" (Windschitl, 2011) orientation to curriculum which situates the learner in challenging tasks that require autonomous thinking, inquiry skills, metacognition, and collaboration. But to limit the impact of the NGSS to victories in cognition is a disservice to students, schools, and society as a whole. The NGSS also have the potential to advocate for equity in science education. This is an opportunity teachers must not overlook. 


\section{All Standards, All Students}

The type of reform proposed by the NGSS is reminiscent of the Progressive movement in education dating 100 years ago. Joseph describes the goals of a progressive educational philosophy as "to transmit culture and societal structure to promote social change; to give learner practical knowledge and problem-solving skills, to reform society" (p. 16). Throughout his life experiences and written work, John Dewey (1916) epitomized this movement. He believed that education should be informed by the study of students' experiences, interests, and abilities, sustained by the active exploration into problems and contexts that are relevant to these characteristics, and provided for the purpose of social progress and reform. Appendix D of the $N G S S$ framework provides a rationale for the standards through the lens of a diversity and equity team and presents seven case studies describing experiences with teaching lessons within diverse classrooms that are aligned with the NGSS (NGSS Lead States, 2013). According to Stephen Pruitt, senior vice-president of Achieve. Inc., "Science can really be the great equalizer. But because science has the stigma for only being for a select group of students, we couldn't afford to come out of the gate without having our diversity and equity work, and some resources for teachers as a companion to the new standards" (...as cited by Maxwell, 2013, p. 26). The seven case studies offer insights and specific strategies for NGSS implementation with economically disadvantaged students, students from minority racial and ethnic groups, students with disabilities, students with limited English proficiency, female students, students in alternative education programs, and gifted students. Recommendations common across all of the case studies rely on the following strategies: (1) use cultural and linguistic resources as intellectual resources in the science classroom, (2) connect students' background knowledge with science disciplinary knowledge, and (3) allocate resources to support science learning including 
extensive professional development for teachers (Januszyk, Miller, \& Lee, 2016; Lee, Miller, \& Januszyk, 2014).

Students' everyday experiences- the energy they consume, the materials they use, or the quality of air they breathe- can be used as contexts to study natural phenomena. Funds of knowledge (Moll, Amanti, Neff, \& Gonzales, 1992) are the intellectual resources students acquire as a consequence of their lived experiences and interactions with cultural, linguistic, and social practices. It is not enough to approach NGSS implementation with a generic focus on the development of scientific knowledge and skills; in order for teachers to offer equitable science education to all students, they must value and allow students' funds of knowledge to inform learning opportunities. They must shift from a deficit model to an affirming view of student ability. Valencia (2010) describes deficit thinking as an endogenous theory of school failure which places the blame on the individual, citing student deficits such as immoral behavior, inadequate linguistic and intellectual abilities, and lack of motivation as the driving force behind students' lack of success in the classroom (p. 6-7). As a guide for preparing teacher candidates to be advocates of change for social justice, Villegas and Lucas (2002) present six characteristics that define a culturally responsive teacher. In addition to a constructivist approach to teaching, another strand emphasizes the importance of shifting from a deficit view to an affirming view of student ability. They describe an affirming attitude as, "acknowledging the existence and validity of a plurality of thinking, talking, behaving, and learning... all students, not just those from the dominant group, are capable learners who bring a wealth of knowledge and experiences to school." (p. 23). The title of Appendix D of the NGSS must become a mantra as teachers reform practice to incorporate the NGSS- "All Standards, All Students." 


\section{Implementing the NGSS- Theory to Practice}

Although student-driven, first-hand investigations may be a novelty in many K-12 classrooms, their inception is rooted in cognitive and socio-cultural constructivist learning theories of the $20^{\text {th }}$ century. A cognitive constructivist theory of learning, often associate with the psychologist Jean Piaget, characterizes the process of "sense making" as constructing knowledge through the assimilation and accommodation of new information against the backdrop of existing conceptions or schemas from past experiences (Herron, 1996). A sociocultural constructivist theory of knowledge describes sense making as a socially-mediated process of cognition; learning is shaped through contexts of communication and interactions with others (Vygotsky, 1978). Vygotsky's zone of proximal development refers to the gap between the understanding students can achieve as sole investigators in their learning environment versus the understanding that can develop through collaborating with a more experienced mentor or peer. A helpful synthesis of these two important views of learning is offered by Tobin and Tippins (1993) who explain that while knowledge is constructed and molded through personal experiences, both past and present, it is also influenced by the social and cultural aspects of the learning environment.

The tenets of these learning theories have significant implications for the teaching and learning of science. Children from a young age behave like scientists, asking questions about the world around them and formulating explanations based on their observations. As a result, students enter the classroom with preconceptions of how the natural world works that are not consistent with the current theories accepted by the scientific community. Teachers must be purposeful in planning in order to reveal student preconceptions, demonstrate the short-comings of the preconceptions, and offer plausible and intelligible alternatives to students' naïve beliefs; 
in other words, there must be intrinsically motivating learning experiences to catalyze conceptual change (Bruning, Schraw, Norby, \& Ronning, 2004, p. 340-346). Students must also be given the opportunity to grow in their understanding through peer collaboration.

During the 1960's scientists and science educators begin to frame research on how students learn science from a teaching perspective. As an instructional approach to teaching science, the learning cycle mimics the process by which scientists explore natural phenomena, introduce ideas to explain phenomena, and apply scientific ideas to new contexts (Atkin \& Karplus, 1962; Karplus, \& Their, 1967). Used as an instructional model, teachers facilitate students' transition between three phases of learning activities: (1) exploration, which provides students the opportunity to explore natural phenomena; (2) concept or term introduction, which uses instructional materials and classroom discussions to introduce relevant scientific vocabulary and explanations; and (3) concept application, which prompts students to apply newly discovered scientific ideas to a different context (Brown \& Abell, 2007). After a meta-analysis conducted on several empirical studies exploring the effects of the learning cycle on student outcomes, Lawson, Abraham, and Renner (1989) concluded that this approach and sequence to teaching science encourages positive attitudes toward science and science learning, enhanced content achievement, and improved general thinking skills (p. 69).

While the NGSS can be used to guide instruction and assessment, they do not include a list of instructional tasks or evaluation tools to be used with the performance expectations. The implementation of these standards in the classroom presents significant challenges and requires resources in addition to the framework itself. High-quality curricular resources can be used by teachers as a model of what three-dimensional learning looks like in the classroom; however, currently, an NGSS aligned K-12 curriculum cannot be found. Instead, educators must search for 
units of instruction that meet some of the standards or evaluate existing units for NGSS

alignment (Penuel, Harris, \& DeBarger, 2015).

\section{The BSCE 5E Instructional Model}

For teachers searching for guidance to support their implementation of the NGSS, the learning cycle can be a useful mechanism to initiate the appropriate changes in practice. When planning instructional units that adhere to the spirit of the NGSS, the Biological Sciences Curriculum Study (BSCE) 5E Instructional Model can be an invaluable tool. Built with teacher characteristics and needs in mind and inspired by the learning cycle approach, conceptual change models, and cooperative learning, this model can set the stage for student-led inquiries in the science classroom (Bybee, 2014). This model expands upon the learning cycle phases to include five phases-engage, explore, explain, elaborate, and evaluate. The explore, explain, and elaborate phases align with the learning cycle sequence phases- exploration, concept introduction, and concept application. The engage phase serves to spark student interest, expose preconceptions, and focus students' attention on the content of the instructional unit. The evaluation phase provides students with formalized feedback on their performance and provides teachers with evidence of student learning. Teachers applying this sequence of five phases to lesson planning should keep three action goals in mind: (1) intrinsically motivating students to

learn, (2) orchestrating a series of activities that reveal and confront students' preconceptions and support the construction of new understandings and skills, and (3) encouraging students to mediate and solidify their ideas through peer collaboration and teacher feedback.

\section{Project-Based Science}

In addition to the BSCE framework, teachers can use a project-based science (PBS) approach to develop lesson activities that engage students in the NGSS science and engineering 
practices within authentic contexts. According to Krajcik (2015), science education professor and CREATE for STEM coordinator at Michigan University, PBS is an instructional approach that aligns with the three-dimensional learning advocated by the NGSS. He states, "At the core of PBS is asking and investigating real world questions, a concept that dates back to Dewey, who promoted teaching about topics relevant to students' lives” (p. 25). PBS encompasses driving questions, investigations, and collaboration; together these processes integrate science and engineering practices with learning concepts and communicating scientific knowledge. Not all science "projects" meet the criteria endorsed by the PBS approach. Projects that stimulate and model the real work of scientists and engineers incorporate eight features: (1) significant content (the CDIs presented in the NGSS), (2) inspire a need to know, (3) a question that gives the project a sense of challenge and purpose, (4) student voice and choice, (5) $21^{\text {st }}$ century competencies (critical thinking, collaborative skills, communication skills, creativity/innovation), (6) engagement in inquiry, (7) critique and revision (peer review, self-evaluation), and (8) a public audience (presentation of work to a community) (Larmer \& Mergendollar, 2012).

\section{Subject-Based Learning Versus Problem-Based Learning}

In subject-based learning or SBL, the teacher informs students of what they need to know about a particular topic, the students learn the information, and then the teacher explains how this knowledge could be applied in a societal context. In problem-based learning or PBL, a problem is posed (by the teacher or by a student), and then the student must determine what information is needed to address the problem. In the quest for a solution, students must compile and evaluate resources, create and conduct investigations, collect and analyze data, and evaluate and communicate the findings. These educational tasks, prompted by PBL, reflect the true nature of science and support scientific literacy. Ram (1999) describes the premise of PBL as follows, 
"If we give students a challenging task that engages them, they will learn to solve problems and acquire the associated knowledge in order to solve the particular problem at hand" (p. 1122). Problem-based learning demands a higher level of inquiry than subject-based learning, making its use attractive to educators who wish to improve students' science process skill sets as well as their content knowledge. When implementing problem-based learning, educators must consider the quality of the problem; the problem determines how valuable the learning experience can be. The problem should be complex, relevant to students' lives, and reflect real-world issues that involve multiple perspectives (Chin \& Chia, 2008). The goal of the PBL experience is not for students to find one right answer but to propose a solution and support its validity through research and investigation.

\section{Implementing PBS}

A project-based science approach incorporates PBL and aligns well with the NGSS; however, the leap from a SBL approach requires educators to step into a different role as a facilitator of student-led inquires. Despite the student learning outcomes possible with PBS, there are practical reasons for teachers' use of a subject-based learning (SBL) approach. A subject-based approach to teaching science will expose students to content knowledge and the advancements made in science to date; however, it does not promote the development of the skills required to do science and to communicate within the scientific community. Ertmer and Simons (2006) identify teachers' abilities to create a culture of collaboration and interdependence, to adjust to changing roles, and to scaffold student learning as major challenges to successfully implementing problem-based learning in the classroom. Ertmer and Simons argue, "In order to increase the likelihood that PBL will be effectively integrated within $\mathrm{K}-12$ contexts, a variety of resources are needed to support both teacher and student efforts. For 
example, teachers will need guidance as they adopt new roles, facilitate student inquiry, provide constructive feedback, and apply new types of classroom management strategies" (p. 41).

Quality PBS units can be found in the literature and serve as a starting point for developing and evaluating science lessons for NGSS alignment. Rivet and Krajcik (2004) describe a simple machines PBS unit asking $6^{\text {th }}$ grade students, "How do machines help me build things?" The project was developed by university professors from the University of Michigan in partnership with Detroit Public Schools and included twenty-four teachers and 2500 students spanning four years. Rivet and Krajcik studied the impact of the project on student learning outcomes over the course of the project and found gains in student achievement sustained when professional development for classroom teachers transitioned from university professors to teacher leaders in the schools. While the PBS unit effectively translated the reform science standards of the time to practice, the effort hinged on intensive professional development opportunities that became sustainable through the training and availability of teacher leaders. In their review of STEM education initiatives since the 1990s, Zollman, Tahemezhadi, and Billman (2012) identify teacher quality as the greatest factor impacting students' academic achievement. Successful STEM projects help practitioners improve their content pedagogical knowledge and increase their self-efficacy toward teaching science. Projects fitting this description share three characteristics: (1) a strong focus on teacher content and pedagogical knowledge, (2) relevancy to teacher's classroom situation, and (3) intensive and sustained support (p. 106). In order for PBS activities to be more prevalent in K-12 environments, policy makers, administrators, teachers, and researchers must collaborate to break down the barriers preventing initiatives presented in the literature and articulated in the standards from impacting student learning in the classroom. 


\section{Challenges at the Elementary Level}

Science is a discipline designed to empirically describe and explain natural phenomena, and it has flourished as a body of knowledge over the centuries because of humans' natural curiosity of the world around them. Science teachers must not lose sight of this fundamental aspect of learning about the natural world and mechanism for advancing scientific knowledge. According to the NGSS, quality science instruction must begin with young children and progress over time to sustain students' interest, excitement, and aptitude for building and applying scientific knowledge. As Kovalik and Olsen (2010) describe in their book, Kid's Eye View of Science: A Conceptual, Integrated Approach to Teaching Science, K-6, children behave like scientists; their curiosity prompts them to question what they observe in the natural world, and they form inferences informed by their personal experiences and unique perspective. However, after formal science instruction begins, children lose their propensity to ask and explore scienceoriented questions. A longitudinal study conducted by Aschbacher, Li and Roth (2010) examined students' interest and self-efficacy toward science and STEM careers throughout their secondary schooling. The participants reported an initial intrinsic interest in science by age eight, with that interest fading over time. The participants identified more out-of-school experiences as motivators to pursue science versus in class experiences. Findings suggested that elementary education played a minimal role due to the lack of science instruction in elementary school. In a recent podcast, Michael Wysession (2015), member of the writing team for the $N G S S$, emphasized the need for financial resources to develop new curricula and provide professional development opportunities that build K-12 educators' confidence to embrace the $N G S S$ and support their integration of science and engineering practices in the classroom. He 
proposes the NGSS framework be used to capitalize on children's sense of wonder and build science understandings through student-centered experiences. He claims:

Once students see what science and engineering are really like, with the joys of discovery into how the universe operates, the camaraderie of teamwork, the sharing and debating of ideas, and the hands-on approach of designing and refining solutions to real problems with their own hands, there is a good chance they will stay more engaged and interested in science throughout their K-12 education and into adulthood.

\section{Teacher Characteristics}

Children at the elementary level may hold the innate curiosity and intrinsic motivation to engage in science learning, but unfortunately, their teachers face many challenges when attempting to incorporate effective science instruction into the classroom. For example, elementary educators identify time and resources, assessment ambiguity, limit of topics that can be covered, classroom disorder, and loss of teacher as authoritative knowledge provider and classroom manager as disadvantages of teaching inquiry-based science (Choi \& Ramsey, 2010; Howes et al., 2008). In contrast with secondary educators, their teacher preparatory program did not allow for extensive coursework in all sciences, and as practitioners their time and effort must be split among multiple subjects. According to the 2012 National Survey of Science and Mathematics (as cited by Banilower et al., 2013), fewer than half of elementary teachers have coursework in chemistry or physics and less than five percent of elementary science teachers have post-secondary coursework in engineering. A majority of elementary educators do not feel as prepared to teach science as they do mathematics and language arts, and they spend less than half the time per week on science instruction than these academic subjects as well. 


\section{Teacher Practices}

Appleton's (2007) review of research on science education at the elementary level reveals that due to a lack in background knowledge and low self-efficacy for teaching science, elementary teachers tend to avoid reform-based teaching practices in science. Instead, teachers tend to minimize instructional time and emphasize only a select number of topics (which tend to favor the biological sciences over the physical sciences), stress right answers instead of exploratory activities, rely heavily on expository teaching and textbooks, and avoid open-ended practical experience using equipment. Roth's (2014) review reports similar findings and also points out that elementary educators struggle to adapt instruction to meet the needs of underrepresented students in science. Any professional development model designed to assist elementary educators with NGSS implementation must consider this set of challenges unique to the elementary setting.

\section{The Classroom Climate}

In addition to these limiting factors, standardized testing influences science instruction at the elementary school. A heavy emphasis on student achievement in reading and mathematics often prompts teachers to enhance focus on those subjects at the expense of teaching science. Schools across the United States have reduced and in some cases eliminated science instruction in order to provide more time to teach reading and mathematics. This shift in instruction is a consequence of the No Child Left Behind (NCLB) Act which required states to administer two standardized assessment tests in reading and mathematics to be reported to determine a school's Academic Yearly Progress or AYP (Griffith \& Scharmann, 2008). The time and effort teachers spend on improving students' reading and mathematics test scores can make time for science instruction difficult and professional development opportunities and resources for science scarce. 
Many limiting factors work against children's exposure to effective science instruction and their development of the skills required to "do" science. While embedding the NGSS into every day practice is no small task for educators, the integration of science and mathematics instruction with literacy skills is necessary for the successful implementation of the NGSS and well suited for a mathematics and language arts rich curriculum. The NGSS can actually pave the way for science instruction to be effectively integrated with mathematics and language arts. Proponents of standardized testing argue for its use to quantify student performance and hold schools across the country accountable for providing quality, equitable education to their students. Opponents favor local control of education, and some advocate for the use of performance-based assessments that measure student growth (Edwards, 2016). In a recent study exploring reform-based instruction, elementary educators reported that although a studentcentered, NGSS-inspired approach to exploring science improved student engagement and interest in science, its implementation was at odds with the standardized testing climate of the school (Nariman \& Chrispeels, 2016). Standards-based reform, based on the NGSS performance expectations, also necessitates changes in how assessment tools are developed and used to measure students' learning.

\section{The Call for Professional Development}

Over one hundred years ago, Maria Montessori spoke passionately about the squelching of the inquisitive spirit of children by the overly prescribed and sedentary nature of classroom curricula. She compared teachers working with students restricted to desks to a zoologist studying butterflies pinned in place through a glass case. She believed in a student-driven, active learning approach to education as opposed to a "pouring" of content into children's intelligence. She wrote, "It is not enough, then, to prepare in our Masters the scientific spirit. We must also 
make school ready for their observation. The school must permit the free, natural manifestations of the child if the school scientific pedagogy is to be born. This is the essential reform" (p. 28 as cited in Flinders \& Thorton, 2009). Her words resonate with the classroom inquiries inspired by the NGSS, but history reveals a pattern of student-centered reform efforts failing to cross the threshold of classroom doorways.

The national survey Looking into the Classroom: A Study of K-12 Mathematics and Science Education in the United States, supported by the National Science Foundation and conducted by Weiss et al. (2003), reported that out of the 186 science lessons observed in K-12 classrooms, $70 \%$ of the lesson content was influenced by state standards, yet only $5 \%$ of the lessons' instructional strategies were influenced by state standards. Interview analysis with teachers revealed that while the topics taught were dictated by state standards and district policies, the methods employed to teach those topics were selected by teachers, and teaching through inquiry was not a common practice. The 2000 National Survey of Science and Mathematics Education (Hudson, McMahon, \& Overstreet, 2002) conducted with 5,278 teachers reported that instructional practices consistent with inquiry-based teaching occurred less frequently than traditional teaching methods (as cited in Wilson et al., 2010). The 2012 National Survey of Science and Mathematics (Baniflower et al., 2013) indicates a similar trend; activities associated with student inquiry such as citing evidence when making claims, representing and analyzing data, and engaging in project-based learning were incorporated regularly in only $16 \%$ or less of K-12 classrooms. How will the newest version of science standards, the Next Generation Science Standards be different? Among the national studies mentioned, another common finding indicates that professional development and teacher collaboration were minor 
factors in affecting teachers' instructional decisions. Could these factors represent the missing link between reform on paper and reform in practice?

The work to complete the Next Generation Science Standards (NGSS) took two years and an all-star cast of writers including K-12 science teachers, science coordinators, science specialists, and school administrators; STEM initiative curriculum experts and directors; university professors from science and science education departments; and practicing scientists, engineers, and cognitive psychologists (NGSS Lead States, 2013). Considering the time and range of professional power commissioned to draft these standards, the notion of resting the implementation of these standards solely on the shoulders of classroom teachers seems an absurdity. This writing process was a collaborative effort, and the work to bring them to fruition must be also. Moving forward, it is critical to look to the past; history reveals the story of science education standards that never permeated the classroom. For example, Wilson, Taylor, Kowalski, and Carlson (2010) through their exploration of the effectiveness of inquiry-based instruction on student learning concluded, "From Dewey to the present, inquiry has been an increasingly prominent theme in multiple science education reform movements worldwide. However, the transition from theory and advocacy to practice and policy has been unsatisfactory" (p. 276). Even standards that are written by a team of respected science educators, scientists, and educational psychologists, supported by a wealth of educational research, and effectively articulated will remain a theoretical framework if changes in curriculum, instruction, and assessment at the classroom level do not follow.

How can educators nurture the inquisitive spirit of the child, sustain students' interest in natural phenomena, and support their identity as scientific thinkers throughout K-12 education? Educators must situate science learning in meaningful contexts and build a classroom community 
that supports student-led inquiries. In his book, Translating the NGSS to Classroom Instruction, Rodger Bybee (2013), NGSS writer and former director of the Biological Sciences Curriculum Study, advocates for students' active learning of science content. He also argues that this approach would demand significant changes in curriculum, instruction, and assessment in the science classroom. Throughout the future, elementary educators with limited planning and instructional time, gaps in background knowledge in science content, and minimal experience with science and engineering practices will have to drastically change science instruction to align practice with the standards. This transition requires intense and sustained support, and this support must be provided in consideration of the constraints present in elementary schools. He writes:

From the late 1980s to the present, K-12 science teachers and the larger science education community have witnessed an era of standards-based reform. Basically, the idea is to develop clear, comprehensive, and challenging goals for student learning. Beyond learning goals, the implicit assumption is that standards would be used to make other components of the of education system more coherent. Curriculum, instruction, assessments, and the professional development of teachers would be aligned. Common sense supports this view. But in education reform, common sense does not always carry the day. (p. 12)

\section{The Goals of Professional Development}

Teachers enter their professional environment with a set of preconceptions about teaching gathered through a lifetime of observations from the perspective of a pupil. Lortie (as cited in Darling-Hammond \& Bransford, 2005, p. 369) described the acquiring of this knowledge base as the apprenticeship of ownership. While teachers' experiences as students familiarize them with 
the classroom setting and can provide inspiration for future work, some critical misconceptions can develop. For example, novice teachers, having not experienced the behind-the-scenes work of teachers, may hold an over-simplified view of teaching. Also, if their education primarily consisted of traditional, teacher-centered lessons, then they may also assume the role of an authoritative figure who "transfers" knowledge to students. Just as students' conceptual change can be framed from the constructivist learning theory, so should the changes in attitudes, beliefs, and knowledge that affect teachers' change in practice from traditional approaches to inquirybased teaching. Darling-Hammond and McLaughlin (2011) eloquently summarize the dilemmas and demands associated with accomplishing reform-based work:

The success of this agenda ultimately turns on teachers' success in accomplishing the serious and difficult tasks of learning the skills and perspectives assumed by new visions of practice and unlearning the practices and beliefs about students and instruction that have dominated their professional lives to date... Teachers learn by doing, reading, and reflecting (just like students do); by collaborating with other teachers; by looking closely at students and their work; and by sharing what they see. This kind of learning enables teachers to make the leap from theory to practice. (p. 81-83)

Research has shown that teacher quality (including factors such as years of experience and expertise in teaching area) has a significant impact on student achievement (Fuller, Carpenter, \& Fuller as cited in Valencia, 2010, p. 117-119). In their review of Science, Technology, Engineering, and Mathematics (STEM) education initiatives, Zollman, Tahernezhadi, and Billman (2012), state, "The quality of the public school teacher has the greatest in-school impact on nurturing cognitive abilities, developing content knowledge, and increasing motivation of students" (p. 103). More specific and germane to this paper is the 
strong correlation between teachers' content knowledge and student achievement and the even stronger correlation between the number of content methods courses and student performance (Monk, 1994; Goldhaber \& Brewer, 2000); Darling-Hammond and Bransford (2005) summarize these research findings and conclude, "All of these studies suggest that learning how to teach allows teachers to better use their knowledge of what to teach (p. 26). Shulman (1986) described this type of teacher knowledge as pedagogical content knowledge (PCK); PCK requires a knowledge of how to best teach content including a sense of what makes the subject difficult to students, the preconceptions students bring to the classroom, and the strategies best suited to promote students' conceptual understanding (p. 6-7). The How People Learn or HPL framework (National Research Council, 2000) paints a picture of an optimal learning environment that is created by teachers' PCK and students' learning needs. The four aspects of the environmentlearner-centered, knowledge-centered, assessment-centered, and community-centered- comprise a space that is student-driven, collaborative, informative, authentic to the discipline, and relevant to society.

\section{Features of Effective Professional Development}

Effective PCK is not developed overnight, and the successful infiltration of the science education reform embedded in the NGSS hinges on the reform efforts in schools. Teachers must be provided with high quality curricular materials and assessments to model, professional development sustained over time, and support from all educational professionals including peers, school and district leaders, administrators, and community partners (Penuel, Harris, \& DeBarger, 2015). Professional development (PD) opportunities exist in a variety of shapes and sizes; teachers can have their pick from summer institutes, workshops, university courses, in-service days, conferences at the district, state, and national levels, mentoring, and coaching (Whitworth, 
B. A. \& Chiu, J. L, 2015). With all of these options it is important to study and identify the factors of PD that stimulate and sustain changes in teacher practice that lead to increased student achievement. From a comprehensive review and synthesis of research conducted on professional development programs in science for K-12 teachers, Luft and Hewson created a list of 4 elements present in effective PD models: (1) the PD offers context-specific and enduring support for teachers, (2), PD opportunities allow for collaboration among educational professionals, (3) the PD program is coherent and goal-oriented, and (4) PD goals are focused on developing pedagogical content knowledge. These findings confirm the recommendations offered by Darling-Hammond and McLaughlin (2011). Effective PD engages teachers in the tasks of teaching, assessing, observation and reflecting that reveals processes of learning and development; is grounded in inquiry, reflection, and experimentation that is participant-driven; is collaborative and focused on developing communities of practice; is connected to teachers' work with students; must be ongoing and supported through modeling, coaching, and cooperative problem solving; and is part of larger school changes that allow for changes in practice (such as changes in schedule, availability of resources, money for materials, community partnerships, etc.) (p. 82). Desimone (2009) offers a conceptual model for studying professional development opportunities. Her "path model" offers a lens to investigate how teacher knowledge, teacher practice, and student achievement are connected to one another and can be influenced by quality PD. In this model, high-quality PD is defined according to five core features that emerged from over a decade of research on PD experiences. Consensus across the literature reveals these features as (1) content focus, (2) active learning (3) coherence, (4) duration, and (5) collective participation. 


\section{Professional Development with Coaching for Elementary Level Science Teaching}

Searching through the National Science Teachers Association (NSTA) website

(www.NSTA.org), K-12 teachers can find information about the NGSS framework, instructional activities and assessments that are aligned to the NGSS, rubrics to evaluate teaching materials, informational videos, and national conference agendas that offer NGSS training (often by a member of the NGSS writing team). While resources and training opportunities are becoming plentiful for NGSS implementation, the problem of transfer still exists. As Joyce and Showers (1982) explain:

Once a teaching skill has been obtained, it needs to be transformed when it is transferred into the active repertoire. The conditions of the classroom are different from training situations, one cannot simply walk from the training session into the classroom with the skill completely ready to use- it has to be changed to fit the classroom conditions...Like athletes, teachers will put newly learned skills to use- if they are coached. (p. 5)

Joyce and Showers also identify five functions of the process of coaching that support teachers' application of newly developed skills to practice: (1) provision of companionship (through mutual problem solving and reflection), (2) giving of technical feedback (constructive feedback of the skill is use), (3) an analysis of application (developing the ability to discern when skill should be used), (4) adaptation with the students (paying attention to student responses and adapting skill appropriately, and (5) personal facilitation (providing encouragement and support through the practice phase) (p. 6-7). This work provides helpful insights into the activities of coaches. Perhaps a useful way to define the role of a coach is to distinguish coaching from other types of interactions among professionals in the educational setting. As cited previously, coaching provides more teacher autonomy than the processes of evaluating, supervising, and 
mentoring (Barkley, 2010, p. 23) and represents a "relationship between two equals committed to an idea of personal and professional improvement" (p. 6). According to Knight (2011), instructional coaches listen and ask questions to identify teacher goals, explain and provide resources on teaching practices to see how research-based strategies align with teachers' goals, and they provide feedback as an iterative process, avoiding a power-ridden, top-down traditional coaching approach (p. 20-22).

\section{Gap in the Literature}

Currently, in many elementary schools, literacy and mathematics coaches provide on-site, on-going training and support for teachers' instruction in the classroom. The duration of the coaching experience has been shown to have a positive relationship with an increase in teacher confidence and implementation of new teaching strategies (Dixon, 2015) and student achievement (Stewart, 2000). Darling- Hammond (as cited by Wren \& Reed, 2005, p.1) reports that researchers who examine issues related to teacher professional development find that the best-trained, most knowledgeable teachers in any domain (not just reading and mathematics) have had substantial support from a strong mentor or coach. Wren and Reed argue that the coaching support must be embedded and ongoing; the coach works with the teacher as an equal, supporting the teacher as he or she "experiments and applies new knowledge" (p. 3).

Literature examining the impact science teacher-coach partnerships have on teacher and student learning outcomes is surfacing but limited. For his dissertation, Kraus (2008) studied how a teacher-coach partnership could address challenges in implementing inquiry-based teaching at the high school level. McFaddens's (2015) doctoral work studied the interactions and conversations between elementary teachers and their coaches throughout the process of designing a STEM integrated curricular unit over a 12-day summer professional development 
session. DeChenn et. al (2014) examined how experienced science teachers, trained as science coaches according to Knight's partnership model, could facilitate teachers' ability to develop and implement a guided inquiry lesson that used an engineering context to teach a science or math concept. The professional development experience included three days of instructional coaching professional development and seven days of professional development for teachers using coaches as support. All of these studies share a common theme in terms of exploring the impacts coaching can have on specific teaching outcomes. None of the studies explored a model for science coaches as an "embedded and on-going" support in the school.

One promising study describes a professional development program that provided coaching support over a three-year period for teachers implementing an integrated math, inquirybased science, and literacy project (Miller, Curwen, White-Smith, \& Calfee, 2015). Findings suggest that the program was successful at addressing the limiting factors present in the elementary setting and enabled teachers to create an inclusive, student-driven learning environment and teach reform-based science more confidently and frequently. Teachers cited that the collaboration with other educational professionals greatly assisted in cultivating this classroom culture. Findings suggest that coaching as a means of support and collaboration can assist teachers in enacting reform-based science teaching. However, there is a still a gap in the literature examining how science coaches, as a fixture in the elementary setting, can facilitate elementary educators' ability to plan, implement, and assess learning using an NGSS- aligned curriculum. 


\section{CHAPTER III: METHODOLOGY}

\section{Qualitative Methods}

The work of educators is dynamic and complex, influenced by a plethora of factors such as student characteristics, school culture, district policy, standardized testing, parent and community involvement, teacher experience, classroom setting, and the availability of resources. A context so rich with variables deserves a deep and comprehensive representation in the literature. According to Luttrell (2010),

Qualitative research insists upon a face-to-face, heart-felt encounter between knowing subjects, a recognition that each of us is unique in our effort to make sense of ourselves and the world around us. To approach another as a knowing subject- to care about a person's integrity, joys, sufferings, and self-definition- takes intellectual and moral courage, scientific risk-taking, and artful representation of what one has learned. (p. 1)

Because of the diverse nature of educational settings, the goal of this research is not to generalize, but to offer a detailed account of one context. By sharing ample information about the research content, another can make an informed decision regarding the applicability of the findings to his or her situation (Green, 2010). Interpretive research assumes that reality is socially constructed; there are multiple, possible interpretations of a single event. By studying how people interpret or give meaning to their experiences, the researcher constructs knowledge and attempts to describe participants' perceptions (Merriam, 2009, p. 8-9). Knowledge accumulation under an interpretivist paradigm is context-specific, yet with rich descriptions of study contexts comes transferability- the possibility of applying knowledge to other contexts. This study may provide elementary educational professionals with a reference point to guide their own journey into reform-based science teaching. 
Merriam (1998) describes six characteristics of qualitative research: (1) research is focused on understanding the meanings people construct, (2) the researcher serves as the primary instrument for data collection and analysis, (3) research often involves field work, (4) research employs inductive reasoning more so than hypothesis testing, and (5) the final product is richly descriptive. (p. 6-8). Creswell (2009) provides a helpful list of descriptors as well; in addition to the characteristics proposed by Merriam, he also suggests that qualitative research is (6) emergent, not prescribed, (7) applies a theoretical lens to frame the study and guide analysis, (8) is interpretive in describing findings, and (9) paints a holistic painting of the research context (p. 175-176). Table 1 outlines how these characteristics align with my vision for exploring the research questions.

\section{A Case Study Approach}

Case study research is a type of qualitative research and is defined by the unit of study. Merriam (2009) describes a case study as an "in-depth description and analysis of a bounded system" (p. 40). A case study explores a phenomenon within a particular context; the unit of analysis or case is containable. For example, this study examines NGSS implementation within the bounded system of an intermediate level learning environment. Case studies are characterized as being particularistic (focused on a phenomenon), descriptive (thick portrayal), and heuristic (contributes understanding regarding the phenomenon) (p. 43-44). A case study approach is like applying a magnifying glass to a context to focus attention on the specifics of the system and to richly describe and assign meaning to a phenomenon. Stake explains, "Readers can learn vicariously from an encounter with the case through the researcher's narrative description" (as cited by Merriam, p. 51). This study has the potential to provide 
Table 1

An Alignment of Research Goals with Qualitative Procedures and Qualities

\section{Qualitative Research Characteristics Goals of Study}

$\begin{array}{ll}\text { 1. Focus on Understanding Participants } & \begin{array}{l}\text { An exploration of teacher needs for NGSS } \\ \text { implementation }\end{array}\end{array}$

2.Researcher as Instrument

Data collected through observing, journaling, interviewing, and reviewing instructional documents

3. Field Work

4. Inductive Reasoning

5. Highly descriptive

6. Emergent Design

7. Theoretical Lens

8. Interpretive

9. Holistic Account
Observations of and interactions with students and teachers in schools

Interpretations emerged from the generation and analysis of data sources

The study provides a rich, detailed description of elementary teachers' journey to transition toward reform-based teaching in science

Research questions initially guide the study, but were open for revision in response to initial findings

Conceptual models describing roles of coaches, the coaching process, the teacher-coach relationship, teacher perceptions and practices, and student learning outcomes were used to inform data generation and analysis

The researcher's observations, interactions, and understandings were subject to her own personal experiences and biases

The study considered and gave a voice to multiple perspectives, including the teacher-participants and recognized the many variables influential in the research setting 
elementary science educators with a vivid image of the type of resources, strategies, and collaborations that encourage and enable NGSS implementation.

\section{Research Setting and Participants}

Participants include the researcher as the science coach and two sixth grade teachers in an intermediate (grades 4-6) building located in a Midwestern, small-urban setting. In all discussions of the teacher-participants, they will be referred to by pseudonyms to maintain confidentiality. Elizabeth has 15 years of teaching experience and Ruth has 22 years of teaching experience in K-6 classrooms. Their teaching of other content areas demonstrated an interest and excitement for teaching in a student-centered, problem-based learning manner. Therefore, in recruiting participants, these teachers were targeted as potential subjects. The researcher served as a support professional to the classroom teachers, providing guidance and assistance as a coach. The coach-participant has three years of experience as a high school science teacher and twelve years of experience as a university professor teaching chemistry content and chemistry methods courses. In the presentation of the research findings the coach will be referred to in the first-person. Through a collaborative effort among all participants, an NGSS-aligned science unit was built and implemented over a six-week period in each $6^{\text {th }}$ grade classroom.

\section{Theoretical Frameworks}

Maxwell (2013) describes a theoretical framework as a system of concepts, assumptions, expectations, beliefs, and theories that directs (but not dictates) a study. The framework represents the variables pertinent to a study and the relationship between them. It can be used as a conceptual guide, informing the design and providing a lens through which to examine data. Maxwell provides a helpful metaphor to demonstrate the usefulness of a theoretical framew ork but also its limitations. Existing theory is like a spotlight that illuminates what a researcher 
observes, but while it sheds light on some relationships that may otherwise go unnoticed, it inevitably casts darkness onto other areas of possible study (p. 49-50). It is with this understanding that I built and applied a theoretical framework for my study.

\section{Features of High-Quality PD}

Research Question \#1 asks, "How can a coaching approach to teacher collaboration be used to offer high quality professional development for NGSS implementation at the elementary level?" Coaches work with teachers to tackle problems of practice, combining brain power to make smart, collaborative decisions that are enriched by the shared practice of the community (Killion, 2007). Over the last 30 years, coaching has become more prevalent in K-12 settings, in particular in the literacy and mathematics fields, and takes on a variety of forms including peer coaching, content-coaching, and instructional coaching. PD models with coaching supports for reform-based science teaching at the elementary level have emerged more recently. A close look at these opportunities can inform the design of PD opportunities for NGSS implementation. From a review of literature on effective professional development (PD) models, DarlingHammond and McLaughlin describe the type of institutional arrangements that are critical for reform-oriented PD:

To create new structures for individual and organizational learning, the usual notions of in-service training or dissemination must be replaced by possibilities for knowledge sharing anchored in problems of practice...professional development activities must allow teachers to actively engage in cooperative experiences that are sustained over time and to reflect on the process as well as on the content of what they are learning. (p. 84) After a review of literature on characteristics of effective PD, Borko, Jacobs, and Koellner (2010), outline seven features of high-quality PD: (1) content is situated in practice, (2) content 
is focused on student learning, (3) the process includes a modeling of instructional strategies, (4) the process situates teachers as active learners, (5) PD environment builds learning communities and supports collaboration, (6) PD is grounded in school practice and integrated with applicable reform efforts and (7) PD activities are ongoing and sustainable. This research study examined the coaching process as an effective model of PD according to these seven attributes that describe the content, process, environment, and duration of the PD experience.

\section{A Coaching Model for NGSS Implementation}

Research question \#2 asks, "Based on the characteristics and needs of the teacherparticipants, how does the coaching model develop throughout the implementation of the NGSS unit?" The work of Joyce and Showers (1982) provides helpful insights into the activities of coaches. They identify five functions of the process of coaching that support teachers' application of newly developed skills to practice: (1) provision of companionship (through mutual problem solving and reflection), (2) giving of technical feedback (constructive feedback of the skill in use), (3) an analysis of application (developing the ability to discern when skill should be used), (4) adaptation with the students (paying attention to student responses and adapting skill appropriately, and (5) personal facilitation (providing encouragement and support through the practice phase) (p. 6-7). As Knight (2001) suggests, "When coaches and teachers interact equally as partners, good things happen" (p. 18). Knight (2011) also describes seven principles that can be used to characterize the partnership between teacher and coach. The partnership principles include: (1) equity- sharing ideas and making decisions as equals, (2) choice- teachers choose coaching goals and practices, (3) voice- conversations are open and candid, (4) reflection- a continual reflection on learning, (5) dialogue- discussions are two-way, with the ideas of others just as important and heard as ideas from self. (6) praxis- new knowledge 
and skills are applied within context or omitted from practice, and (7) reciprocity- interactions are fruitful and allow everyone to learn (p. 18-20). Together these frameworks helped focus the study on supportive coaching activities and identify the principles behind a positive and productive teacher-coach relationship. They served as that spotlight moving forward to guide the study; however, this exploration was open to the possibility that other activities and/or principles might be added to these lists depending on the research context. The researcher was also responsive to the teachers' specific characteristics and needs and considered challenges present in the research setting.

\section{Changes in Teacher Perspectives and Practices}

Research Question \#3 asks, "How can a coaching model as PD for NGSS implementation be used to catalyze changes in elementary teachers' science teaching practice?" According to Grossman et. al (2009), "Practice in complex domains involves the orchestration of understanding, skill, relationship, and identity to accomplish particular activities with others in specific environments" (p. 2055). This definition applies to educational settings in which teachers collaborate to implement new instructional strategies with their students. Changes in teacher practice were evaluated according to the understandings, skills, identity, and relationships conducive to reform-based science teaching.

\section{Exploring Student Outcomes}

Research Question \#4 asks, "How can coaching as a model for professional development for NGSS implementation impact student outcomes?" The How People Learn (HPL) framework provides a useful illustration of a learning environment that exists where quality teaching intersects with students' learning needs (National Research Council, 2000). Throughout the coaching-based implementation of the NGSS-aligned unit, the HPL framework was used as a 
guide to examine and characterize changes in the teacher-participants' science teaching practice that impact student outcomes. Table 2 presents a description of how each $H P L$ perspective contributes to an effective learning environment.

Table 2

How People Learn (HPL) Framework- Perspectives of an Effective Learning Environment

\begin{tabular}{|c|c|}
\hline Perspective of Environment & Description \\
\hline Learner-Centered & $\begin{array}{ll}\checkmark & \text { Recognition of student preconceptions, out-of-school } \\
\text { experiences, and interests. } \\
\checkmark \quad \text { Sensitivity to students' cultural and language practices }\end{array}$ \\
\hline Knowledge-Centered & $\begin{array}{l}\text { Learning activities... } \\
\checkmark \text { connect to student characteristics } \\
\checkmark \text { focus on problem solving and thinking skills including } \\
\checkmark \text { metacognition } \\
\checkmark \text { are authentic to the discipline }\end{array}$ \\
\hline Assessment-Centered & $\begin{array}{l}\checkmark \text { Formative assessments provide students with feedback } \\
\text { and guidance for individual growth } \\
\checkmark \text { Summative assessments provide teachers with } \\
\text { information on student learning that can inform } \\
\text { practice }\end{array}$ \\
\hline Community-Centered & $\begin{array}{l}\checkmark \text { Classroom allows for peer collaboration and socially- } \\
\text { constructed knowledge } \\
\checkmark \quad \text { Students' out-of-school experiences and community } \\
\text { spaces and resources are used as contexts for learning. }\end{array}$ \\
\hline
\end{tabular}

Summative and formative assessments were created during the planning of the unit to shed light on how students' science epistemological knowledge, conceptual understanding, and science process skills change over time. These assessments also allowed the participants to provide individualized and whole-group feedback to students. 


\section{A Synthesis of Frameworks}

Desimone (2009) emphasizes a model for effective PD that studies PD experiences within the context of teacher and student outcomes. This model provided a useful backbone for the study, upon which other pertinent conceptual frameworks were added and considered. In general, this study aimed to explore how coaching as a method of PD can be used to facilitate teachers' implementation of an NGSS-aligned unit of instruction. As the study progressed, the following factors were examined: the features of effective PD, the nature of the coaching process, changes in science teaching perspectives and practices, and changes in students' science learning. Figure 1 illustrates the relationship between these factors and the corresponding conceptual models that were employed throughout the study to guide an analysis of data sources.

\section{Researcher and Participant Roles}

An ideal context for this study is located within a K-6 classroom, and the participants demonstrate a passion for learner-centered, inquiry-based science teaching that advocates for all students. Situated learning theory (Lave \& Wenger, 1991) asserts that knowledge is best constructed within an authentic context and that people learn concepts through active participation in real world experiences and through their interactions with others. Wenger and Snider (2000) describe communities of practice as "groups of people who share a concern or a passion for something they do and learn how to do it better as they interact regularly" (p. 139). The purpose of the community of practice is to "develop members' capabilities and share knowledge," and it is a shared passion and commitment that holds the community together (p. 142). A shared commitment to the goals of the study, a collaborative spirit, and an openness to try new strategies form the foundation of the teacher-coach relationship. 
The researcher was an active participant, serving as a coach within the community of practice. The teacher participants served as practitioners and as co-researchers, sharing insights that shaped the study as it proceeds. Ulichny and Schoener (2010) describe mutuality in research as a relationship of "equal status based on mutual respect and concern" (p. 422). Mutuality

Figure 1. Coaching as Professional Development for NGSS Implementation- Analysis Model

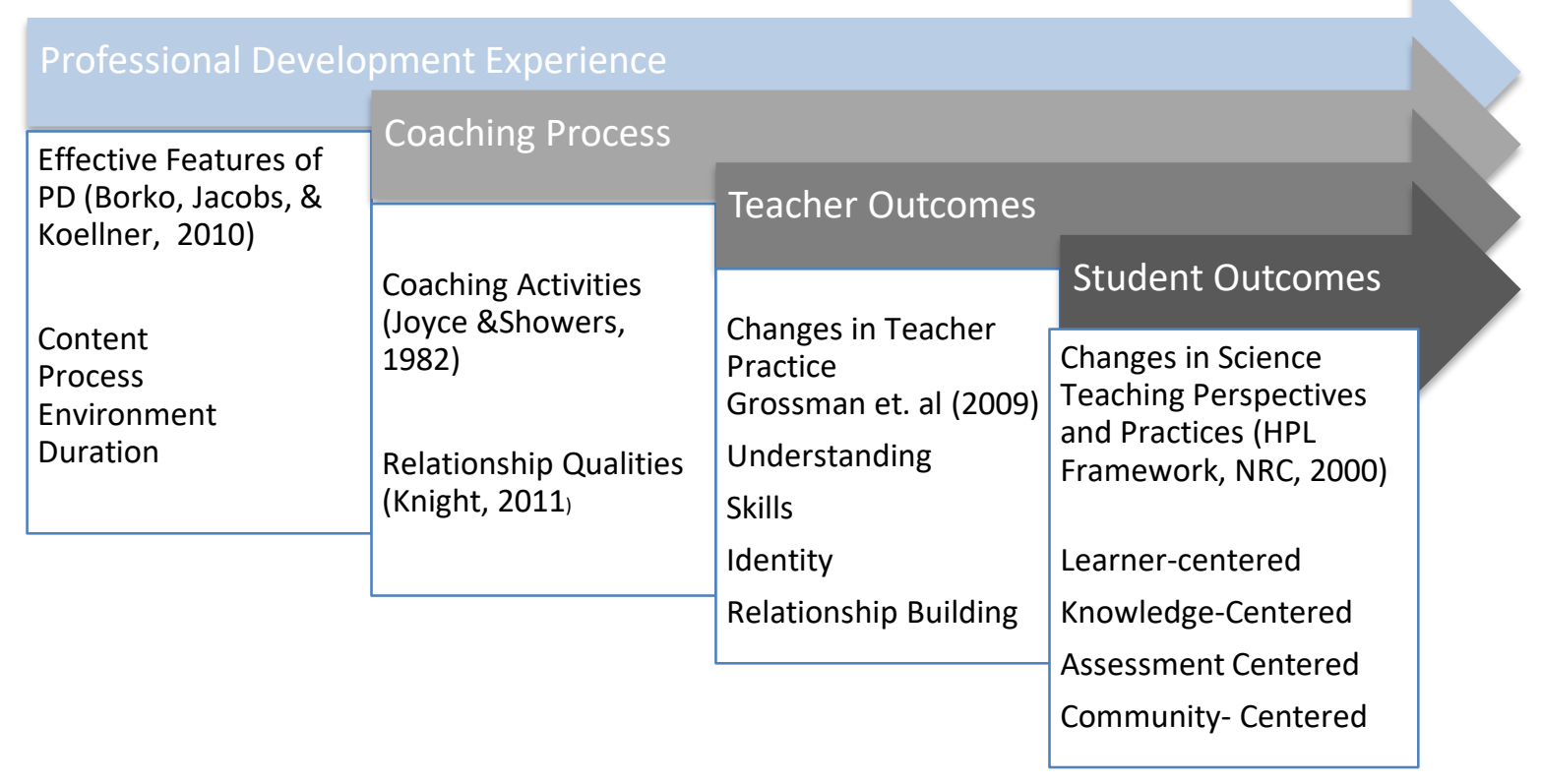

Figure 1 illustrates an integration of conceptual models relevant to the research study.

between researcher and participants in the contexts of the field and in the study is consistent with the type of relationship that exists in a shared community of practice and between a coach and practitioners. They describe a relationship and level of action among participants that inspired the collaboration in the study, " Rather than eliminating the researcher from the enterprise of creating knowledge about teaching, the model we present is one in which both teacher and 
researcher have a voice, because in our study, we have profited from a successful collaborative effort that has provided knowledge that we both value. Neither of us on our own would have been able to produce the study that emerged through the collaboration" (p. 423). The researcher and participants were actively involved in the classroom setting as educational professionals and all also contributed to the research process.

\section{Data Collection}

From the first interaction between the researcher and teacher-participants to the last, data collection followed an interpretivist approach to reveal initial findings, to shed light on the research questions, to bring awareness of personal biases and sensitivities, and to inform and document how the study evolved over time (Corbin \& Strauss, 2015). Sources of data included researcher and participant journals (throughout all collaborations and classroom activities), classroom observations, teacher and student artifacts, unstructured interviews or group planning and implementation reflections (audio-recorded) and interviews conducted by the principal investigator with the participants (audio-recorded).

\section{Participant Journals}

The interactions between the researcher and the teacher participants (the coach and teachers) and their perspectives were at the heart of the study. A thorough account of this journey from the beginning to the end was documented through the use of journaling. Each participant recorded her personal thoughts on how the collaboration developed and adapted to meet the demands of planning and implementing an NGSS-aligned unit

\section{Semi-Structured Interviews}

A semi-structured interview protocol was used to socially construct knowledge in a focused but conversational tone with the participants, to make what is implicit in the minds of 
the teacher participants explicit, and to minimize power asymmetry between the interviewer and interviewees (Brinkmann \& Kvale, 2015). To place the researcher as a coach-participant in the same shoes as the teacher-participants, the principal investigator conducted an initial and final interview with all three participants as a group. Thus, the researcher was the interviewee, not the interviewer.

\section{Unstructured Interviews}

The research was researcher and participant-driven. The teacher participants carry out the important work in the classroom with students and had a voice in topics discussed when reflecting upon and constructing understandings from the instructional experiences.

Unstructured interviews, characterized by not having an interview protocol with questions, have great potential for providing rich sources of data as participants can talk more freely about the issues and ideas that are the most relevant to them (Corbin \& Stauss, 2015). To openly and informally discuss feelings and thoughts on the trials and successes of planning and teaching the lessons, the participants engaged in a group conversation of these issues. The researcher audiorecorded this meeting and used this data to compare participant perspectives across multiple sources from personal journal entries to more formal interviews to this informal discussion.

\section{Observations}

Making observations of teachers in action in the classroom with their students is an essential part of carrying out the processes of coaching proposed by Joyce and Showers (1982). For example, in order to provide feedback on new strategies in use, the researcher must have first-hand knowledge of these practices with students. It is also critical for the participants to observe one another to provide constructive, reciprocal feedback. As a co-teacher in the classroom, the researcher documented observations of teacher-student interactions and teacher- 
coach interactions after each lesson was taught. Thus, these observations were documented from first-hand experiences and not a passive observer in the field.

\section{Documents}

Teaching materials can offer another rich source of data. Similar to classroom observations, these documents represented the products of the planning and assessment phases of teaching and offered great insight into how a coaching-facilitated implementation of the NGSS unit affected teacher perspectives and practices and student outcomes.

\section{Data Analysis}

As discussed earlier, qualitative research is based on the process of induction and is emergent. As opposed to employing a deductive approach of hypothesis testing, rich sources of data are compared for relationships, and theory emerges from the data or is grounded in the data. According to grounded theory as proposed by Glaser and Strauss (1967), theory is derived from concepts that emerge from a constant analysis and comparison of data collected during the research process. In order to make sense of the data and identify units of information relevant to the research questions, a constant comparative method was used in which data from the various sources were compared to identify similarities and differences, ultimately generating categories and themes (Corbin \& Straus, 2015). This process of coding entailed a close examination of the interview transcripts, in-field observations, journal entries, and documents, and required an interpretation of the data to label, group, and categorize data into meaningful themes. According to Charmaz (2010), the constant comparative method of grounded theory means "comparing different people, comparing data of the same person collected at different times, comparing incident with incident, comparing data with category, and comparing categories with other categories" (p. 188). It is through this comparative analysis of data sources that the 
researcher began to describe a coaching model that supports teachers in their efforts to implement the NGSS.

\section{Open Coding}

During the open coding stage of data analysis, journal entries, observation notes, and interview transcripts were read multiple times to describe the data. During this process, notes were marked in the margin for small samples of data, sometimes on a line-by-line basis. The purpose of this initial coding was to give the researcher the first opportunity to offer written interpretations of the texts. Identifying these potentially interesting bits of data was influenced by her personal background in education, the research questions, and related theoretical frameworks from existing literature.

\section{Axial Coding}

Once the participant journal entries and transcripts were marked with initial interpretations, these initial findings were reviewed for meaning and grouped together according to similarities (axial codes). The axial codes were compared between participants, between different sources of data (journal entries, observations, formal and informal interviews), and at different points during the collaboration. Diagrams were constructed to visually present the relationships between the axial codes to identify recurring patterns that cut across the data (Merriam, 2009, p. 181.)

\section{Constructing Categories}

Patterns in the data were assigned a category name or theme. These categories were created from the data after open and axial coding of each data source and were modified after these data sources were compared for regularities and irregularities. The categories were then re- 
evaluated through the lens of the research questions and applicable theoretical frameworks.

Figure 2 provides an example of a diagram constructed during this process.

Figure 2. Data Analysis Example- Using Data to Describe the Coaching Process

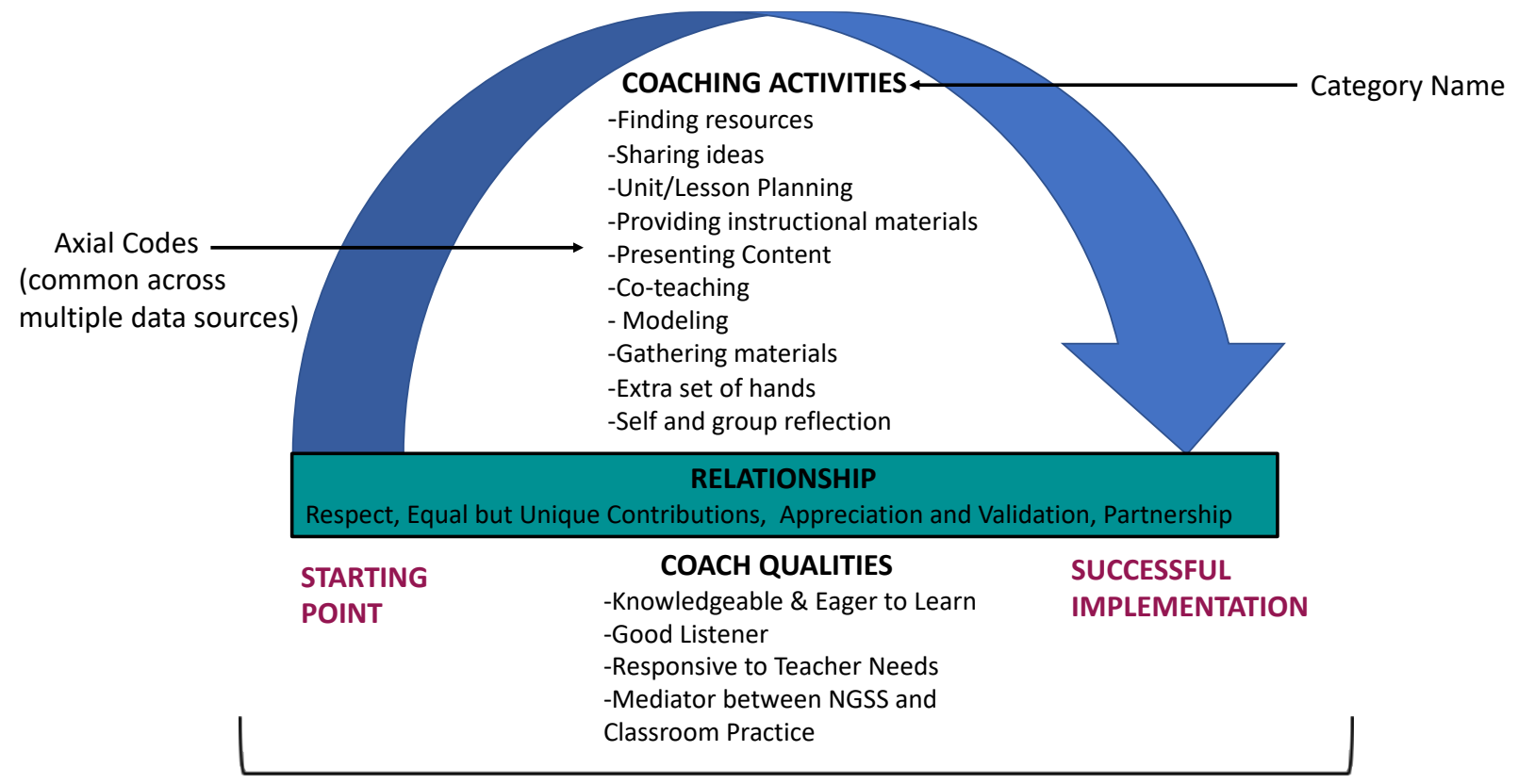

Together the categories describe how the coaching process developed throughout the collaboration to implement an NGSS-aligned unit (Research Question \#2).

Figure 2 illustrates the process of using axial codes from multiple data sources to form categories that combine to describe the coaching process.

\section{Addressing Validity}

The qualitative approach to the study lends itself to transferability, not generalizability. Consequently, in discussing issues of validity and how to address them, the researcher focused on issues of internal validity or credibility (Merriam, 2009). Data analysis relies on an 
interpretivist paradigm, so an important question to consider is, "How valid are the interpretations or the conclusions drawn about the research context?" Maxwell (1992) poses that "validity in a broad sense pertains to this relationship between an account and something outside that account, whether this something is constructed as objective reality, the construction of actors, or a variety of other interpretations." He continues, "Validity is not an inherent property of a particular method, but pertains to the data, accounts, or conclusions reached by using that method in a particular context for a particular purpose" (p. 5-6). This reference to an account, the interpretation of the account, and the difference between these two things represents the issue of internal validity. Maxwell (2013) describes two threats to validity- researcher bias and reactivity- and shares a list of validity checks researchers can apply to research design to minimize issues of validity (p. 124-129).

\section{Researcher Bias}

Peshkin (1988) describes subjectivity as an inherent quality of all human beings and compares it to a garment that cannot be removed (p. 17). This is problematic when the findings of a study depend on the researcher's interpretation. Peshkin (2000) eloquently phrases this dilemma of practice and proposes a way of addressing it, "An important reason for reflecting on the development of an interpretation is to show the way a researcher's self, or identity in a situation, intertwines with his or her understanding of the object of the investigation" (p. 5). Since it was impossible for the researcher to remove her "cloak of subjectivity" when conducting this research study, she must consider its impact on the study design and findings. To be cognizant of this lens she uses for interpretation is to pause and consider its effects and to be mindful and careful when making conclusions. 


\section{Reactivity}

The presence of the researcher in the research setting influences the environment and participants. As a full participant in the field, the researcher was directly involved with teachers and students in the school. This proximity and connection to the field afforded the researcher rich, detailed descriptions of teacher-coach, teacher-teacher, teacher-student, and student-student interactions. In addressing this threat to validity, eliminating the researcher as a factor in the setting is not possible, or desirable, but the researcher can make a concerted effort to understand how she is affecting the variables present in the setting and how this closeness impacts the generation and analysis of data sources.

\section{Reflexivity}

Qualitative research situates the researcher as the instrument. Not only does the researcher need to be critically aware of how personal biases, background experiences, perceptions, and expectations dull her instrument and hinder her ability to "see" clearly, the researcher must be transparent in reporting and publicizing this in her work. In this particular study, the researcher was directly involved as a coach, and this is a role that influenced the entire research design, from posing questions to data collection and analysis. According to Luttrell (2010), “Understanding one self and stake in one's project is crucial for knowing both the limitations and strengths of one's instrument" ( $\mathrm{p} 3$ ). Luttrell goes beyond this idea of researcher self-disclosure to describe a gold standard of ethical reflexivity. Ethical reflexivity considers also the power distribution among researcher and participants in the field and how the researcher can give back as much as is taken from the research setting. She writes, “...ethical reflexivity means searching for ways to incorporate human subjects as thinkers in research about their lives rather than data producers for experts" (p. 4). This significant aspect of reflexivity greatly influenced 
the researchers' approach to exploring the research questions with the teacher-participants. The collaboration between researcher and participants or the coach and teachers was designed to contribute knowledge to a general body of literature and just as importantly to assist teachers in their journey to adapt practice to implement reform-based science teaching and impact student outcomes.

\section{Peer Review}

Allowing colleagues who are both unfamiliar and familiar with the research topic places fresh sets of eyes to review the findings and explore the validity of the interpretations and conclusions the researcher makes as an insider. The principal investigator was not part of the research setting, but he played a critical role in conducting the initial and final interviews. He offered a fourth perspective for all the participants to consider prior to the planning and teaching stages and an important voice prompting deep reflection after the unit was implemented with students. In addition to the principal investigator, committee members were provided a draft to question and critique, pushing the researcher to re-evaluate and examine initial findings.

\section{Respondent Validation or Member Checking}

Throughout the data collection and analysis, the researcher elicited and applied feedback from the participants regarding how the data was generated and analyzed. For example, in proposing methods of data collection, the researcher proposed to be an observer of the participants' teaching of the lessons. Prior to the first lesson, Ruth suggested the researcher as the coach co-teach the lessons. This suggestion was more consistent with the type of relationship that had developed during the initial planning sessions. The three participants worked as partners to plan the lessons, so teaching these lessons together in the classroom validated this equal partnership. All of the participants had a stake in the success of these lessons and also a 
stake in what could be learned in the research setting. For the duration of the collaboration, whenever the researcher was in the classroom with students, she taught the lesson with the teachers. After each lesson, the researcher summarized observations made during the teaching of the lesson and wrote in her journal to capture her personal thoughts and perspectives on fulfilling the co-teacher and/or coach role for that day. After coding the data sources, the researcher compared her interpretations with the participants' interpretations. To avoid making assumptions or relying solely on conclusions of what the participants said and did, the researcher asked, clarified, and confirmed how the participants felt about the support they needed and received in the classroom throughout the collaboration.

\section{Rich Data}

Intensive, sustained engagement in the research setting provided the greatest opportunity for the researcher to explore the research questions thoroughly and offer an in-depth description of all of the variables present in the setting and how these variables change over time. This allowed for repeated observations and interviews to be conducted and compared.

\section{Triangulation}

Data was generated from multiple participants from multiple data sources at multiple points in time throughout the study. As Charmaz (2010) discussed, this allows for a comparative analysis between participants, points in time, and across different sources of data. The triangulation of data can corroborate research findings and reveal how researcher interpretations vary across these multiple points of comparison. Table 3 provides an example of data source comparison of data that describes the teacher-coach relationship. Data sources span multiple participants (Coach, Elizabeth, and Ruth), multiple points in time (initial interview, group 
reflection, and final interview), and varying types of data sources (journal entries, semistructured interviews, and unstructured interview).

\section{Human Subject Protocol}

Prior to data collection, Institutional Review Board (IRB) approval was obtained to ensure the proposed research was ethical and designed to maximize benefits and minimize risks of harm to participants. This study was assigned an IRB number of IRB-2017-1023509 (See Appendix I).

\section{Organization of Findings}

Chapter IV provides a description of the instructional unit. Chapters V-VIII discuss the findings in this study distilled according to each research question. The reader can reference Chapter IV whenever the researcher and participants refer to specific lesson activities during the presentation of findings. The conceptual framework proposed by Desimone (2009) was used by the researcher to guide an inquiry into coaching as an effective delivery of teachers' professional development. Professional development in the case of this study was directed toward a specific goal, to assist elementary teachers in their efforts to create and teach an NGSS-aligned unit of instruction. Desimone's path model traces the potential impact effective PD can have on teacher perspectives, teacher practice, and student learning. The quality of the coaching approach to PD was evaluated according to a set of core features identified by Borko, Jacobs, and Koellner (2010) as being universally reported in research-based literature as affecting teacher and student outcomes. 
Table 3

A Comparison of Data Sources for the "Coach-Teacher Relationship" Theme

\begin{tabular}{|c|c|c|c|c|}
\hline Data Source & $\begin{array}{l}\text { "In-Vivo" } \\
\text { Words }\end{array}$ & Margin Note & Axial Code & Category \\
\hline Journal-Coach & $\begin{array}{l}\text { We use all of } \\
\text { our skills }\end{array}$ & $\begin{array}{l}\text { Everyone } \\
\text { contributes a } \\
\text { personal skill }\end{array}$ & $\begin{array}{l}\text { Equal but } \\
\text { Unique } \\
\text { Contributions }\end{array}$ & $\begin{array}{l}\text { Coach-Teacher } \\
\text { Relationship }\end{array}$ \\
\hline $\begin{array}{l}\text { Journal- } \\
\text { Elizabeth }\end{array}$ & $\begin{array}{l}\text { Validated } \\
\text { strengths Ruth } \\
\text { and I contribute }\end{array}$ & $\begin{array}{l}\text { Coach validates } \\
\text { contributions of } \\
\text { teachers }\end{array}$ & $\begin{array}{l}\text { Appreciation and } \\
\text { Validation }\end{array}$ & $\begin{array}{l}\text { Coach-Teacher } \\
\text { Relationship }\end{array}$ \\
\hline Journal- Ruth & $\begin{array}{l}\text { Everyone brings } \\
\text { something } \\
\text { valuable to the } \\
\text { table }\end{array}$ & $\begin{array}{l}\text { Everyone } \\
\text { contributes } \\
\text { something } \\
\text { valuable }\end{array}$ & $\begin{array}{l}\text { Equal but } \\
\text { Unique } \\
\text { Contributions }\end{array}$ & $\begin{array}{l}\text { Coach-Teacher } \\
\text { Relationship }\end{array}$ \\
\hline $\begin{array}{l}\text { Group } \\
\text { Reflection }\end{array}$ & $\begin{array}{l}\text { You validated } \\
\text { what we } \\
\text { brought, too } \\
\text { (Elizabeth) }\end{array}$ & $\begin{array}{l}\text { Coach validates } \\
\text { what teachers } \\
\text { contribute }\end{array}$ & $\begin{array}{l}\text { Appreciation and } \\
\text { Validation }\end{array}$ & $\begin{array}{l}\text { Coach-Teacher } \\
\text { Relationship }\end{array}$ \\
\hline Initial Interview & $\begin{array}{l}\text { Respecting what } \\
\text { each person } \\
\text { brings to the } \\
\text { table (Ruth) }\end{array}$ & $\begin{array}{l}\text { Valuing what } \\
\text { each person } \\
\text { brings is } \\
\text { important }\end{array}$ & $\begin{array}{l}\text { Appreciation and } \\
\text { Validation }\end{array}$ & $\begin{array}{l}\text { Coach-Teacher } \\
\text { Relationship }\end{array}$ \\
\hline Final Interview & $\begin{array}{l}\text { I felt so } \\
\text { appreciated as } \\
\text { like being able } \\
\text { to contribute } \\
\text { something } \\
\text { (Elizabeth) }\end{array}$ & $\begin{array}{l}\text { Teacher } \\
\text { appreciated } \\
\text { being validated } \\
\text { by other } \\
\text { participants for } \\
\text { contributions }\end{array}$ & $\begin{array}{l}\text { Appreciation and } \\
\text { Validation }\end{array}$ & $\begin{array}{l}\text { Coach-Teacher } \\
\text { Relationship }\end{array}$ \\
\hline
\end{tabular}




\section{CHAPTER IV: THE INSTRUCTIONAL UNIT}

The three-dimensional learning (NRC, 2014) purported by the NGSS positions student learning as an active process of first-hand explorations. Teaching concepts in this manner encourages students to employ science and engineering practices to investigate science-oriented questions and develop an understanding of the epistemological nature of scientific knowledge. In contrast, teaching students content first with a subject-based approach and then using prescribe, or so-called "cookbook" labs to verify the content places the dimensions in isolation of one another and does not represent how knowledge is constructed within the scientific enterprise.

\section{The Topic- Nature of Science}

One of the main goals of the instructional unit was to situate students as active learners who engage in science and engineering practices to explore concepts and apply knowledge to problem solving. Lesson activities placed instructors as facilitators of these classroom experiences and promoted student autonomy and student collaborations. The decision to do an extensive unit on the nature or science (NOS) was based on the following three factors: (1) the unit was to be the first science unit of the year, (2) the NGSS outline eight understandings critical to students' understandings about the scientific enterprise, and (3) the teachers wished to confront and correct the misconceptions they held about the nature of science. With the NGSS NOS understandings in hand, in consideration of performance expectations articulated for grades 3-5 and 6-8, and with the BSCS 5E instructional model as a guide to lay out the progression of lessons, we began to plan instructional activities for the unit.

\section{Instructional Activities}

During our initial planning sessions, our compatibility as collaborators came to light. We each contributed ideas, resources, and materials to orchestrate a set of grade-level appropriate, 
student-centered activities for each of the five phases outlined in the BSCS 5E instructional

model. Table 4 presents an alignment of all unit activities with the BSCS 5E instructional model.

Table 4

Alignment of Unit Activities with the Five Phases of the 5E BSCS Instructional Model

\begin{tabular}{lll}
\hline “E” Phase & Description & Unit Activities \\
\hline Engage & -Capture student interest & Nature of Science Puzzle \\
& -Identify student preconceptions & Activity \\
& -Provide first-hand experiences & NOS Misconceptions T/F Quiz \\
forplore & Stations Activities \\
& concepts & 1. Using Models in Science \\
& & 2. Mystery Boxes \\
& & 3. Scientific Experiments \\
& & 4. Identifying Patterns and \\
& & Making Predictions \\
& & 5. Observations and Inferences \\
& & 6. Theory Vs. Law \\
& -Students develop explanations & Anchor Chart (+/ $\Delta$ ) \\
& of phenomena, citing & Kahoot Group Review \\
& experiences & Word Sort \\
& -Scientific terms are introduced & Quantitative and Qualitative \\
& Students apply understandings & Data Activity \\
& and/or skills to a new context & \\
Elaborate & Teachers assess students' new & Citing Evidence for NOS \\
& understandings and skills to & Understandings \\
Evaluate & inform support and next steps in & Engineering Challenge \\
& teaching & \\
\hline
\end{tabular}

\section{Engage}

To spark students' interest in how scientists investigate the physical world, we gave them a puzzle activity that served as an analogous activity to illustrate that (1) scientific knowledge is reliable, yet tentative; (2) exploring natural phenomena is an experiential, creative process; and 
(3) accumulating and communicating scientific knowledge is a collaborative endeavor (Choi, 2004). We also created a True/False quiz based on the NGSS NOS understandings and the work of McComas (1996) to assess students' preconceptions regarding the nature of science. The True/False quiz is included as Appendix B.

\section{Explore}

We designed six station activities that gave students an opportunity to explore the nature of science first-hand. These stations spanned six instructional days and set the stage for students to work autonomously (little reliance on teacher for assistance) and collaboratively. The students had to carefully read the prompt at each station and work together as team to conduct the work. The teachers and I circulated the classroom and provided guidance as students asked questions. Students recorded responses to guiding questions in a science notebook. Station 1- Using Models in Science explores the use of models in science to explain phenomena. It uses the evolution of the model of the atom to demonstrate that scientific knowledge while rooted in empirical evidence is subject to change with new discoveries. It also demonstrates that models while helpful are limited in their ability to represent reality. Students also interacted with computer animations of matter at the particle level to describe how a particle model can be used to explain the observable properties of the physical states of matter. Station 2- Mystery Boxes explores the use of observations other than sight to make inferences about the structure of the inside of the three different boxes. This activity focused students' attention to the difference between observations and inferences, the importance of creativity in exploring phenomena, and the subjectivity of human-drawn interpretations. Station 3- Scientific Experiments introduces the terms- cause and effect, control, independent variable and dependent variable. Students study data from an example scientific experiment and then design their own experiment working with a 
large pendulum. Station 4- Identifying Patterns and Making Predictions challenges students to use available data to identify patterns and make predictions. Within this activity, they are given more "advanced technology" to collect additional data to see whether their existing pattern is validated or should be modified in light of new evidence. Station 5- Observations and Inferences presents a dig site of tracks and asks students to make observations and then inferences. This station also points to the difference between observation and inference and also demonstrates how scientific explorations do not solely rely on experimentation but can be based in careful observation over time. Station 6- Theory Versus Law presents an animated TED-Ed talk on the terms, hypothesis, theory, and law (Zedem Media, n. d.). The students then could discuss these NOS terms and use the interactive presentation board to create a Venn diagram to compare and contrast the attributes of scientific laws and theories. Appendix C provides an example of one these station activities, Station 4 . Table 5 shows an alignment of the True/False statements, the station activities, and the NGSS NOS understandings found in Appendix $\mathrm{H}$ of the standards (Achieve, 2013).

\section{Explain}

After the students completed the station activities, we facilitated a whole-class discussion of the "big ideas" of the station activities. The teachers had an idea to facilitate students" construction of an anchor chart which solicits student feedback about what they enjoyed about the stations and what they would change. Appendix D shows a picture of the feedback generated from Elizabeth's students. Following the anchor chart, the students used electronic tablets to participate in a quiz game. Ruth created this quiz using the same True/False statements from the pre-quiz and a student-response game application found online (Kahoot!, 2008). This served as a formative assessment to gauge students growth in their NOS understandings. The teachers also 


\section{Table 5}

An Alignment of the NGSS NOS Understandings with the True/False Pre-Quiz

Statements and the Six Explore Station Activities.

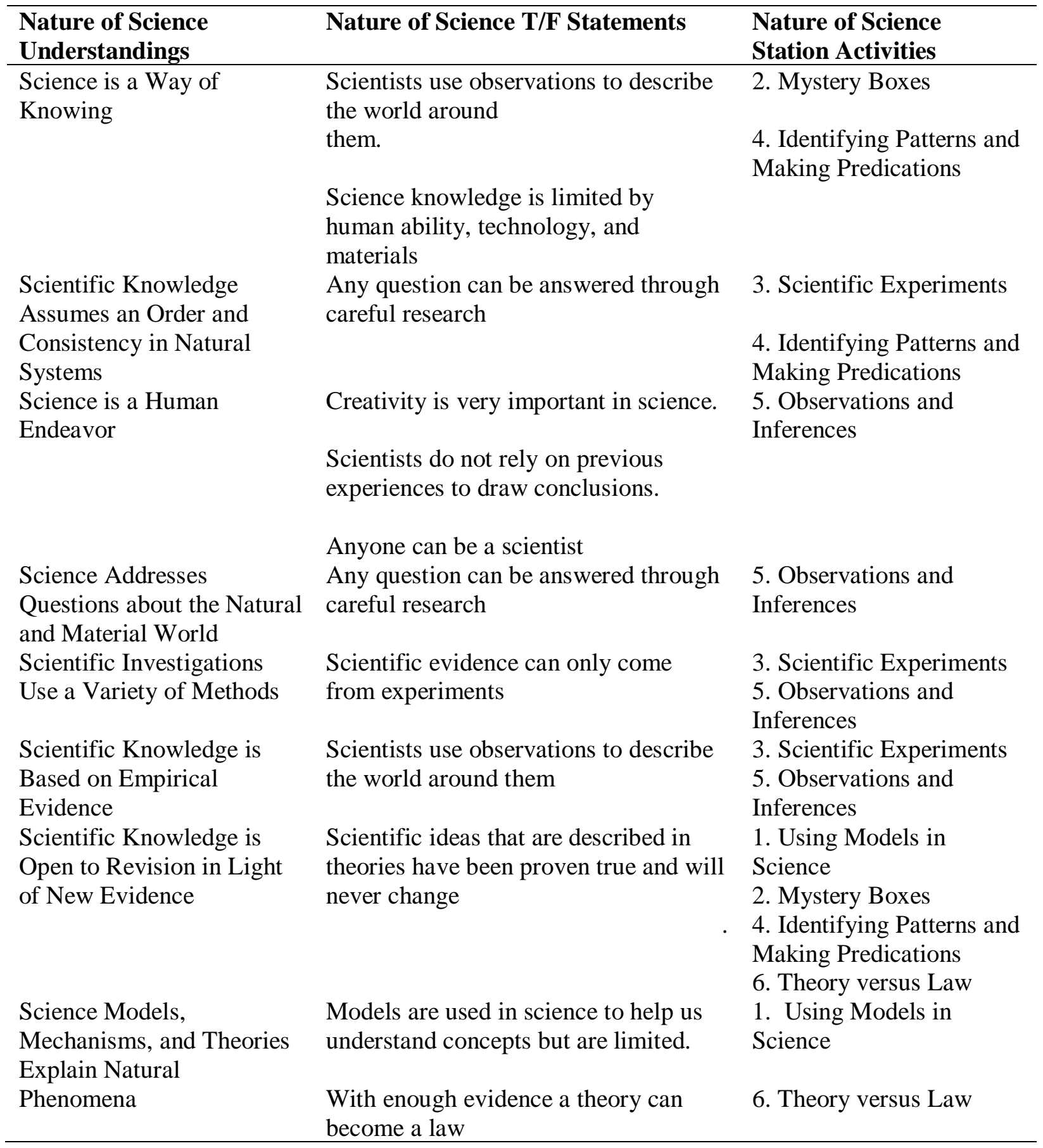


created a word sort activity to review the terms introduced through the station activities. The students matched a list of terms with the corresponding definitions and pasted these pairings in their science notebooks. The following terms were included in the word sort activity: science, scientific inquiry, observation, inference, hypothesis, theory, law, variable, independent variable, dependent variable, experiment, predict, conclusion, bias. Students also completed an activity on collecting and organizing data. This assignment prompted students to distinguish between types of data: qualitative and quantitative (refer to Appendix E). Lastly, students added additional scientific terms to their science notebooks through a second word sort assignment (refer to Appendix F). The following terms were included: data collection, data analysis, measure, procedure, quantitative data, qualitative data, and problem/question.

\section{Elaborate}

To give students an opportunity to collect and analyze data and make claims based on empirical evidence, we implemented a lab exercise called The Mystery Powder (refer to Appendix G). The students had to identify an unlabeled white powder based on careful, detailed observations of labeled white solids.

\section{Evaluate}

During the evaluate stage, students had to apply newly developed skills and understandings to complete an engineering design challenge. According to Larmer and Mergendollar (2012), projects that stimulate and model the real work of scientists and engineers incorporate eight features: (1) significant content (such as the CDIs presented in the NGSS), (2) inspire a need to know, (3) a question that gives the project a sense of challenge and purpose, (4) student voice and choice, (5) $21^{\text {st }}$ century competencies (critical thinking, collaborative skills, communication skills, creativity/innovation), (6) engagement in inquiry, (7) critique and revision 
(peer review, self-evaluation), and (8) a public audience (presentation of work to a community audience). As a culminating assessment for our unit, students were challenged to design a cookie according to specific qualities requested by the school principal. The school site has a café for both students and teachers to enjoy. The manager of this café visited both classrooms to present the challenge. The manager presented the scenario as a real-world problem in order to encourage student buy-in at the start. The engineering design challenge consisted of five tasks: Task 1- Design an Experiment and Share your Design, Task 2- Develop a List of Materials and a Procedure in Consideration of the Problem Constraints, Task 3- Create the Prototype (in this case, your cookies), Task 4- Collect and Analyze Data on your Product, and Task 5- Report your Findings. Table 6 presents an alignment of the engineering project with the NGSS Engineering Principles for middle school grades, 6-8 and with the eight features of project-based learning. The tasks created checkpoints for us to assess their work and keep them on a timeline. In addition to a limit on time, students were limited to a five-dollar budget for materials and had to consider all applicable issues of safety. Students also were limited by the availability of certain materials and equipment to make and bake their cookies. After completing the engineering challenge, the teachers administered one last assessment to evaluate students' competency with the eight NOS understandings. All of the original True/False statements from the pre-quiz were written as true statements. Students had to explain each statement, citing specific experiences they engaged in throughout the unit. 
Table 6

An Alignment of the Engineering Project with Project-based Learning Features and NGSS Engineering Principles.

\begin{tabular}{|c|c|}
\hline $\begin{array}{l}\text { Aspect of Engineering } \\
\text { Project }\end{array}$ & Project-based Learning \\
\hline $\begin{array}{l}\text { The Problem } \\
\text { Create a chocolate chip } \\
\text { for the principal with } \\
\text { specific qualities. Mrs. } \\
\text { White is also looking for } \\
\text { a good recipe for her café. }\end{array}$ & $\begin{array}{l}\text { 1. Significant Content } \\
\text { 2. Inspire a Need to Knov }\end{array}$ \\
\hline $\begin{array}{l}\text { The Constraints } \\
\text { Safety Concerns, } \\
\text { Timeline, Budget, } \\
\text { Available Materials }\end{array}$ & $\begin{array}{l}\text { 3. Project Has a Sense of } \\
\text { Challenge and Purpose }\end{array}$ \\
\hline $\begin{array}{l}\text { Task } 1 \\
\text { Design an Experiment to } \\
\text { develop a prototype } \\
\text { cookie }\end{array}$ & $\begin{array}{l}\text { 4. Student Voice and } \\
\text { Choice } \\
\text { 6. Engagement in Inquiry }\end{array}$ \\
\hline
\end{tabular}

Task 2

Develop a list of materials and a procedure in consideration of problem constraints

\section{Task 3}

Create a prototype cookie

6. Engagement in Inquiry

\section{*NGSS Middle School} Engineering Principles

MS-ETS1-1. Define the criteria

and constraints of a design problem with sufficient precision to ensure a successful solution, taking in to account scientific principles and potential impacts on people and the natural environment that may limit possible solutions. MS-ETS1-2. Evaluate competing design solutions using a systemic process to determine how well they meet the criteria and constraints of the problem.

MS-ETS1-3. Analyze data from tests to determine similarities and differences among several design solutions to identify the best characteristics of each that can be combined into a new solution to better meet the criteria for success.

MS-ETS1-2. Evaluate competing design solutions using a systemic process to determine how well they meet the criteria and constraints of the problem.
MS-ETS1-3. Analyze data from tests to determine similarities and differences among several design solutions to identify the best characteristics of each that can be combined into a new solution to better meet the criteria for success. 


\begin{tabular}{lcc}
\hline $\begin{array}{l}\text { Aspect of Engineering } \\
\text { Project }\end{array}$ & Project-based Learning & $\begin{array}{l}\text { *NGSS Middle School } \\
\text { Engineering Principles }\end{array}$ \\
\hline
\end{tabular}

Task 4

Collecting and Analyzing

Data on your prototype

Task 5

Report your Findings

Online and to the Class
6. Engagement in Inquiry 


\section{CHAPTER V: A COACHING MODEL FOR EFFECTIVE PD}

Education reform hinges on quality professional development (PD) opportunities for teachers; quality PD opportunities promote teacher learning, advance teacher practice, and increase student learning (Sykes, 1996). Not all PD experiences are created equally and should be examined in light of these important outcomes. A constructivist theory of learning situates students in the classroom as active learners, with the construction of ideas dependent upon firsthand experiences connected to the learning environment and the people in it. Teacher learning must also be framed within a context of practice and collaboration. Short workshop or in-service models that teach specific skills in inauthentic contexts are being replaced with PD models that situate teachers within their community of practice and foster the development of pedagogical content knowledge. According to Borko, Jacobs, and Koellner (2010), “The focus in most of the PD literature is on providing a long-term, inquiry or learner-centered structure that supports teachers as they collaboratively develop the professional knowledge they need to use in their own context" (p. 548).

\section{Effective Features of Professional Development}

Also consistent across the literature is the identification of features of effective PD. Borko, Jacobs, and Koellner identify seven features that together describe the content, process, environment, and duration of high-quality PD opportunities. Collectively, these characteristics define experiences that support active teacher-learning, changes in pedagogical content

knowledge, and gains in student achievement Research question \#1 asks, "How can a coaching approach to teacher collaboration be used to offer high-quality professional development for NGSS implementation at the elementary level?" The researcher used this collection of seven 
attributes as an exemplary standard to describe how the coaching model used in this study exemplifies or falls short of high-quality PD.

\section{Content is Situated in Practice}

To be considered a contemporary approach to $\mathrm{PD}$, the experience must be specific to

teacher needs, situated in the classroom, and address problems of practice. A one-size-fits-all approach to teacher PD fails to recognize and validate the diverse characteristics of practitioners in the field (Hattie, 2009). Teachers have a unique set of needs influenced by their background experiences, content understandings, learning style, and teaching personality. Thus, any approach advocating for teacher change must be specific to the teacher and connected to the tasks of teaching. The PD provided through the collaborative coaching model was inspired and informed by the teacher participants' expressed interest in changing their science instruction to include reform-based, student-centered strategies. Elizabeth discussed her specific concern with shifting control to students during a group reflection, "I think the whole idea of science like especially with the new standards, it kind of scares me. A lot of times, it's like, I want to do this stuff where they are investigating and getting their hands in and everything, but then I am losing control in a sense because I do not know what direction they are going to go with it." The content of the PD in the case of this research study was rooted in teacher practice. This is markedly different than a workshop model developed in isolation of teachers' specific problems of practice.

Embedding PD in classroom experience creates an iterative process that is sensitive and responsive to teacher needs. Consider another excerpt from a group reflection session:

Me- So, I think some of the stuff I have read in the literature I think is true in terms of inquiry and some drawbacks in terms of the time it takes, the resources it takes, the 
materials it takes, losing that control, putting it on the students and not knowing how much support they need. That was hard for me as well walking around, like how much do I tell them.

Ruth- I really struggled with that. I kept telling her, I got to stop, I got to stop. Elizabeth- And every year it's going to look different. Cause like next year it could be a really independent group, or it could be a hot mess. You never know what the mix is going to be.

Ruth- I was the over helper, the over, I don't know what the right word is, but I kept telling her, I got to stop. Let it lay.

Supporting student-led investigations places teachers in the role of a facilitator. Fulfilling this role requires a set of instructional skills that differ from a delivery of content using teacherdirected or prescribed activities. What is interesting from this exchange is the notion of a moving target where inquiry-based instruction is involved. Variables within the learning environment constantly change and teachers must adapt. Developing this type of PCK requires studentteacher interactions within authentic learning contexts. Elizabeth summarizes how the collaborative, experiential PD experience was more impactful than a workshop model, "There is nobody there to ask. But I really want to try this. Or, things were great, but you don't remember that workshop until after you already taught that unit. And then it's like, oh, I should have done that, but I didn't. But, I think because we were living it and experiencing it together and problem shooting with the kids as we went through it, this was so much better." PD experiences must engage teachers in these acts of teaching, observing, assessing, and reflecting; teachers must also be able to try new instructional strategies, make mistakes as they are honing their skills, and have 
the opportunity to collaborate and disclose the trials and tribulations of their journey with others who share in their experiences (Darling-Hammond \& McLaughlin, 2011).

\section{Content is Focused on Student Learning}

A science content expert and an expert science educator differ in their roles because an educator moves beyond the level of learner and focuses on how to effectively share scientific content knowledge with others. Thus, any PD experience for educators must stem from their work with students. In addition to knowledge of content and knowledge of general teaching pedagogy, knowledge of student characteristics is required for the development of science content pedagogical knowledge (Shulman, 1986). According to Hawley and Valli (2000), the content of PD must be learner-centered and focus on what students are to learn and address the challenges associated with student learning. As evident in the previous exchange between the coach and teachers, facilitating student-led investigations requires an understanding of students' ideas and abilities and requires a balance between supporting student autonomy and encouraging student growth. What is also revealed through the exchange is that none of the three educators initially entered the collaboration or the classroom with sufficient science content pedagogical knowledge. Only through first-hand experiences with students and group reflection did the educators build confidence and competence in implementing new strategies with the $6^{\text {th }}$ grade students.

\section{The Process Includes a Modeling of Instructional Strategies}

When an educator models instructional strategies in the classroom, another educator can assume the role of a learner and observe and evaluate the effectiveness of the strategy in use with students. Then, this passive observer can transition to an active participant by implementing the strategy on her own and reflecting upon her teaching. The collaboration between the coach and 
teachers was based upon the unique, significant pieces each participant contributed to the team. For example, the coach brought science content knowledge and experience as a university teacher educator. The teachers brought a wealth of experience and knowledge of multiple subjects and student characteristics including an understanding of the range of developmental levels of the $6^{\text {th }}$ grade students. Throughout the collaboration each participant assumed the role of an observer and a modeler of instructional strategies.

An example of this process can be illustrated through participant journal entries. On Day 1 of the unit, Ruth states, "It helped me so much to hear Elisha explain concepts and analogies to terms the students had questions about...It was so nice to have Elisha in class to help guide the lesson." Referencing this same lesson with Ruth, I wrote, "She allows me to take the lead on the quiz and introduce the activity. She gets more comfortable and does an excellent job at leading a discussion of how the puzzle activity is like the nature of science." On this day, I introduced an activity about the nature of science and posed questions that expose common myths regarding the nature of science. As questions surfaced from students, I used specific examples and analogies to describe terms such as theory, law, and bias. By the end of the lesson, Ruth was implementing these same strategies as she guided students through a closing discussion of the big ideas from the nature of science activity.

As the coach I also observed the teacher participants model instructional strategies appropriate for $6^{\text {th }}$ grade learners. After observing Elizabeth's introduction to the engineering challenge, I later introduced the project to Ruth's students. In my journal entry for this day I wrote, "I model Elizabeth's approach of allowing students to read and identify the problem. Students then describe how this is a form of engineering and identify what the constraints are." I also observed the teachers effectively diffuse and resolve conflicts that arose among students as 
they worked in groups throughout the unit. The teachers also demonstrated instructional strategies appropriate for the teaching of math and literacy skills. The PD process consisting of modeling, observing, implementing, and reflecting was the foundation of a very fruitful partnership and the mechanism of change in teacher practice.

\section{The Process Situates Teachers as Active Learners}

The NGSS represent the newest rendition of national standards that advocate for reform in K-12 science education. Reform-based science education by its very nature calls for change in teacher practice. These standards are another example of a top-down approach in which standards are developed primarily by professionals outside of K-12 schools and not by practitioners inside K-12 classrooms. Just as telling a student to understand something is inferior to creating experiences in which students construct their own understanding, an articulation of these standards alone is not sufficient for evoking long-term changes in teacher practice.

Teachers must be active learners, especially when they are asked to teach in ways that are different than how they learned science and/or how they learned to teach science (Borko, Jacobs, \& Koellner, 2010).

PD opportunities that aim to be transformative, that is, they aim to affect teacher practice long-term must avoid the top-down approach to providing support. Lectures, workshops, and inservice days that are orchestrated by professionals at the district level or higher and are presented by external experts and organizations are not teacher-driven and do not account for the specific factors present in the teaching environment (Bell \& Gilbert, 1996 as cited in Appleton, 2008, p. 526). Active teacher learning must be situated in the day-to-day activities of teachers as they interact with their students. Teachers like students construct new understandings through experience. In creating and implementing the $N G S S$-aligned lessons, the participants as teachers 
actively planned, taught, and reflected each step of the way. But these teachers and coach also assumed the role of a learner, engaging in the activities from a student perspective to test and mediate their own conceptions about the nature of science and teaching at the elementary level. For example, once we had developed the teaching materials for six station activities on the nature of science, we set a time to meet together after the school day to run through each station. Ruth writes in her reflection, "Met after school to run through stations. Finalized materials and resources...glad that we did because there was a lot I would have forgotten." In my journal, referencing the same point in time of the planning stage, I wrote, "Teachers have an overwhelming amount of resources in the Google Drive, but explicitly discussing the nature of science and planning the content is the best way to identify gaps in teacher understanding. It also reveals my lack of knowledge of elementary education- terms, specific strategies, and appropriate level of content for $6^{\text {th }}$ graders including math and literacy skills." In order to expose and confront our preconceptions and construct new understandings, we had to actively engage together in the tasks of learning and teaching.

\section{PD Builds Learning Communities and Supports Collaboration}

Wenger and Snider (2000) describe communities of practice as groups of people who are united by a common passion or goal, and through this shared interest interact regularly and expand their knowledge and/or skills through these interactions. A community of practice serves as a palpable example of the socio-cultural constructivist theory of learning proposed by Vygotsky; knowledge construction is socially mediated through purposeful and meaningful communication and interactions with others (Vygotsky, 1978). The heartbeat of the type of PD explored through this study was the successful collaboration between the coach and teachers. The relationship that developed among the participants provided the courage to test out the 
waters of reform-based science teaching and sustained these efforts over the course of a fiveweek unit.

All participants entered unchartered territory in their attempts to plan and implement an $N G S S$-aligned unit with $6^{\text {th }}$ grade students. Each participant made significant contributions to the collaboration, but each participant also lacked expertise in some area critical to the success of the unit. For example, Ruth and Elizabeth expressed a feeling of anxiety regarding the NGSS; they had little familiarity with these standards and were frustrated by the absence of district guidance and the lack of instructional materials available online. I shared my reservations about teaching science to sixth grade students in an intermediate school classroom. I was apprehensive to walk into a classroom that would expose my lack of knowledge of developmentally appropriate content for math, literacy, and science for $6^{\text {th }}$ grade students. Although we had different backgrounds, strengths, and weaknesses, together our differences proved to be very complementary. The following conversation brings the nature of this collaboration to light. Elizabeth- I think too like with our different roles like you validated what we brought, too. We were constantly looking at what you brought, the resources, the clearer understanding of what the standards are. But like we have had coaches that have done a good job of this in the past in language arts and reading and stuff where they validated what we brought too. We felt validated.

Ruth- You made us feel good.

Me- And I felt the same way. It feels good to bring an idea and you were like, wow, I like that. Because you could have shot down the ideas that I brought. So, I think everybody played an important role, and I think that is what made the collaboration feel good. Nobody wants to be part of a collaboration where they feel like they are not doing 
enough. Nobody wants to be part of a collaboration where they feel like they are doing everything. I just feel like we had a good mix where everyone was doing something, bringing something. And, I definitely felt like I learned a lot. I mean there would be things that I did a certain way and they you guys would do in a different way that would make sense for sixth grade and for your students.

We held a shared purpose and passion for creating quality science learning experiences for the students, but we also each made unique contributions, creating a whole that was bigger than the sum of its parts.

\section{PD is Grounded in School Practice and Integrated with Applicable Reform Efforts}

PD should be situated in classroom practice to affect teacher and student outcomes and also should expand beyond the classroom walls as part of school-wide reform initiatives. According to Darling-Hammond and McLaughlan (2011), "New initiatives cannot by themselves promote meaningful or long-term change in teachers' practice if they are embedded in a policy structure that is at odds with the visions of student and teacher learning that reforms seek to bring alive" (p. 82). This study took place in an intermediate building where the $6^{\text {th }}$ grade teachers, like most elementary teachers, are responsible for teaching multiple subject areas including math, English language arts, social studies, and science. Within the research setting, the school and district levels seem to be the missing link between the reform advocated by the NGSS at the top level and the PD support provided in the classroom at the ground level through the coach-teacher collaboration.

In the initial interview Elizabeth and Ruth discussed long-term changes in their teaching of mathematics due to district-wide initiatives that provided school-wide policy changes and ongoing classroom support. Elizabeth revealed, "But it is always literacy and math-based stuff. We 
have had Math Solutions come, but we have never, at least since I have been in the district have had science professional development or something for social studies. It is totally for math and reading or writing." Ruth explained further, "There have been so many changes that I think they are struggling to keep up with the math and the reading that science hasn't been a focus. So, they have told us they want us to use the new standards, but we haven't really sat down and looked at them at the grade level. We just were recently given the units we need to focus on because we are not really junior high, and they are written $6-8$, so $7^{\text {th }}$ and $8^{\text {th }}$ grade sat down and kind of did a scope and sequence with them, so out of that they told us what units we should be covering. We just have titles, titles are all they gave us." Her journal echoes this feeling, "I am excited to work with Elisha to develop a science unit. I feel completely lost when it comes to understanding and implementing the new standards. We have been given very little direction from the district."

Compounding the issue is the pressure applied by more frequent state-mandated standardized testing in literacy and mathematics, forcing the district to focus time and resources on those subjects. During the initial interview, the principal investigator, Elizabeth, and myself discussed this as a limiting factor present in the participants' school environment.

Me- I want to be helpful, but I want to know how to help you and what works best. I just have always found it interesting that schools have coaches in literacy and math, but they don't have science coaches. Why not? Would that be helpful?

Elizabeth- I absolutely think it would be. Because I feel like so much is weighted on math and reading for professional development. But then...

Principal Investigator- That's what the test are.

Elizabeth- Exactly. 
Based on my own observations in the field and my interactions with the teachers, I concluded that these educators were eager to engage their students in the practices of scientists and engineers; but to take this leap into reform-based science teaching, they wanted to collaborate with other professionals to plan and implement NGSS-aligned lessons.

Administrators can strengthen teacher efforts in the classroom by shaping the school landscape to encourage collaboration among educational professionals. Opportunities to build supportive learning communities among educators can take many forms: school/university partnerships to bridge theory and practice, classroom teacher/classroom teacher collaborations to share in the day-to-day challenges of teaching, school/school networks to compare curricular design, school/community-based organizations to connect learning experience inside the classroom with authentic contexts outside the classroom, and teacher participation in district, regional, and national activities than inform policy and standards decisions (Darling-Hammond \& McLaughlan, 2011). The collaboration between the coach and teachers provides an example of a partnership between a university faculty member and classroom teachers. The findings in the study suggest that this form of professional development embodied most of the features of effective PD. However, through my eyes as the researcher/coach, this "data point" felt like an isolated case of science PD and not part of an expansive agenda for school-wide change in the teaching of science.

\section{PD Activities are On-going and Sustainable}

The literature suggests that the duration of PD in terms of contact hours- a recommended minimum of 20 hours- and the span of time over which the PD extends correlates to the effectiveness of the PD. (Desimone \& Pak, 2017). Coaching as a regular fixture in the school setting certainly meets this criterion. Desimone and Pak state, "Unlike the much-maligned PD 
one-shot workshop, coaching is usually an activity that is ongoing throughout the school year. Coaching involves continuous cycles of reflection and action to foster teacher growth" (p. 7).

The coaching process used in this study was of a sufficient duration to impact teacher and student learning. Over a period of six weeks, the coach and teachers met at least three days a week to plan and co-teach a unit of instruction focused on students' exploration of the eight NOS understandings presented in the NGSS framework. Chapter VI delves into the participant characteristics and needs, coach-teacher activities, and the nature of the coach-teacher relationship as a function of time. Chapter VII discusses changes in teacher perspectives and practice. Chapter VIII describes how the changes in teacher perspectives and practice influenced student outcomes.

In the initial interview the teachers were asked, "If your district required you to select and implement an NGSS-aligned science unit, how comfortable would you be with completing this task?" At this point in time, the teachers had only looked at a list of science topics provided by junior high teachers in the district.

Elizabeth-We were just given three of them in June and we have printed them and that is about as far as we have gone.

Ruth- You did a little research and found that there is not a lot out there.

Elizabeth- One of them is the water cycle and the research I was finding was more for primary and then trying to find out what that looks like with junior high, middle age level kids is ugh.

Ruth- I think the inquiry-based and the STEM is what we want to move toward, but like you said, it is going to be uncomfortable because we are not as familiar and it is something we might struggle with, but it is something we both want to do. 
When this same question was posed again during the concluding interview, Elizabeth and Ruth appeared more confident in their ability to implement the NGSS-aligned NOS unit.

Ruth- I think if it was this one, I would be very confident... I am really happy with the end product. I am really comfortable with it. I don't know if we could do as good of a job as when we had Elisha helping us. She was definitely a powerful resource for us.

But, I do know where to look now. I know what it is supposed to look like. I would feel comfortable taking a stab at it. I make no promises.

Elizabeth- Yes.

While the collaboration reflected most aspects of high-quality PD, when examining the coaching approach according to its sustainability, findings suggest the potential for long-term effectiveness is present but dependent upon on the allocation of time and resources afforded to teachers by the district. Again, this short-coming directly relates to this study's case of PD in science being an isolated example- the exception, not the rule within the participants' district.

The participants have had previous experiences with coaching as a form of professional development in literacy and mathematics. During the initial interview, they shared these experiences and identified the specific qualities of these coaches and the collaborative activities that they felt improved their instruction. However, even in areas of literacy and mathematics, this type of classroom support is limited by available funding. Elizabeth expanded upon this issue during the initial interview.

Elizabeth: I feel like, too, and this is not their fault, but I feel that sometimes our coaches are spread too thin. Like in the building the size of ours...there are 600 kids in our building. And, so, usually they are mentoring the new teachers which this year we have three new teachers... and even though she was in my room last year we would plan 
together, but it may only be one day where she could be there consistently, or I am going to come but it will only be for the last half. So, I feel that is not the coach's fault at all, but it is a funding issue. It is a great idea, but you need more of them.

After a review of research exploring the effectiveness of PD in improving science education, Whitworth and Chui (2015) emphasized how PD can be enhanced or thwarted by teacher motivation, school culture, and the working conditions of the school context; they also conclude that more research needs to be conducted on the role of school and/or district-based leaders to provide domain-specific PD. As a mechanism of science PD for educators working within budget constraints and limiting planning time, the idea of teacher leaders providing coaching support to colleagues was discussed in the initial and final interviews. Consider the following excerpts on this topic from the initial interview, prior to the planning and teaching of the instructional unit:

Coach: That is why maybe a model could be teacher leaders. You know, this starts a chain reaction. You guys become comfortable and do some units and it spreads. Other teachers might be like, hey, my students might like to do that. You have been through it. Ok, now I can help you. So, basically it becomes that the workload is spread out. You guys are leaders on certain units and other teachers are leaders and someone takes the lead on getting resources, so it is not on you all of the time, kind of a sharing of resources and sharing that leadership role.

Elizabeth- I think that is. I think that spreading that way. When I look at some of the professional development we had, some people were grumbling because one of the presenters was a coach, but the only interaction with students was a group of five kids. Well, they don't really get what it is like. It is not real when you have only one 
intervention group and you're telling me to do all of these assessments and do all of this stuff, but I think coming from other teachers it's...

Coach- They walk the walk.

Elizabeth- You are living it.

Ruth- I think they are moving toward teacher leaders. Wasn't that on the table? I think there was some discussion about how we were going to go away from the coaching and go more towards teacher leaders.

Elizabeth- Because of budget stuff

Coach- Well, that is what I am thinking. How logistically will it work out to hire science coaches if you said you are already limited in resources, the number of coaches per teacher per student. Maybe a better model that could be implemented more quickly is teacher leadership.

Elizabeth- Yeah. And with every year with budget cuts, we have lost our interventionist. It has been several years since we have been able to have small groups for interventions. The coach we still have been able to hold on to, but is that just a matter of time? Because I think it is valuable.

Ruth- Being part of the curriculum team, Elizabeth and I have lead out in the past and we talk about what we do in the summers with our $6^{\text {th }}$ grade...That is not something we are uncomfortable with. So, that is something I would definitely do. I would be interested in that opportunity to share with others in the school what we are doing... That is probably the only way that we will get the science curriculum going is if we take it on ourselves. Sixth grade, for us, we have to do it on our own time. 
In the concluding interview, after the participants implemented the NGSS-aligned unit with students, the principal investigator posed the following questions to the teachers, "If your district asked you to support a colleague with NGSS implementation, how comfortable would you be with completing this task?" Both Ruth and Elizabeth indicated that they supported other $6^{\text {th }}$ grade teachers in implementing the same unit with their students. They shared the unit's instructional materials and resources on the nature of science with an entire team of sixth grade teachers and each assisted a partner teacher with the implementation. Elizabeth cited Ruth's role as a teacher leader for Ruth's partner teacher, "Well, I think it is neat that your teaching partner did the unit that we had created together right after. So, she was able to look at Ruth and be like, how do you do this or what should I expect with this. So, that was like the domino effect." The $6^{\text {th }}$ grade team at the school plan to sustain the implementation of the nature of science unit and will teach the unit at the beginning of the next academic year.

How sustainable will the changes in teacher practice be in the absence of a coach as additional science units are modified to better reflect the expectations for student performance outlined in the NGSS? When asked in the concluding interview if the teachers plan to incorporate more reform-based science teaching in the future? Both teachers indicated that they absolutely planned to continue to modify science lessons to incorporate the NGSS. However, they did express concerns over the feasibility of taking on that task in the absence of a coach. Even though we proclaimed our collaboration and its product a success, this victory did not change the plethora of obstacles present in the research setting. Moving forward, these teachers continue to face situational constraints such as a lack of materials to conduct science activities, little planning and instructional time for science, zero professional development in science, and little 
opportunity for teachers in grades K-8 to collaboratively plan lessons in science that follow a scope and sequence. Ruth explains:

We attempted to do the water cycle together and then we kind of quickly got...with conferences and report cards and grades, and then we couldn't, we pulled resources but then the collaboration got put to the waste side. It has been a struggle, I feel like we haven't done as many hands-on things. We didn't push ourselves as hard as we could of. We started out with the water cycle and the problem is that a lot of the things we wanted to do with the water cycle, they required heat and it is hard to do when you do not have a lab, and you can't have heat in the classroom other than warm water. So, that was difficult. I will say though that we did use some of those resources that she had listed for us to go and look at. So, that helped a lot. It is always nice to have an extra set of hands in the classroom. I know that is not always feasible... but, we did use those resources and we did try to attack it from more of a hands-on, but it just wasn't as hands-on as we were the unit before because of the materials, more than anything.

The demands of teaching multiple subjects made finding time for these teachers to collaborate and plan for the water cycle unit difficult. The teachers did try to select hands-on activities from websites I had suggested for the nature of science unit, but these activities required equipment, lab space, and/or materials the teachers could not access easily. I was not surprised to hear that these teachers tried to approach the next science in a manner consistent with the NOS unit, but unfortunately, I also expected that this would be a difficult feat, given the demands of their everyday workload. In the concluding interview, I shared this concern, based on my first-hand experience as a fellow collaborator: 
Me- I will say from my perspective, we worked really well together, and I felt like it was very rewarding to come each day and put things together. But, it was a lot of work. For me, it was a lot of hours a week to help. And, so for you to have to tackle that on your own in addition to everything you are doing, I really see now... is it feasible, yes, but without support, no. After this experience I really don't think it is. I feel like these standards are very ambitious...quality, I think, but like I have said before, just like you have math support and reading support, I think there needs to be science support.

Ruth- I whole-heartedly agree with that.

Elizabeth- Yes.

Over a three-year period, as a district-wide initiative and with on-going professional development and external organizational assistance, these teachers began to shift their teaching practice toward standards-based mathematics teaching. While the seed for reform-based science teaching was planted through the coaching approach to PD, this "seed" will not establish roots or produce fruit without the proper supports in place. To nurture teacher growth, on-going support must be provided over an entire school year to assist teachers with the planning of multiple science units. The planning and implementation of these units requires the greatest level of collaboration, gathering/creation of instructional resources and materials, and cycles of teaching and reflection. Beyond this stage, it is possible that teachers can assume leadership roles to sustain the teaching of these units and catalyze changes in teacher practice across the district. Table 7 summarizes the alignment of the coaching approach with effective features of PD. 
Table 7

Alignment of Coaching Approach with Effective Features of PD

\begin{tabular}{|c|c|c|c|}
\hline Aspect of PD & Feature of PD & Coaching PD & Rationale for Rating \\
\hline \multirow[t]{2}{*}{ Content } & $\begin{array}{l}\text { 1. Content is situated in } \\
\text { practice }\end{array}$ & + & $\begin{array}{l}\text { Support informed by } \\
\text { specific teacher } \\
\text { characteristics and needs }\end{array}$ \\
\hline & $\begin{array}{l}\text { 2. Content is focused on } \\
\text { student learning. }\end{array}$ & + & $\begin{array}{l}\text { Collaboration focused on } \\
\text { the goal of improving } \\
\text { student learning }\end{array}$ \\
\hline \multirow[t]{2}{*}{ Process } & $\begin{array}{l}\text { 3. The process includes a } \\
\text { modeling of instructional } \\
\text { strategies. }\end{array}$ & + & $\begin{array}{l}\text { Coach and teachers } \\
\text { modeled instructional } \\
\text { strategies }\end{array}$ \\
\hline & $\begin{array}{l}\text { 4. The process situates } \\
\text { teachers as active } \\
\text { learners. }\end{array}$ & + & $\begin{array}{l}\text { Teachers planned, } \\
\text { implemented, and reflected } \\
\text { upon science teaching }\end{array}$ \\
\hline \multirow[t]{2}{*}{ Environment } & $\begin{array}{l}\text { 5. PD environment } \\
\text { builds learning } \\
\text { communities and } \\
\text { supports collaboration. }\end{array}$ & + & $\begin{array}{l}\text { Collaboration was the } \\
\text { foundation of supporting } \\
\text { teacher practice }\end{array}$ \\
\hline & $\begin{array}{l}\text { 6. PD is grounded in } \\
\text { school practice and } \\
\text { integrated with applicable } \\
\text { reform efforts. }\end{array}$ & - & $\begin{array}{l}\text { Isolated cased of PD in } \\
\text { science }\end{array}$ \\
\hline Duration & $\begin{array}{l}\text { 7. PD activities are } \\
\text { ongoing and sustainable. }\end{array}$ & $+/-$ & $\begin{array}{l}\text { Collaboration was intensive } \\
\text { and a sufficient duration to } \\
\text { impact teacher and student } \\
\text { outcomes. To maintain } \\
\text { changes in teacher practice, } \\
\text { support must continue } \\
\text { beyond one science unit. }\end{array}$ \\
\hline
\end{tabular}




\section{CHAPTER VI: THE COACHING PROCESS- EVOLUTIONARY CHANGES}

Teachers who venture into the world of reform-based teaching require support as they translate research to practice; Knight (2009) suggests that coaching can offer the right level of support, "Coaching is not a one-shot workshop, but rather differentiated professional support, meeting each teacher's unique needs over time" (p. 18). Research question \#2 asks, "Based on the characteristics and needs of the teacher-participants, how does the coaching model develop throughout the implementation of the NGSS unit?" The coaching process employed throughout the study was directed by the needs and characteristics of the teachers. It evolved over time in response to changes in the teachers' perspectives and practice.

\section{Teacher Characteristics}

The introductory interview, participant journal entries, and teaching reflections served as rich data sources for describing teacher characteristics at the beginning of the teacher-coach collaboration. The following dispositions, common among both teachers, surfaced from a close

review of these sources. These teacher perspectives proved to be critical to the collaboration and the success of the unit.

\section{The Teachers Were Comfortable with Collaboration}

When the PI asked how the teachers would feel about their district providing another educational professional to support their efforts throughout the planning and teaching phases of teaching science units, Elizabeth replied, "It would be awesome," and Ruth immediately agreed, "Yes!" These teachers are no strangers to collaboration. In fact, they seek out and take advantage of opportunities to collaborate with other educational professionals, often sacrificing their lunch time to do so. Working collaboratively with other educators to plan and reflect upon teaching is embedded in their daily practice. They collaborate each week with a team teacher to 
plan and implement lessons, they meet monthly as a $6^{\text {th }}$ grade team to share ideas and discuss problems of practice specific to $6^{\text {th }}$ grade, and they coordinate their teaching efforts over the course of the year with $6^{\text {th }}$ grade teachers from the other intermediate school in the district. Ruth and Elizabeth also participate in on-going collaborations with literacy coaches and mathematics specialists. They view all of these instances of collaboration as opportunities to grow as teachers. They do not view these collaborations as intrusive on their space or time. For example, when we reflected upon the nature of our collaboration, I voiced my concern about my continual presence in their classrooms.

Me- Some days I felt bad. You guys are so busy and I felt like oh, am I being intrusive? Here I am coming again and you guys are trying to juggle so much, so I just kind of wondered how you really felt about having this person who just kept constantly hopping in all of the time.

Elizabeth- We will keep you every day...No, it was awesome.

Ruth- No, we were grateful for you being there. On the days that you weren't there for science, I was a little like, oh... it's just me today. I am running this ship alone! (laughs) Knight (2009) suggests that mutual interest and investment in working together toward a common goal can protect and sustain the coaching relationship. Throughout the collaboration, these teachers exhibited a balance between commitment and flexibility, a willingness to teach me and learn from me, and a confidence from old experiences and a humility in entering new experiences.

\section{The Teachers Were Willing to Take Risks}

Ruth and Elizabeth expressed how this leap into reform-based science situated them outside of their comfort zone. In her journal, Elizabeth wrote, "Science done right makes me 
nervous at times because I don't always know what is going to happen! It can feel uncomfortable because as teachers we like to be in control and ready for all possible situations, and the idea of releasing some of this control scares me! It is good to know that I have Ruth and Elisha to back me up though!' In the student role, these teachers also appreciated and thrived off of structure and routine. Consider the following conversation about the possible risks associated with this type of teaching from the introductory interview:

Elizabeth- I think it's just a little bit...it's not what we are used to. So, it's uncomfortable and you can't really predict what is going to happen. I mean you can have a goal, but if the goal is for them to explore then you don't know where that is going to lead.

Ruth- I think...I agree with Elizabeth, with being uncomfortable. The risk I see is that we will have some kids that will shut down. Maybe we might need to talk about how we are going to help those kids when they shut down.

Me. Um hmm. I have definitely seen, and it's interesting to see, from observing different student teachers... We have a requirement in our program where they have to teach an inquiry-based lesson or unit. And what is interesting, what we have found, is that the straight-A, top of the class students are struggling because for the first time they are not told exactly what to do. They are very good at, you tell me, and I will show you, I will do it. And a teacher walked up to me and said, "You see that student right there, almost in tears, that is my top student. She is really struggling with this." And then you have some students who are the ones that can't normally sit still and are always asking, sometimes pushing you...but these students really strive because they are like this is cool; they are naturally curious and want to mess with things. 
Elizabeth- And they are used to that almost inquiry process because that traditional way of I teach it, you repeat it doesn't work for them. So, this is a whole new learning thing for them.

Me- And I wonder what we will find with students...that might be interesting. But, you are right, some students might shut down because it can be frustrating.

PI- Some things I discuss with my students is... how comfortable are you with ambiguity. And I have students who want to know what we are doing every day. The high-end students, they want the whole schedule on the first day. But I am like yeah, this course doesn't work that way. So, they are like, what are we going to be doing on October 17 because I am not going to be here. I am like, I am not going to tell you what we are doing on October 17.

Me- And I bet they are so uncomfortable.

Ruth- I was that kid. I still am that kid.

Elizabeth- Well, I feel like a lot of teachers were that kid though. That might be why they are drawn to teaching.

Ruth- I wanted to know what I needed to do. I wanted to make sure I did it. I was a teacher-pleaser. That was me. So outside of the box... there is no showing the right answer... that is scary and especially for those kids who are anxious about their grade. Me- I would have been like...if I get this wrong, can I still have all of my points? Despite their own instinctual desire for routine and predictability as learners and their reservations about shifting control to the students in the classroom, these teachers were still willing and excited to embark on this journey with me. 


\section{The Teachers Care Deeply About Student Needs}

Initially, Ruth voiced concerns about our ability to adapt science instruction to meet the diverse needs of her students. She wondered how we could differentiate the lessons to accommodate students with varying exceptionalities.

Ruth- Do we have an alternative for them? Do we give them... you know what I mean? I also have an inclusion class, so I may have kids that are working on it at a much lower level, $1^{\text {st }}, 2^{\text {nd }} .3^{\text {rd }}$ or $4^{\text {th }}$ grade depending on what they come within that range. So, I am obviously going to have to have an alternative. I am going to really have to make some accommodations, too.

Me- Maybe it is the level of support we give to them. If we are both in the classroom, maybe we can divide and conquer and give different levels of support.

PI- With those students, you may be asking different questions... which is absolutely fine. Based on interactions with the teachers to plan the unit, my experiences co-teaching the lessons, and my observations of their interactions with students, I concluded they these teachers keep their students' needs as a top priority. During a time of reflection, I asked them, "Do you think teaching in this way requires more time, materials, resources, and things like that?' Ruth responded, "Absolutely, but based off of the level of engagement with the kids and how much they learned, it is well worth it. I mean, this is what you are shooting for; this is what you want for your kids. So, I definitely think it was worth it.”

\section{The Teachers Were Eager to Identify Misconceptions and Develop PCK}

In the initial interview, one of the questions asked the teachers to describe a science unit that they are proud to have implemented with students. They discussed a unit on the scientific method. 
Ruth- I would just say that the scientific method one we did at the beginning of the year. It seemed to be the most engaging, but I wouldn't say any of them are stellar. I don't know.

Elizabeth- We have done cells and matter, and again like trying to make those...but again I think it's kind of how we were taught. The engaging part or the exciting part is that they are making the cookie cell, but it is not inquiry-based.

Ruth- No. And I did one with genetics this year that I really liked. I started but I don't think any of them are a finished product. You know what I mean?

Elizabeth- Yeah.

PI- What was is about the scientific method unit you said you felt they were really engaged?

Elizabeth- I think we kind of... it has evolved. Because the first few years we did it, we had activities we did that we liked. But then it ended to where we had a science fair. And the kids were really excited about that. But we even saw where like the first year we did it the kids just found their project, and they were like, this is cool, but they were basically repeating a project they found on the internet to prove that yeah the person who put it on the internet is right. Well then next time we did it we had them pose the questions and you try to figure it out. And they came up with some really cool questions. One kid was always really annoyed that the garbage bags that they use at the school are really thin and when you go to take them out, they always rip, so he was testing with different textbooks and how many textbooks, and he was testing different garbage bags. And like I would have never thought about that and I don't think he found it on the internet. 
Later in the interview, the PI asked, "Is there a particular science unit or project you have implemented in the past that situated your students as scientists?" The teachers referenced the scientific method unit again.

PI- The only wrench in that is going to be... according to the NGSS, there is no such thing as the scientific method.

Elizabeth- Oh?

Ruth- Really?

PI- As long as you are logical, as long as you are using facts and you are arguing with evidence...those sorts of things...there is not one method or another that is better or worse...Well that kind of like you know, that's typically how it was taught. You memorize the five steps and then it is well, how boring must it be to be a scientist is everything you do, you have to follow the same five steps.

Me- Well, yeah. There used to be posters... every step was a poster. Step 2 Gather information...That is what I grew up with.

PI- Well science isn't done that way. They write it up that way, but it is not in that order. I remember doing research at the university and well, this professor is just doing trial and error. He is not following a procedure. When you get it all done... Elizabeth- To report it out...

PI- Yes, you ended up having to kind of put it in those steps. The scientific method didn't come from science. It came from John Dewey. He was writing about what some good steps to critical thinking would be; some educator said that seems like a good way to teach science. The scientific method was born, but scientists have never done it. 
These teachers did engage students in the practices of scientists by prompting them to ask questions that could be explored by gathering empirical evidence. Their teaching of one universally-applied scientific method did reveal a common misconception about the nature of science. These teachers were surprised to hear that scientists do not follow a prescribed sequence of steps but can approach investigations differently depending on the nature of the question. These teachers were ready to confront this misconception head-on and anxious to develop the skills necessary to facility student-led investigations. When the PI asked them what they needed from a science coach, Elizabeth answered, "Show us how to teach science. Well, I think a way to address misconceptions that we might have about how to teach this.

Because...because my mind is blown right now that the scientific method wasn't intended for science. That's... that's wow...I would be curious what kind of class... what would be the breakdown of that how much of it is what I do, how much of it is what we do, how much of it is what you do?” And Ruth replied, "Well, I am sitting here thinking that I am over-teaching science. I am doing too much of the teaching when they should be doing more."

\section{The Teachers Were Willing to Learn Alongside Students}

In the initial interview, Elizabeth and Ruth were cognizant of how this experience could expand their own understandings of the nature of science. They welcomed the role of learner. Elizabeth stated, "I think it also might be good that it is something that we are not familiar with because we are going to be learning right along with them. When they are asking questions, neither one of us is scared to say, "I don't know." You know I think we need to say how are we going to figure this out. So maybe this is a good thing." And Ruth agreed, "When you are struggling, that is not a bad thing. That means you are learning." This attitude toward learning alongside students was evident as we began to teach the lessons together. We all entered each 
lesson well-prepared with instructional and activity materials ready to go for the students, but the open-endedness of the activities meant that we could not anticipate all of the students' questions nor have all of the answers up front. Both Ruth and Elizabeth were comfortable referring students' science content questions to me and sometimes they looked to me to validate or elaborate upon their explanations. This created an atmosphere where students and teachers were free to ask questions and construct new understandings together. I also felt comfortable calling upon the teachers' expertise when interacting with the students. It was also really helpful to hear Ruth and Elizabeth make connections between science and the other subject areas they teach.

\section{Teacher Needs}

The positive dispositions held by the educators were an encouraging factor that facilitated the planning and teaching of the unit over time. However, this work did not occur in a vacuum and was subject to other factors present in the teaching environment. The teachers' instruction of science has been influenced by limiting factors present in the school setting, and some of these factors we had to address to successfully implement the unit. Three central themes emerged from the data in regard to limiting factors present in the teaching environment- time, resources, and support. The teachers need additional time to plan and implement lessons, a greater availability of instructional resources and class materials, and support focused on science instruction.

\section{Time}

At the school site, the daily schedule allots 45 minutes total for both science and social studies. Science instruction alternates with social studies instruction, so a unit in science is followed by a unit in social studies. As Ruth explained in the introductory interview, "I don't think it is a lack of caring about the science and social studies. I think our principal is $100 \%$ 
absolutely behind us doing it, and wanting us to do this, but it's time, it's time." Instructional time for science is limited by the daily schedule and planning time for science is also minimized due to the school's emphasis on science and mathematics. The following conversation gives a clearer picture of how the teachers approach instructional planning on a daily, monthly, and yearly basis.

PI- Do you have time to collaborate with other teachers when planning and implementing units of instruction?

Ruth- Yes, sixth grade meets on Tuesdays mainly to discuss math, but that doesn't mean we can't talk about science. So, we do collaborate a lot. However, we haven't put a lot of time in for science. Would you agree with that?

Elizabeth- Uh huh, yes, the main focus in our district has been on math and language arts. But then we also meet with language partners and then with the other intermediate school.

Ruth- Uh huh, once a month we do that and then we meet at our own school within our own grade level, weekly.

PI- Has there always been time built in for the $6^{\text {th }}$ grade team to plan? Elizabeth- The only time we have built in is our lunch.

PI- Okay, so you're just motivated enough to work that out. Elizabeth- Yeah P1- do it over sandwiches... (Both teachers laugh and audibly agree) These teachers are highly motivated to collaborate with other professionals that share common goals and teaching experiences. However, the way they divide this time amongst the multiple 
subjects they teach is heavily influenced by standardized testing, district goals, and school policies.

\section{Resources}

The teachers also emphasized a lack of resources for science teaching as a significant barrier to implementing learner-centered activities. For example, during the initial interview the PI asked, "What factors influence the time and resources you spend on teaching science each week?" Elizabeth notes, "I feel like there is a limited amount of resources that the school is

providing. Because I mean we have a textbook, but it is so old. It came with a nice kit that if we wanted to do the labs that came with the textbook, but again, it's so old. So, a lot of it is us finding the resources, too." In addition to instructional resources, the teaching environment lacks materials, equipment, and a space suitable for laboratory-based activities. I asked how feasible applying the NGSS would be to their everyday practice, and the teachers cited some specific examples of these types of resources.

Me- Yeah, like taking these standards, moving forward, how feasible is it for you guys to do?

Ruth-Without your help, really, really hard.

Elizabeth- Yep, Yep

Ruth- But I mean together, I think we definitely can do it. As far, well, really, honestly, once we get into it, finding the resources is going to be really, really hard. And we don't have a lab. We are in a sixth-grade classroom, so we don't have those things. Elizabeth- No sinks.

Ruth- Yeah, no sinks, we don't have those things. So those might be some obstacles. Me- So, like situational constraints, like the classroom. 
Ruth- Yes, we have some obstacles to hurdle.

\section{Support}

These teachers were able to share many past experiences with PD in mathematics and language arts, but not one instance of PD in science. The district has indicated that the NGSS should inform science instruction, but these $6^{\text {th }}$ grade teachers have not been given any guidance beyond this directive and the $7^{\text {th }}$ and $8^{\text {th }}$ grade teachers giving them a list of science topics to teach over the course of the academic year.

Ruth- There have been so many changes that I think they are struggling to keep up with the math and the reading that science hasn't been a focus. So, they have told us they want us to use the new standards, but we haven't really sat down and looked at them at the grade level...I don't think there is a clear vision on what they are expecting. I feel like across the board, no one knows what these are supposed to look like when we are teaching.

PI- Yes, right.

Me- Yeah, like what the final product should be?

Ruth- Yes, Yes.

Elizabeth- and I love the idea that it isn't like "it has to be just like this." I like that it is more open-ended, but then we still need some type of gauge of what is acceptable. The way I understand them is by the end of eighth grade, you will be able to do this. But it's kind of like, where should we be by the end of sixth grade in order to be there by the end of $8^{\text {th }}$ grade.

Me- Yeah, so it's a bit ambiguous. Especially for you guys being caught in the middle. You'll see 6-8 units and K-5 and the way your school is, you are in the middle. 
Elizabeth- And even in our ability to collaborate with the junior high teachers, with them not being there, that makes it hard. They don't get to see what is happening in our classrooms and we do not get to see what is happening in their classrooms.

Elizabeth and Ruth have enjoyed opportunities to collaborate with other sixth grade teachers; however, they have not collaborated with teachers from other grade levels to plan out a progression of science content. They have not collaborated with fellow practitioners, nor have they collaborated with any other type of educational professional to interpret and apply the NGSS to their teaching of science.

One theme that is often reported in the literature as a factor that affects the quantity and quality of science education at the elementary level is the teachers' background, or more specifically, an examination of the teachers' course work in the sciences and science method courses. The researcher purposely chose not to focus on this factor because she felt to do so would be approaching the collaboration from a deficit point of view of teacher ability. The participants reciprocated with an affirming view of coach ability; the researcher did not question the ability of these teachers to implement reform-based science teaching, and the participants did not question the researcher's ability to serve as a coach for science instruction at the sixth grade. We entered the collaboration confident in our ability to contribute something valuable toward our shared goal of implementing and NGSS-aligned unit. We felt that our collective approach gave us a "strength in numbers" mentality, and we were eager to learn from each other as well. So, although we identified obstacles in our path, we were prepared to address them together. 


\section{Teacher Expectations for Science Coaching}

Based on their experiences with literacy and math coaches, Elizabeth and Ruth could easily identify specific coach qualities and activities that collectively supported their classroom practice. Consider the following descriptions of Elizabeth and Ruth's first-hand experiences with coaching.

PI- I think that you have good relationships with the coaches that you have. So, what was good about those relationships?

Elizabeth- I think that knowing that they were both bringing something to the table. I have had three different coaches and I think knowing that they were knowledgeable in their content area and what they were training us in, I guess. And also being appreciative of there being another set of hands that are there to help with problems.

Ruth- Previously the two coaches prior I worked with were amazing in the fact that I could just be honest and say that I am really struggling with this. What do you think about this? No judgement. You were free to brainstorm and come up with ideas. And they were not dismissive of your ideas. They tried to incorporate your vision for the lesson or the unit. And then she would just run with it. She was a wealth of information and then she would say that is great. Let's do this and this and what do you think about this. So maybe it was your seed but she made it happen and you would need more resources. She would come in and say, ok, I got this and I got this. She would go above and beyond. She would pull resources. She was amazing.

Elizabeth- Whatever she could take off your plate, she would. And she saw the value of each teacher individually. And could see that this is something that you are passionate about so how can we pull that in because that passion will spill over to the kids. So, if it 
was a nonfiction unit we were supposed to be doing, well, this is a topic that you like teaching so let's pull that in here, too.

Me- What you are describing. It just reminds me of research of what I have seen on coaching and characteristics of a positive relationship.

In consideration of these past experiences with coaching, the teachers' characteristics, and the challenges present in the teaching environment, a list of expectations were constructed to identify the type of support a science coach should provide educators moving forward.

During the introductory interview, the PI asked, "What is the first thing you would need from a science coach?" And Ruth simply stated, "a starting point." These teachers had been given a mammoth task to perform, to implement science units aligned with the NGSS standards with zero support. They had little familiarity with these standards and little instructional and planning time to tackle a renovation of their science teaching. They were looking toward me as the coach to help them navigate the NGSS framework, to identify where $6^{\text {th }}$ grade fits within the learning progressions, find valid instructional resources, provide helpful background information on science content, assist in co-teaching lessons to model instructional strategies, engage in the cycle of teaching and reflecting together to develop the right level of teacher guidance during student-led investigations, and to adapt instruction to meet student needs. When the PI asked, "What roles could a science coach fulfill that would assist you in teaching science in a manner consistent with the NGSS?" Elizabeth replied, "I think they would, kind of going back to the literacy coach, not only would they have to jump in and help us plan lessons, but they would have to teach us what it can look like and how to implement it." Ruth agreed, "Exactly. And, I think time is our biggest enemy when it comes to doing these science units. So, having their knowledge of the standards and also having how they would implement it with the inquiry- 
based. I think they would have to break it down for us. That right there is huge." Figure 3 illustrates the relationship between these factors- teachers' characteristics, needs, and past experiences with coaching- and the expectations for science coaching.

Figure 3. Factors Influencing Expectations for Science Coaching

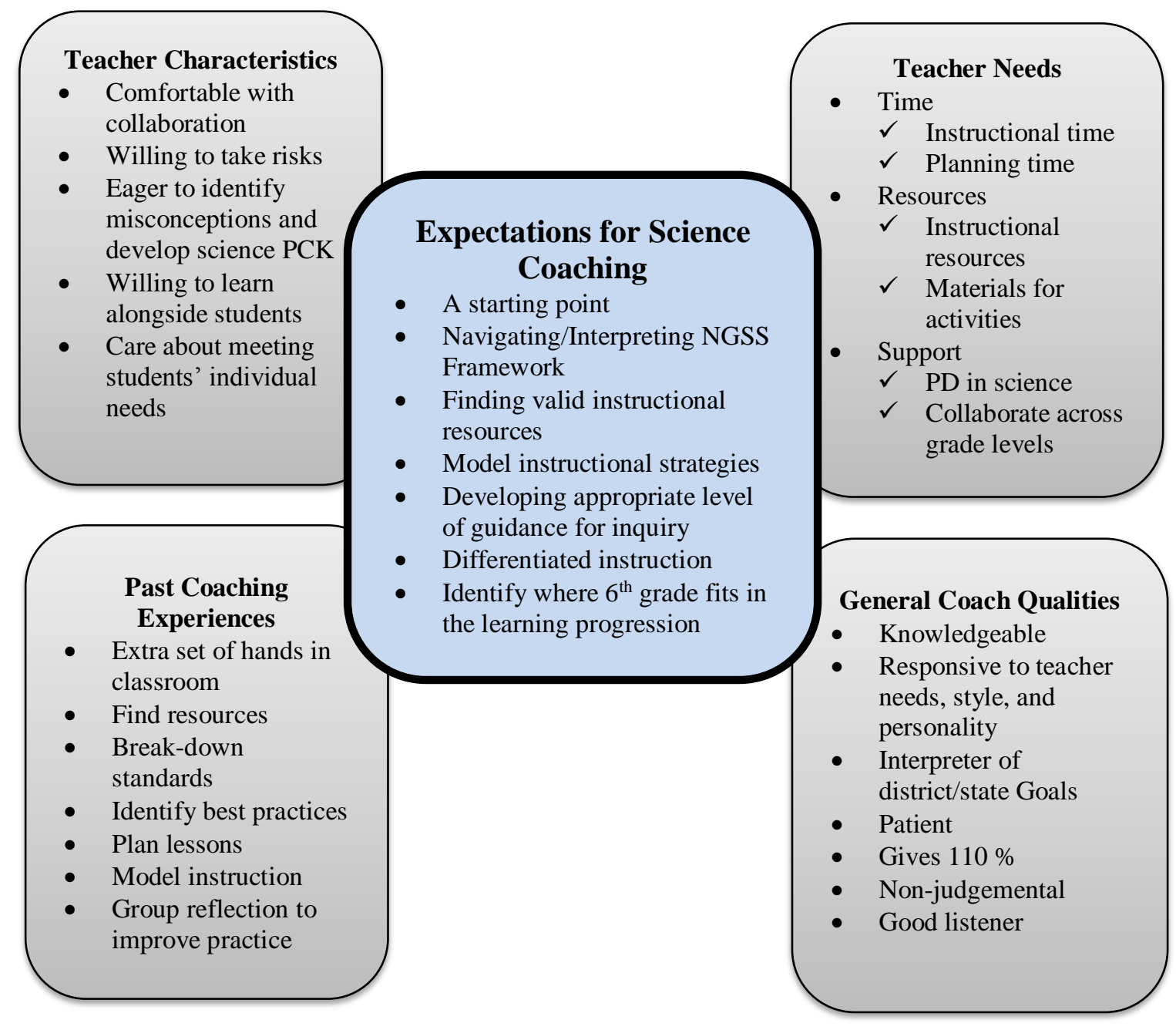

Figure 3. The researcher created a list of expectations for science coaching based on the

synthesis of the following factors: the teacher characteristics, needs, and past experiences with math and literacy coaching. Figure 3 illustrates these contributing factors in relationship to the list of expectations. 


\section{Coaching Activities as a Function of Time}

\section{A Starting Point}

My strategy to provide support as a coach was to focus my attention on the teachers as assets to the collaboration and as the directors of activities. I summarize this method in the instruction for students on the nature of science, with the goal of laying a foundation of science skills that would be relevant to all the remaining science units throughout the school year. So, with these needs in mind, I created a shared, password-protected folder online to share resources on the NGSS framework, the nature of science, the 5E instructional model, and examples of $N G S S$-aligned lessons across grade levels. Using these resources, we began to plan our unit on the nature of science using the learning cycle and the 5E BSCS instructional model to inform student-led activities. As we planned these activities, our team approach revealed itself. We exchanged ideas and used our individual strengths to create and modify lessons appropriate for the $6^{\text {th }}$ grade students. Our journal entries provide a time stamp of our feelings at the beginning of this process.

Me- I need to provide resources on the NGSS and use backward design starting with the performance expectations.

Elizabeth- I am so grateful for the resources Elisha has shared with us! At first it felt overwhelming to have so many things to choose from, and that is where her expertise and suggestions help to guide us in the right direction.

Ruth- Elisha set up a shared Google account and loaded it up with resources.

Brainstormed possible layout of unit and identified standards. Feel better because I am starting to grasp or get an idea of where we are headed. 
We were excited to dive in and co-create materials, but we did have our work cut out for us. We were planning a five-week unit on the nature of science considering the students' characteristics, the NGSS, the 5 "E" of the learning cycle, and common core standards to integrate math and literacy. In my journal, I describe this initial hurdle, "This process is like organizing a messy closet. It gets worse before it gets better. When you pull everything out, decide what to keep and throw away, and worked to organize the space, it is messy and complicated. However, the end product is beautiful and makes life cleaner and simpler in the end." Elizabeth also recognized our struggle at the beginning to make sense out of a wealth of information, "And I think the amount of support being heavier at the beginning; our meetings were long and we were doing more researching and reading. But, once we got into it and it got rolling, that is really when that partnership was like kind of unspoken at times. I don't know, it just flowed really well."

\section{In the Thick of It}

Once we mapped out our unit, it was time to add the meat to our skeleton. To create the instructional materials and supply the necessary materials for student activities, we took a "divide and conquer" approach. We all contributed to the lesson planning, co-taught the lessons, and spent time reflecting together each day. One of my journal entries provides a specific example at how we effectively combined efforts to prepare for the unit. I wrote, "This collaboration is becoming seamless. We each contribute something. Elizabeth suggested we review vocabulary. Ruth suggested we use a word sort activity. I said, let's focus on these words." We also described this working relationship in the concluding interview.

PI- What roles should a science coach fulfill to assist elementary educators who are teaching science in a manner consistent with the NGSS? 
Me - I think finding resources and getting materials together. It was actually really awesome. We did a lot of co-teaching together, which I thought was...I enjoyed that. This was an interesting project because I was the researcher, but I was also a participant and I am so glad they said... like at the beginning you said, why don't you co-teach, and I was like great.

Ruth- And we were like, yes!

PI So, how did the co-teaching helping you?

Ruth- She was role modeling for me. I would listen to her explain things and then I would be like ok, this is how I need to explain it next year. By watching Elisha I know what I needed to do for the unit next year.

PI- What qualities should a science coach have?

Elizabeth. I think one of the things I appreciated most about Elisha was that she didn't come in and was like this is how to be and I am in the science guru and I know everything. She very much validated us and was like you know the kids, you know this age level and like what are they capable of. And, if we said say something that was a management thing or an organizational thing, she would be like, oh my gosh, I never thought of that, like, that's awesome, thanks for bringing that in...it was just very positive. And even though everything science related, I would still look at her, like, are we doing this right? I felt so appreciated as like being able to contribute something. Ruth- I agree with that $100 \%$.

In the midst of teaching the lessons, we leaned on each other for support. As a unit we gained the confidence and the facility to implement these lessons; we divided up the workload and had one other in the classroom to model instructional strategies that were new to us, based on our 
background experiences. Throughout the collaboration, we engaged in a continuous cycle of coplanning, co-teaching, and group reflection.

\section{The Homestretch}

Toward the end of the unit, we presented an engineering challenge to the students. I provided support in terms of outlining student tasks in alignment with the NGSS engineering design principles. However, once the instructional packet was created, the teachers took the lead during the teaching phase. The teachers arranged the logistics of implementing the tasks. They also used heterogeneous grouping to establish teams of students and advised me through the process of integrating math skills appropriate for their students. They created a procedure for students to survey the teachers and principal at the school to evaluate their product. They arranged for a member of the community to present the engineering challenge, which added an authenticity quality to the project. On the last day of the project, I walked in to observe, Ruth facilitating students' presentation of findings. At that point in the collaboration, I was an extra set of hands in the classroom, and I had the opportunity to observe reform-based science teaching in action.

To gauge students' growth in their understandings of the nature of science, the teachers developed an assessment in which students had to select specific examples from their experiences as learners during the unit to explain each of the nature of science standards.

Elizabeth provided a detailed explanation for the PI in the concluding interview.

Elizabeth-We had taken some of the...our initial assessment had some of the standards as true/false statements and we took those and made those true statements and then the kids had to look at the different explore activities and then identify which of the standards they had learned in the activities. And it was interesting to see because it wasn't like 
there was a right or wrong answer in that. All of them saw different standards in play in different activities. Because there was so much in there.

Me- Because that was the nature of science statements. At first, we just started out with the myths, the True/False statements. And this was something they did on their own. I wasn't even here for this. They came up with this assessment where it had the statements as all true and then the students had to pick out evidence of how they understood and could explain.

Figure 4 illustrates how coaching activities progressed over time as we planned, taught, and reflected upon our unit of instruction. Figure 4 also provides a review of the valuable and unique contributions we made toward accomplishing our shared goal. The nature of these contributions changed over time as the teachers' needs, perspectives, and practice changed.

Knight (2011) describes seven principles that can be used to characterize the partnership between teacher and coach. The partnership principles include: (1) equity- sharing ideas and making decisions as equals, (2) choice- teachers choose coaching goals and practices, (3) voiceconversations are open and candid, (4) reflection- a continual reflection on learning, (5) dialogue- discussions are two-way, with the ideas of others just as important and heard as ideas from self. (6) praxis- new knowledge and skills are applied within context or omitted from practice, and (7) reciprocity- interactions are fruitful and allow everyone to learn (p. 18-20). The coaching activities presented in Figure 4 provide an example of these principles in action in the classroom as coach and teachers collaborated to plan, teach, and reflect upon the NGSSaligned unit. 


\section{Coach-Teacher Relationship- The Foundation of Support}

A review of all the data sources brings to light three themes or pillars that together established a collaboration based on mutuality. Ulichny and Schoener (2010) describe mutuality within research as a relationship of "equal status based on mutual respect and concern" (p. 422). Equal status, respect, and concern was demonstrated through trust and dependability, an appreciation and validation of equal but unique contributions, and a shared sense of community

\section{Trust and Dependability}

To engage in educational practice that differs greatly from how you learned science as a student, and how you generally instruct science as a teacher involves risk. To practice a new skill, there is a learning curve, and putting more decision-making and control in the hands of students can generate a fear of the unknown. The teacher-participants expressed these concerns, but they also indicated that a collaborative effort could provide comfort and strength as they took on this challenge. Because we each had both strengths and gaps in our abilities based on our different backgrounds, we trusted in each other to contribute unique pieces while also having a willingness to learn from each other. We discussed these feelings in the concluding interview.

PI- Well, even, to me, it sounds like that even though there were risks, the fact that you were doing this together really kind of minimized that because even if you would have left the baking soda at home or whatever, but the fact that you have someone upstairs that you can rely on.

Elizabeth- That whole team approach

Me- Yeah, being able to collaborate and know that you are not alone. But, I think that is a risk these teachers took. It was more involved, more work, more materials, more prep. And you do not necessarily know how your students are going to do with it. How 
Figure 4. An Illustration of Coaching Activities and Participant Contributions over Time

-Searched for NGSS-

vetted lessons

-Created and filled

shared folder with

resources on the

NGSS, NOS, 5E

Instructional model, \&

Engineering Design

-Shared background

knowledge of science content and

instructional strategies

for teaching science

Interpreted NGSS

framework to plan

lesson activities

Shared ideas for lesson activities and lesson modifications
-Created instructional

materials

-Gathered and prepared activity materials

-Co-taught lessons

-Modeled instructional strategies

-Integrated math skills into engineering challenge

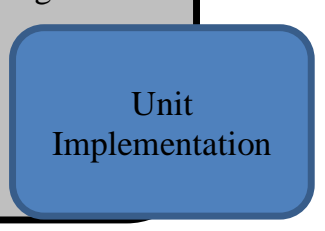

Day 1

Planning

$\leftarrow$ Continuous cycle of Group Planning, Implementation, and Reflection $\rightarrow$

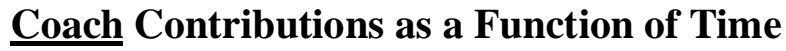

Extra set of hands in the classroom

-Observed teachers organize and teach lessons

Conclusion of Unit
-Studied and discussed content of folder with resources on the NGSS, NOS, 5E Instructional model, \& Engineering Design

-Shared background knowledge of teaching science, math, and literacy skills to $6^{\text {th }}$ grade students

Shared ideas for lesson activities and lesson modifications

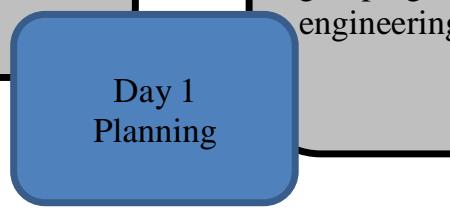

-Created instructional materials

-Gathered and prepared activity materials

-Co-taught lessons

-Modeled instructional and classroom management strategies

-Informed level of math skills and student grouping for engineering challenge
-Organized parent help for engineering challenge

-Organized Café manager to propose engineering challenge

-Implemented tastetesting survey for student products

-Guided Student Presentations of Findings

-Created Assessment on NOS standards
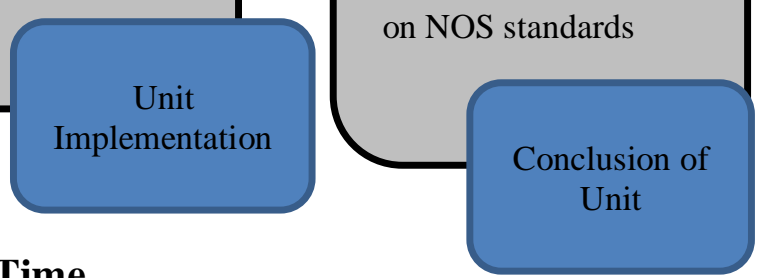

\section{Teacher Contributions as a Function of Time}


Figure 4 outlines the progression of coaching activities as a function of time and teachers' needs. It demonstrates the contributions made by the coach and teacher participants toward the collaboration to implement the NGSS-aligned unit of instruction.

responsible they are going to be with the materials. Because it was a chemistry thing and they had to be productive and safe. It is a risky thing.

This conversation describes a mystery powder activity we did with students in which they collected qualitative data on a set of powders and then had to use this data as a reference to identify an unknown. This activity required a lot of materials, and we spent a lot of time putting together kits for the activity. There was a potential for students to be distracted by the materials, a potential for spills, and a potential for students to misuse the chemicals. On the first day, we realized that the kits were missing certain items and we also noticed the students, so excited to do the lab exercise, had difficulty focusing on the work to be done. I was not surprised by how hectic this activity was in the beginning, but Elizabeth and Ruth were frazzled on this first day. Elizabeth beautifully narrates how this learning curve, while scary and steep at first, levels out with practice.

Entry 1-I am realizing that once we hand them the kits, I am losing a bit of control! I am glad that we were able to map out what this needs to look like, but I think that I really need to experience it to truly know what it will look like.

Entry 2- Day one did not go as planned, but there were many successes. The excitement of the kids was like puppies in a playroom! They are craving this type of learning, and I 
feel guilty that my fear has held me back from doing this...I am glad we have time to debrief and think it through again before Ruth's class has science.

Entry 3-The second day was so much smoother. The kids were engaged and acting like real scientists!

These teachers took a risk and put faith in the collaboration to pull them through these moments in which experience is the best teacher. This example illustrates a teacher being put out of her comfort zone but trusting in the approach and in her partners to get her to the other side.

\section{Validation and Appreciation for Equal but Unique Contributions}

On day one of the collaboration, we established that our relationship was based on mutual respect, a true partnership. In her journal after our first meeting, Ruth wrote, "Elisha has a wealth of knowledge that we lack, and she wants our knowledge of the students and their skill level." Midway through the collaboration, Ruth wrote, "We seemed to have established a great rapport and everybody brings something valuable to the table. We are all excited when we're planning." This sense of mutuality yielded a fruitful partnership that supported and sustained our efforts to successfully plan and implement an NGSS-aligned unit of instruction. We emphasized this in our concluding interview.

Me- I think we all came into this thing nervous. We knew some things but there were things we didn't know. So, it is always nerve-racking when you are going into something and you feel like you don't have the background. I definitely felt that way. I knew I had a lot to learn from the experience.

PI- So a partnership, maybe as much as it was coaching

Elizabeth- yeah, yeah.

Ruth- mmm hmmm 
Me- Yeah, I wouldn't really say I felt like, hey I am your coach. It was a collaboration, and we all had pieces that we contributed

Elizabeth and Ruth audibly agree.

PI- We all bring pieces.

Elizabeth- mm hmmm

\section{Shared Sense of Community}

I was a secondary science educator for three and half years, and unfortunately, I never experienced a collaboration of this nature. I never felt a sense of belonging with my colleagues. As participants in this study and as educators in the classroom, we fostered a sense of community that supported our work. Looking back at my short stint in the high school classroom, I think it is possible that I would still be teaching high school chemistry today if I could have developed this same sense of community in my school. I expressed this in our informal interview which explored our thoughts and feelings on the planning and implementation phases of the unit.

Me- When I was a high school teacher, my department chair was like one of your goals should be to teach more inquiry-based science, but I got absolutely no support. I would send her things and she wouldn't get back to me. And I was like I do not know if this fits or not? And then I would try to do it, but then I was like I don't know if this is what I am supposed to be doing. And I was all alone, like all alone. I think if I had another teacher that was teaching the same subject...

Ruth- Yes, someone to bounce ideas off of and get feedback Me- ...so you don't feel like you are flying solo. It is more comfortable when you are collaborating, and you have that other person like you said to bounce ideas off of. 
Having a common purpose, a genuine concern for one another and the students, someone to lean on during times of tribulation, and someone to share in the joy of triumphs tethered us together. This connection continued to support the teachers in my absence. Ruth explains, "It was nice that it wasn't just two people involved, that there were two teachers involved. Because when you were not here, then we could talk. We did a lot of talking about ok, what are we looking at, how do you think this is going to look... you know just helping each other plan and prep." Our sense of community personifies Wenger and Snider (2000) description of communities of practice as "groups of people who share a concern or a passion for something they do and learn how to do it better as they interact regularly" (p. 139). Figure 5 illustrates the aspects of mutuality present in the research setting. 


\section{Figure 5. Components of Mutuality}

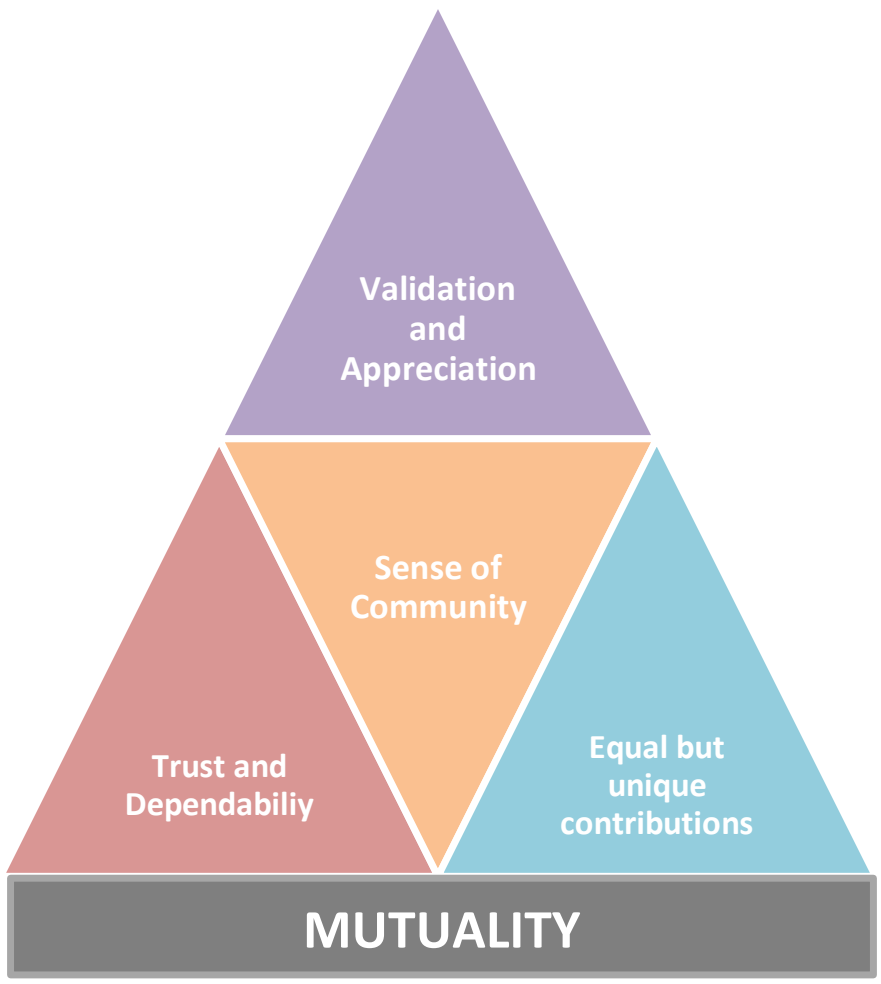

Figure 5. The coach-teacher relationship was based on mutual respect and equal partnership. In the research setting this mutuality was built from trust and dependability, a validation and appreciation of equal but unique contributions, and a sense of community. 


\section{CHAPTER VII: TEACHER PRACTICE- REVOLUTIONARY CHANGES}

Research Question \#3 asks, "How can a coaching model as PD for NGSS implementation be used to catalyze changes in elementary teachers' science teaching practice?" In the initial interview, the teachers were surprised to discover that their teaching of one scientific method does not truly capture the complex, iterative, and creative activities scientists engage in when exploring scientifically-oriented questions (McComas, 1996). They were also intrigued with the learning cycle approach to lesson planning and the 5E BSCS instructional model. One hope or expectation they expressed for me as a science coach was to simply point them in a direction, to get the lesson planning ball rolling. They had reviewed the NGSS and were overwhelmed by the task of applying the framework to their classroom practice. During the initial interview, the PI suggested using the learning cycle as that starting point.

PI- One of the things in the NSTA journals that they use a lot of to focus lesson planning on is the learning cycle. Do remember that?

Elizabeth- Of course I do (we all laugh)

PI- Every article is a 5E lesson plan.

Elizabeth- Really?

PI- Yes,

Ruth- What? The 5E what? What is the learning cycle?

PI- The learning cycle is a lesson plan that basically is engage, explore, explain, elaborate, and evaluate. So, those are the 5Es.

Ruth- Oh, ok 
PI- So, basically, I don't know if the NSTA adopted it or what but basically if you are looking at any science field article, and it's about a science lesson, it is all done in the 5E format. The learning cycle is very consistent with the NGSS.

Elizabeth- The learning cycle is not necessarily something new.

PI- No, it's been around since the 60 s

Elizabeth- That is what I thought.

Me- It's kind of like a mechanism, I kind of think it is a slick mechanism to use the $N G S S$. It meshes well with the NGSS. You were talking briefly about it. You know first, you perk their interest, then you start to ask more questions, then you begin to experiment or explore more, and then they kind of explain. It is a natural progression that has inquiry embedded into it.

PI- Yes, that would be my suggestion as a way to get started looking at lessons if you are looking at the NGSS, think, "Well, can I put it into a 5E lesson plan?

Elizabeth- Yes, I like that.

During our first week of planning, I posted resources in a shared online folder for the teachers to review. These sources gave the teachers more background on the NGSS and how to interpret the framework, examples of $N G S S$-vetted lessons, readings on common NOS misconceptions, and more information on using the BSCE 5E instructional model and projectbased science to implement the NGSS. While our first planning sessions were long and challenging due to quantity of resources and the chore of applying this information to create a five-week unit, once we started to outline student activities in alignment with the learning cycle, the pieces started to fall into place. In the concluding interview, the PI asked, "What have you learned about the NGSS framework and its vision for K-12 science education?" We respond 
with a discussion of how we used the BSCS 5E instructional model to apply the standards to lesson planning and how through its implementation we observed the students progress through the learning cycle.

Elizabeth- I think the biggest thing I learned was the 5E format and seeing how that can apply not just even in science but in other like lessons but then the whole idea of like the engineering and how that played into it and like I'm seeing like bits and pieces I feel like of different standards where I wasn't really aware of them before. But now it's like, Oh I recognize that because we had talked about that.

Ruth- I feel like she really helped us break them down and learn how to find resources to meet those standards, so I really felt like I also got a better understanding of how we can even attempt to approach them because they're so general and broad, and so she really just helped us by let's get our bite size off and attack it from there. And I also love the 5E format and the way it was taught.

Me- So, the way we approached it, it was like the 5E model on steroids. Like, each phase was really long and in depth, but we really followed that. They progressed. They were able to do it. Their explorations helped them to be able to explain, and then they could elaborate. It was cool to see them progress through those stages.

After implementing our unit with students, I think my initial description portrays a true depiction of the BSCS 5E instructional model; the model provided us with a mechanism to plan lessons that put students' active learning as the central focus and embedded the three-dimensional learning advocated by the NGSS. 


\section{Changes in Practice}

According to Grossman et. al (2009), "Practice in complex domains involves the orchestration of understanding, skill, relationship, and identity to accomplish particular activities with others in specific environments" (p. 2055). Changes in these variables- understanding, skill, identity, and relationship building- were examined to describe changes in practice as teachers shifted their instruction toward reform-based science teaching.

\section{Teacher Understandings}

Like the students, the teachers held specific preconceptions regarding the nature of science. These preconceptions came to light during the introductory interview and the initial planning sessions. As co-collaborators with related but different professional experiences, we all made significant contributions to the planning and teaching of the unit. We were able to have open and candid conversations about any gaps in our background knowledge. If the teachers had questions about science content, they were not afraid to say so and ask questions to clarify their Ideas about the NOS. Ruth and Elizabeth's understandings evolved as they actively participated in lesson activities as learners and teachers. As an example, consider how Elizabeth's conceptions regarding the nature of science changed over time. She references her preconceptions about the NOS prior to the planning of the unit:

I think like even though it was kind of over whelming at first, the amount of information and resources, it was good that we looked through that stuff, especially the one that had the 15 misconceptions, that was one that we were like, there is a lot of stuff in here, but make sure you read this one because this is all kind of stuff where we were like, wait this isn't a thing? We thought this was true. 
Later in her journal, she documents her change in thought as a result of planning and walking through the station activities together, "By dividing up the writing out of the station directions, I think it gave me a better understanding of the standards that we were hoping to address with the pre-test. I am so glad we were able to meet several times to get ready for this first experience with the kids." During the concluding interview, the PI, teachers, and I discussed our use of the engineering design project to engage students in the NGSS Science and Engineering Practices.

PI- I mean it's kind of cool because part of the engineering part is... you do this test, you gather your data, you make your decision to make this kind of a change. Then you collect the data, you analyze the data, and then you make another change. So, you can almost argue that when you start doing NGSS and inquiry, you start engineering. Because inquiry...it makes so much sense to start with engineering rather than science. Elizabeth- It does.

Ruth- mm hmm.

Elizabeth- And it breaks down that whole idea of a scientist sits down and they write a hypothesis and then they begin the process. It really is a trial and error thing.

The previous academic year Ruth and Elizabeth taught a unit on using the scientific method to investigate student questions. This unit gave students a voice and choice in what they studied, tapping into their natural curiosity. However, the prescribed set of scientific method steps used to guide their investigations did not reflect the complex, diverse, and creative work of scientists. Our collaboration- the continual process of group planning, teaching, and reflecting- and our use of the NGSS to inform our instruction affected the teachers' NOS understandings. This is especially evidenced by Elizabeth's final comment during the concluding interview excerpts above. 
As a researcher in the field I observed this transformation first-hand as well. In Ruth's journal, she wrote, "We then created a plus/delta anchor chart of each station to gain feedback, and the students related the Big Ideas on every station that we were trying to teach! Yay us!!” Referencing this same day, I documented in my journal, "Ruth reviewed all of the Big Ideas from each station while also probing students for the pluses and deltas." These Big Ideas directly connect to the eight NGSS NOS student understandings. Ruth effectively facilitated a class discussion that explained each of the NOS understandings introduced in various station activities. In this teaching moment, she demonstrated her own personal growth in NOS understandings.

\section{Skills}

The work of Joyce and Showers (1982) outlines five functions of the process of coaching that support teachers' application of newly developed skills to practice: (1) provision of companionship (through mutual problem solving and reflection), (2) giving of technical feedback (constructive feedback of the skill in use), (3) an analysis of application (developing the ability to discern when skill should be used), (4) adaptation with the students (paying attention to student responses and adapting skill appropriately), and (5) personal facilitation (providing encouragement and support through the practice phase) (p. 6-7). This list captures the functions of the coaching process employed throughout our collaboration and also the type of support our partnership provided to foster the teachers' shift toward reform-based science teaching. Every task, challenge, and feeling of anxiety associated with trying something new, we experienced together as a team. We searched and evaluated resources suitable for our unit of instruction and through the application of our separate filters, we created a unit of instruction that successfully translated the NGSS from paper to classroom practice. In addition to Tables 6 and 7, Table 8 
exhibits our application of the NGSS framework to lesson planning. Table 8 presents an alignment of unit activities with the NGSS science and engineering practices.

Table 8

An Alignment Between the Instructional Activities and the NGSS Science and Engineering Practices

\section{NGSS Science and Engineering Practices Instructional Activity}

\begin{tabular}{|c|c|}
\hline 1. Asking Questions and Defining Problems & $\begin{array}{l}\text { The Mystery Powder, Engineering Design } \\
\text { Challenge }\end{array}$ \\
\hline 2. Developing and Using Models & Station Activities \\
\hline 3. Planning and Carrying Out Investigations, & $\begin{array}{l}\text { Station Activities, Engineering Design } \\
\text { Challenge }\end{array}$ \\
\hline 4. Analyzing and Interpreting Data & $\begin{array}{l}\text { Quantitative Versus Qualitative Data, The } \\
\text { Mystery Powder, Engineering Design } \\
\text { Challenge }\end{array}$ \\
\hline 5. Using Mathematics and Computational & Station Activities, Engineering Design \\
\hline Thinking & Challenge \\
\hline 6. Constructing Explanations and Designing & The Mystery Powder, Engineering Design \\
\hline Solutions & Challenge \\
\hline 7. Engaging in Argument from Evidence & $\begin{array}{l}\text { The Mystery Powder, Engineering Design } \\
\text { Challenge }\end{array}$ \\
\hline $\begin{array}{l}\text { 8. Obtaining, Evaluating, and Communicating } \\
\text { Information }\end{array}$ & $\begin{array}{l}\text { Station Activities, The Mystery Powder, } \\
\text { Engineering Design Challenge }\end{array}$ \\
\hline
\end{tabular}

One particular problem of practice associated with facilitating student investigations, is knowing the appropriate level of guidance to give students. As cited in Shabani (2010) Vygotsky's Zone of Proximal Development provides a basis for scaffolding students' learning experiences, "The idea is that individuals learn best when working together with others during 
joint collaboration, and it is through such collaborative endeavors with more skilled persons that learners learn and internalize new concepts, psychological tools, and skills (p. 238).” As facilitators of this learning process, teachers must provide assistance that boosts students' current level of development toward the next level of achievement in skill and/or knowledge. What level of assistance is appropriate? This question depends upon the learning environment, the characteristics of peer collaborators, and the characteristics of the learner. As we hashed out the complexities of developing this skill as practitioners, one common thread was revealed, facilitating student investigations requires experience and must be adapted according to factors present in the classroom setting. The following conversation took place during the concluding interview.

Elizabeth- And I know with the research because we have used research for reading and writing things too and knowing how much because they are not really very experienced with it and then we are constantly in those other content areas, like man, their research is terrible, but they really didn't know how to do it. But the folders you put together for them were awesome because it focused what they needed to do but it wasn't like the answer is in paragraph 2. They had lots of things they had to read through, they had specific purposes of what they were looking for but it wasn't like Google.

Me- I think that is some of the pitfall with inquiry is that the right level of support is not given to the students. It isn't implemented correctly in terms of the level of guidance that you have to give. It wasn't like we were like, hey, you have to make a great cookie. We made sure that we gave them support in terms of what are the ingredients in a cookie and what is their role...we kind of gave them some direction. 
PI- I am still trying to figure that out. I teach this new inquiry course and students, the last two things they do are independent investigations and you know that I have learned that you do not just sit back and say ok you're ready, these are seniors. You have to step in and do this for this group and this group needs this help. It does feel much more individualized per group.

Me- I think you always have to adapt to what group you have, so it is like a moving target.

Ruth and Elizabeth expressed their natural affinity towards having control in the classroom. They were apprehensive to relinquish that control to the students. Accordingly, our unit's emphasis on student-centered activities and student-led investigations placed them out of their comfort zone. The corresponding shift in practice was difficult for them and not a feat to be accomplished overnight. In my journal, I note Ruth's frustration with her own tendency to interfere and provide too much assistance to students, "Ruth constantly mentions that she interferes too much when students are working on these problems. She is learning through experience what level of support is appropriate in student-centered inquiries." I believe what is so important about this occasion is not that Ruth has perfected the art of inquiry-based teaching, but that she is trying a new approach despite her discomfort and inexperience, and she is beginning to recognize that she must adapt her instruction in the classroom. In the concluding interview, she considers this experience and uses it as a reference to hone her skill for the next group of students, "This year has been completely different. So, then, honestly knowing what I know now and what we planned and knowing the unit, I know how to accommodate it better for next year. This may not go well with this group, but this is going to go awesome. Maybe, we should adapt this..." These examples, pulled from the data sources, provide a powerful 
illustration of Joyce and Showers coaching functions in action. Specific to our context and identifying the "newly developed skill" as supporting student-led investigations as, our collaboration provided the companionship, feedback, opportunity for application and adaptation with students, and personal facilitation necessary to evoke change in teachers' skill development.

\section{Identity}

With experience and an opportunity to practice new instructional skills with other educational professionals and with students in the field, the teachers took on a new sense of identity. At the beginning Elizabeth shared her fear of the type of teaching advocated by the $N G S S$, "Well, I think the whole idea of science like especially with the new standards, it kind of scares me. A lot of times, it's like, I want to do this stuff where they are investigating and getting their hands in and everything, but then I am losing control in a sense because I do not know what direction they are going to go with it." Although Ruth and Elizabeth welcomed this challenge and were excited to participate in the collaboration, this fear exposed itself at my mentioning of the engineering design challenge as a culminating student experience. We reflected upon this time during our unstructured interview.

Elizabeth- Well, I remember when we were throwing out the whole cookie thing... Me- At the beginning...

Elizabeth - I was like, there is no way we can do this. Elisha is crazy. And then she was like and then we can bring in math and dividing fractions and Ruth and I looked at each other and were like, "Oh Lord!" But it was awesome. And the kids were... When parents came in to help them mix the ingredients. Elisha and I were like, what do we do? The kids were all doing what they were supposed to. And we were like ok, we'll just leave. Me- Why is this going so well? (laughs) 
Elizabeth- They don't need us here.

Ruth- And I probably would not have had the guts to jump in and do that.

Elizabeth- Me either.

We shared these feelings with the PI during our concluding interview as well.

Ruth- I would have the guts to do it again since I have done it once, so I know how it can be managed. But yeah, that was one of those things. I remember after that day of planning, I looked at Elizabeth and I was like, oh no, here we go. This is going to be... (laughs)

Me- What did we get ourselves into? (laughing)

Ruth- What did we sign up for?

Me- In my eyes, I could have just retreated more and more and you would have noticed me being gone less and less. I really do feel like you started to take the lead. I mean I was there and I enjoyed it, but I do think you guys just started to roll on your own. Elizabeth- Our confidence went up. And that cookie thing, when you mentioned it, I think it was brought up kind of early when we were doing the readings and stuff as this was something we could possibly do, and I remember looking at you thinking, What?!? Ruth- No way. No way.

Elizabeth- We'll bake the cookies at home, or we'll do something different to where the kids are not making a big mess.

Ruth- It was so not a problem at all.

Elizabeth- Yeah, by the time we were ready, that was my favorite. Me- And then when we mentioned doing it again, you were like, yeah. I got flour, I got this... 
Ruth- It was not an issue at all. I really thought it was. But, again, there is that, you never know until you try.

Elizabeth- And don't you feel more confident, too?

Ruth- mmm hmm.

As Ruth and Elizabeth gained experience with reform-based science teaching, their confidence in teaching science improved, and they began to see themselves as science educators who are capable of using the NGSS to inform practice. In her journal, Elizabeth notes this change in identity, "The nature of science is a brand-new unit that has me questioning my teaching and beliefs from the past. It was exhausting at times, but so rewarding. Seeing that my kids were able to apply what the standards were and what we were trying to teach in the various activities made me so proud of them and us!"

\section{Relationship Building}

Changes in the teachers' understandings, skills, and identity were supported by our relationship; as equal partners and with an equal investment in and dedication toward the collaboration being a success, we created and implemented an NGSS aligned unit of instruction. The following snapshot from our unstructured interview exemplifies the nature of this relationship.

Me- Those first few days that we worked together and planning. All of us were so overwhelmed.

Elizabeth- Yes, those stations

Me- We had this big goal in mind. But, once we started piecing it apart, dividing and conquering, we just got into a well-oiled machine. And there were days where it was like, I do this, you do this, and do this, done! Our planning meetings went from an hour 
and a half to 30 minutes.

Ruth- lunch

Elizabeth- Yeah, we just met over lunch.

Me- So... I didn't want to leave. I wish was this was my job.

We were successful at obtaining our goal despite its complexity and magnitude because we built a relationship on mutual trust, respect, and concern for each other and our shared purpose. As a final example of the importance of this mutuality, I will conclude this thought with Elizabeth's final journal entry, “The support that Elisha has given us has changed the way I look at science. It isn't about the kids remembering everything on a topic but experiencing the process. I think our planning together had been so beneficial as well! We work so well together!" 


\section{CHAPTER VIII: STUDENT OUTCOMES}

Research question \#4 asks, "How can coaching as a model for professional development for NGSS implementation impact student outcomes?" The shift in the teachers' practice toward reform-based science teaching provides an example of how teachers can develop pedagogical content knowledge (PCK) in science with the correct level of support. Science PCK integrates subject matter knowledge with a knowledge of teaching pedagogy to effectively teach science to students. Teachers must develop an understanding of the concepts, practices, and ways of knowing that are central to the discipline, and their practice must facilitate students' growth in understanding these critical tenets of science. The How People Learn or HPL framework (National Research Council, 2000) describes a learning environment that ties teachers' PCK to students' learning needs. The four aspects of the environment include learner-centered, knowledge-centered, assessment-centered, and community-centered. Student outcomes were organized and characterized according to these four important aspects of a student-centered learning environment.

\section{Learner-Centered Outcomes}

According to the HPL Framework, learner-centered outcomes recognize student preconceptions, out-of-school experiences, and interests and are sensitive to students' cultural and language practices. The NGSS framework was built with issues of student equity as a priority. In planning lesson activities, we considered students' funds of knowledge and dispositions toward science learning as assets in the classroom on which we could capitalize.

\section{Sustaining Students' Excitement for Science}

An encouraging factor that supports teachers' science teaching is the students' love of science-related, hands-on activities. They enjoy learning about science, and they like to be 
active participants during the learning process. These student characteristics surfaced during the introductory interview.

Elizabeth- The kids are better at having discussions and asking questions and like looking at things in a different way and not just... uh...I teach you, you repeat type of thing. Have you noticed a difference too?

Ruth- Yes, yeah

Elizabeth- So, I think their readiness is different than what it was five years ago. Does that make sense?

Ruth- It does. I think they are better that they were five years ago. I think we are still going to have some frustrated kids. But I think they would have been frustrated years ago

Me Yes, so like in your eyes, your students are ready?

Elizabeth- Well I think anytime, I mean it can be the lamest lab ever, but if they think they are doing a science lab, they get really excited. Just in general because...

Ruth- Yes, yeah, they love science.

I observed this excitement first-hand when working with these students in the classroom. I wrote in my journal, "I do see a lot of students really excited to do this work. I hear 'This is a great day!' and 'I love this! Science is my favorite." Later in the concluding interview, the PI asked us, "What benefits are possible with this type of teaching?" Ruth replied, "I think our end product and what our students learned and how they learned it was phenomenal. They were so engaged. They looked forward to science every day...They also loved hands-on, everything was hands-on, and they were engaged and the learning process was phenomenal." The students were challenged by lesson tasks and allowed to propose their own inferences from observations and 
employ personal attributes such as creativity and background knowledge to approach problem solving. For example, during the mystery box activity, students were motivated by the challenge of using senses other than sight to characterize the structure of the inside of the boxes. They took turns, shared their ideas, and were excited to see how their ideas compared to the actual internal structure of the boxes.

\section{Sustaining Students' Curiosity of Natural Phenomena}

Another encouraging factor present in the research setting that supported our implementation of the unit was the students' innate curiosity about the world around them. In the initial interview the PI and I discussed how important it to take advantage of students' inquisitive nature.

Me- And I think honestly, that is the spirit behind the NGSS. It's like, we are teaching science out of kids. Their science experiences in classes are not always positive, so by the time they get in high school, they think, science isn't for me. I wasn't good at science. But they are not really shown the exciting, interesting aspects. Like students start out excited and curious, but then there is not time for that. There is really no time just for you to explore your curiosity. (to PI) Don't you think that is true?

PI- Yes, the problem is that science has become just another reading lesson. Applying the NGSS to lesson planning ensures that science is so much more than learning definitions of science terms or simply reading about the work scientists have already completed. It situates students as scientists, so they get to be the trailblazer exploring the landscape. Ruth identified the capacity of our teaching to capitalize on students' excitement for discovering aspects about the natural world on their own. In my journal, I documented her comments regarding one student in particular, "Ruth pointed to a student, and said, 'See him, he typically 
struggles, but he is thriving. This is totally in his wheelhouse." On this particular day, the students were completing the mystery powder lab which challenged them to identify a white powder (found in a kitchen, according to the mystery scenario) by comparing qualitative data collected on known white powders with qualitative data collected on the unknown powder. The challenge played well into students' inquisitiveness; they wanted to solve the mystery and were curious to see what happens when a variety of substances are mixed together. While their excitement to work with all of the materials was like an accelerant used to ignite a fire, their curiosity was the fuel that provided a steady, controlled burn, sustaining the investigation and focusing their efforts to make careful, detailed, and well-organized observations.

\section{Differentiating Instruction}

For the majority of our time in the classroom, we were able to circulate among groups or individual students as they completed the activities. We were able to guide their discoveries based on students' specific questions. During this time, students loved to share how their experiences in science related to their experiences with family outside of the school. For example, when interacting with students during the engineering challenge, most students shared a story about baking at home and/or cookie recipes special to their family.

The teachers also felt that when students required different levels of support to complete a task, they could modify instruction accordingly. Ruth discussed this during our unstructured interview, "I feel like once I modeled it a few times and then gave few of the groups calculators then they were like, yeah ok, we can do this. There were some that were like I can totally do this. There was one group where I had to jump in like, ok, guys we are doing this together." This quote refers to the day when students had to scale their recipe in half to meet their budget constraint of five dollars. Some groups worked independently to complete the task, other groups 
required some modeling of examples to get started, while other groups required a walk-through of the steps with a teacher.

In the final assessment of students' growth in the NOS understandings, students could cite evidence from a multitude of learning experiences. Elizabeth was pleased to see each student contributing a unique set of responses.

I think it was good though because when we did that final reflection and they had to go back and look at which of the different activities, like what standards do you think that you learned. It was neat to see what the kids pulled and connected in the different activities. Because really what was listed on their pre-test was present in everything we did...in the mystery powders and the stations and the cookies...but where they really felt they learned it, it was different for each kid.

Students were given the opportunity to reference the experiences that were most memorable and meaningful to them.

\section{Knowledge-Centered Outcomes}

The instructional unit focused on developing students' understanding of the epistemological aspects of the scientific enterprise by encouraging them to behave like scientists. According to the HPL Framework, learning activities connect to student characteristics, focus on problem solving and thinking skills including metacognition, and are authentic to the discipline.

\section{NOS Understandings}

Students exhibited observable growth in their NOS understandings from the first day of the pre-test to the group Kahoot quiz to the final NOS student summative reflection. I noted a substantial difference in their understandings midway through the unit after the station activities, "I was really impressed by the difference between when we first gave them the true/false quiz 
with the nature of science misconceptions and then the second time when we did the quiz. They got it. They were on it." Elizabeth agreed. Ruth added her observation of student growth as a result of the experimental design task required as part of the engineering challenge.

And the thing is how we worded it. We just kept saying, and we kept reinforcing, ok, what is your independent variable, what did you change? Was is the flour? They just kept hearing that. What is your independent variable. What did you change? So, on the test or the assessment or reflection or whatever you want to call it, we said ok, in the cookie experiment, what was your independent variable? So, they answered with the independent variable. They didn't have to give a definition or come up with a different scenario that they weren't familiar with. They used the scenario that they had and they were able to nail it. So, it's obviously not, I know that when they are older, they need to be able to pull that out of different experiments, but they used one of their own and they were able to identify it. That right there is the beginning. That's awesome.

Elizabeth replied, "And to get transfer from that in the future will be much easier than just, hey, memorize the definition and then transfer that to a real-life thing." Students were able to describe the components of a scientific experiment by conducting their own experiment to show a cause and effect relationship between variables associated with baking chocolate chip cookies. During the previous year, to illustrate terms such as independent variable and dependent variable, the teachers used cartoon character scenarios. Teachers noted a marked difference in students' understanding and retention of terms due to a difference in the instructional approach. The student-led investigations were personal, meaningful, and authentic as opposed to the external, hypothetical, and trivial scenarios presented on paper. 


\section{Use of Science and Engineering Practices}

Implementing a unit on the nature of science at the start of the school year has the potential to set the stage for scientific investigations throughout the rest of the school year. Elizabeth noted this in her journal, "I feel like we can have topics, but I feel that what we hit with our nature of science unit too was the skills that they need to be successful in science. No matter what unit you throw them into, they are going to make observations, they are going to need to you know like cite with evidence. So, I think those skills were important to hit at the beginning." Elizabeth also noted a difference in the students' ability to write a measureable hypothesis compared to past years. "I honestly wasn't sure if the kids were going to be able to write a hypothesis today. In the past I have gone over the definition and done activities, but they still were not able to write a quality hypothesis. I think the end product of today was much higher than what I have seen in the past." During our unstructured interview, she was really excited to share her students' use of their science notebooks to record data when the principal walked into the classroom to return a student.

Elizabeth- And they did like this impromptu, and I was so proud, but it was like in the middle of reading, but he played along of course and sampled their cookies, but a lot of them grabbed their science notebooks. And they jotted down a table to keep track of his stuff. And it wasn't like it was like get this out, do this, it has to look like this. They were doing that on their own.

Me- They understood that it was important to record.

Elizabeth- Yeah, it was awesome.

On the last day of the unit and my last day in the classroom, I was also thrilled to observe the students present their findings from the cookie experiment to their classmates. 
I shared these feeling with Ruth during the same discussion.

Me-It was really rewarding to see the students in your class come up and present their work.

Ruth- Yes.

Me- They were talking about the dimensions of their cookies and the qualities of their cookie, which one was picked over like the control and then overall, would you do...if you were to make them again, would you make the same change. That was fun to see them each do that.

The students recognized the importance of citing empirical evidence to support their claims. In communicating their findings to peers, they identified their independent and dependent variables, presented qualitative and quantitative data, and made recommendations for a cookie recipe based on their investigative work.

\section{Integration of Skills}

A theme that cut across all data sources was the students' integration of skills across subjects. Elizabeth noted this in her journal, "I love the expectations we are setting early for science! I think by letting them dive into some hands-on experiences the kids are excited! I also love that they are learning skills that will help us in so many content areas- reading directions, making observations, gathering evidence, working with partners, and I am sure I am missing some here!” Also, in her journal, she emphasized how students' efforts during the mystery powder lab related to expectations for their work in mathematics, "It wasn't just fun coming out in their conversations, they were mentioning things like the importance of taking good notes on their observations and that they had to make sure they repeated the steps precisely. Both of these skills are also math skills they struggle with, but the hands-on approach is making it stick." 
During our unstructured interview, Elizabeth shared how she used the context of our science unit to assist students with providing evidence for claims in their reading of other types of text.

Well, the carry over into other subject areas, too. Someone brought it up after the fact when we were working on providing evidence for like when they are reading a story and it was like remember guys when we were scientists you had to provide evidence, too, and that's why we made those tables and took all of those notes. So, for those kids that may not have that... reading might be struggle for them, but the science was engaging and that was really fun. So, it's like, oh it's just like the observations we made in science, I can do the same thing when I read. So, I loved seeing that carry over to something that a lot of time students struggle with.

We also discussed this same observation with both literacy and math skills during the concluding interview.

Elizabeth-I know we were somewhat concerned if the math would be too hard by having them scale the recipe in half, but I think the engineering standards align so well with our math!

Me- I think it had sticking powder, power, powder, mystery powder (laugh). It had sticking power. It stuck with them. It was maybe more memorable.

Ruth- mmm hmm (agrees)

Elizabeth- I like it too that, I keep going back to the cookie one, but having that research folder. I would totally do that again with other things too. It totally gives them a chance to research, it gives them a chance to gather the information, but it is not just Google, you can get anything from anywhere. We knew it was quality information that they had. Ruth- Yes, I agree. 
Me- Yes giving them a limited amount so it doesn't become so overwhelming.

Elizabeth- And when they are looking at the same thing over and over again, they get distracted. And having a variety too. The video and the reading. That is our reading standards is that they can look at various texts or multimedia.

These examples of subject integration illuminate the possibility of increasing instructional time for science; if subjects are integrated, science instruction can be threaded throughout the day and extend beyond a segmented 45-minute time block.

\section{Assessment-Centered Outcomes}

To guide students' learning and our instruction, we incorporated formative and summative assessments throughout the unit. According to the HPL Framework, formative assessments provide students with feedback and guidance for individual growth, and summative assessments provide teachers with information on student learning that can inform practice.

\section{Formative Assessment for Student Growth}

Our unit provided multiple opportunities for students to articulate their understandings about the nature of science and demonstrate their ability to apply the science and engineering practices during investigations. We were able to provide individual feedback throughout the unit to support their growth in both areas. We also could use some assessments to generalize student learning as a class. Ruth and Elizabeth's journal entries provides a record of some of the formative assessments we used and what they concluded about whole-class learning at different points throughout the unit.

Elizabeth (during explain phase)- Students participated in group iPad Kahoot activity and a word sort. Students have gained so much understanding about the nature of science. What words they still struggle with, the word sort helps reveal. 
Ruth (after mystery powder activity)- The students learned a ton. They were working together much better than before. All of them learned the value of making good observations and being able to back up their findings.

Throughout each instructional phase, we utilized formative and/or summative assessment tools to assess student learning and reflect upon the effectiveness of our teaching.

\section{Summative Assessment to Inform Instruction}

The engineering design challenge gave us an opportunity to observe and assess whether the students could apply their NOS understandings and the science and engineering practices to complete the tasks and develop a cookie that fit certain specifications. This approach to evaluating student performance gave students a voice and a choice in how they demonstrated their knowledge and skills. This was also the case for the final assessment the teachers created for students to personally reflect upon what they learned throughout the unit. The teachers described this assessment and some interesting take-ways from the students' feedback that they can apply to their teaching of science throughout the future.

Elizabeth- We basically just took the questions off the pre-test, turned them all into true statements, and then just listed the different activities, and they had to say like, the first part was the stations and they had to say which standards they learned through the stations.

Ruth- They just had to choose one, it's not like that had to choose all of the ones that applied, because you know certain stations you could say multiple things. They just had to talk about at least one of the standards that they learned by going through the station and just explain it.

Me- That is a great idea. 
Elizabeth- So, like the with the mystery powder, they talked about quantitative and qualitative data and reflected upon an example of each one of those. And then with the cookies, we got into the independent and dependent and control. And they had to say what those were. And when we have done this for years with the scientific method unit, they had to memorize the definition, and I still remember I would get so frustrated because we would go to take the test, and we went over this and over this and over this, and they didn't know the difference between independent and dependent. But then this time, this day, they got it.

Ruth- They got it.

Me- You think it stuck?

Elizabeth Oh yeah.

Ruth- Yes.

Me- Because more so they lived it. They actually practiced it.

Elizabeth- Yes. And it wasn't 50 different examples or scenarios they read about. They had really like three, but it stuck with them.

Ruth and Elizabeth's experience with administering this assessment with students suggests that our NGSS-aligned, project-based approach to teaching science promoted greater student retention of science terminology than a traditional, subject-based approach to teaching science.

\section{Community-Centered Outcomes}

According to the HPL Framework, the classroom allows for peer collaboration and socially- constructed knowledge. Students' out-of-school experiences and community spaces and resources are used as contexts for learning. 


\section{Collaboration}

Throughout all of the 5E phases, students worked collaboratively to make observations, share inferences, and discuss possible explanations. Through these collaborations they had to learn how to support their ideas with evidence. They also had to learn how to respectfully listen and consider alterative explanations. They had to work as a team to complete the assigned work, which involved taking turns and staying on task. We observed that the students did not always agree, and sometimes a student would shut down if the group did not agree with his or her idea. However, as the unit progressed, collaborations become more amicable and productive. We reflected upon these student interactions during the unstructured interview.

Elizabeth- And I think that is what impressed us about the kids, too. There are definitely some in here that would love to just do everything by themselves. But like, for their science, they had to work with other people. They had to share their ideas with other people. Not everything they could do by themselves. We didn't give them a choice. Ruth- We had some that just didn't want to listen to other people. Me- Yeah, like the war of wills...

Ruth- But it was good that they have to listen to other people's opinion.

Ruth discussed how proud she was of her students' ability to work cooperatively together in the concluding interview.

Ruth- I was really impressed with their overall behavior and expectations within their groups from the day they started. We started at the beginning of the year. So, we just kind of, ok, here we go. And they are not the most well-behaved class. I can say that I have a lot of behaviors, but they did phenomenal. You could see their growth, from the 
beginning to end, I could see their growth with working together, their collaboration, the way they spoke.

An example of the products of the students' collaborative efforts is included in Appendix I.

Each group had to report their experimental design and results during the cookie engineering project.

\section{Recognizing the Relevance of Science and Engineering Outside of the Classroom}

Presenting students with learning tasks that reflect the real work of scientists and engineers and relate to students' everyday lives provides intrinsic motivation for students to stay on task. We noticed a high level of engagement throughout the unit, but students' engagement was particularly high during the engineering challenge. In the unstructured interview, we discussed how posing a real-world scenario with constraints motivated students to stick to a timeline.

Elizabeth- I think it was for us, well, me especially that we had to commit to like, there was so much planning for the day with the baking that we had to stick to our timeframe. They had to be ready. I feel like when I try to do stuff that is big, hands on like this, it makes me nervous, so then I am like we will do this next week, we need another day of this...let's push it back, let's push it back. Then it gets to the point, well, we got to do this and it is never what I...But, I still feel like they had that excitement. They still had all of that, and when I think about how fast we went from write your hypothesis to baking, I mean it was a week.

Ruth- That was amazing for me because like I said I have some kids that literally everything I say I am going to do they will literally doddle...doddle, doddle, doddle. So, 
the fact that they didn't have a choice. This is how much time we were given, this is what we have to do...it forced them to be like ok, let's go and they were on task. Me- they monitored each other, too.

Elizabeth- That was awesome.

Me Yeah, I think that was of those things like the cookie project was the most intimidating. To think, ok, we are going to do this with them and they get to pick what they want to change and logistically how are we going to bake all of these different batches of cookies. I mean it worked out.

Elizabeth- It is totally feasible in the future too.

Me Yeah, but I mean that was kind of the thing that we were like, hmmm, how is this thing going to go? I think playing along with the engineering scenario and making it as authentic as possible ended up helping us. Because we were like here, this is the real world, these are your time constraints, you have to do this. And they kind of bought into it and were like, ok, we got to get it done.

Table 9 presents a summary of student outcomes according to the $H P L$ framework and the implementation of the NGSS-aligned unit. Table 10 presents reported student outcomes as a common thread cutting across all data source types, participants, and points in time. Figure 6 illustrates how students' knowledge and skills progressed over the five phases of instruction. 
Table 9

Evaluation and Organization of Student Outcomes from the NGSS-Aligned Unit with the HPL

Framework

\begin{tabular}{|c|c|c|}
\hline $\begin{array}{l}\text { Perspective of } \\
\text { Environment }\end{array}$ & Description & $\begin{array}{l}\text { Application to } N G S S \\
\text { Implementation }\end{array}$ \\
\hline Learner-Centered & $\begin{array}{l}\text { Recognition of student } \\
\text { preconceptions, out-of- } \\
\text { school experiences, and } \\
\text { interests. } \\
\checkmark \\
\text { Sensitivity to students' } \\
\text { cultural and language } \\
\text { practices }\end{array}$ & $\begin{array}{l}\checkmark \text { Sustaining students' } \\
\text { excitement for science } \\
\checkmark \text { Sustaining students' } \\
\text { curiosity of natural } \\
\text { phenomena }\end{array}$ \\
\hline Knowledge-Centered & $\begin{array}{l}\text { Learning activities... } \\
\checkmark \quad \text { connect to student } \\
\text { characteristics } \\
\checkmark \quad \text { focus on problem solving } \\
\text { and thinking skills including } \\
\text { metacognition } \\
\checkmark \quad \text { are authentic to the discipline }\end{array}$ & $\begin{array}{ll}\checkmark & \text { NOS understandings } \\
\checkmark & \text { Use of Science and } \\
& \text { Engineering Practices } \\
\checkmark & \text { Integration of Skills }\end{array}$ \\
\hline Assessment-Centered & $\begin{array}{l}\checkmark \text { Formative assessments } \\
\text { provide students with } \\
\text { feedback and guidance for } \\
\text { individual growth } \\
\checkmark \\
\text { Summative assessments } \\
\text { provide teachers with } \\
\text { information on student } \\
\text { learning that can inform } \\
\text { practice }\end{array}$ & $\begin{array}{ll}\checkmark & \text { Formative assessment to } \\
& \text { monitor student growth } \\
\checkmark & \text { Summative assessment to } \\
\text { inform instruction }\end{array}$ \\
\hline Community-Centered & $\begin{array}{l}\text { Classroom allows for peer } \\
\text { collaboration and socially- } \\
\text { constructed knowledge } \\
\checkmark \text { Students' out-of-school } \\
\text { experiences and community } \\
\text { spaces and resources are } \\
\text { used as contexts for learning. }\end{array}$ & $\begin{array}{ll}\checkmark & \text { Collaboration essential to } \\
\text { completing lesson activities } \\
\text { through the unit } \\
\checkmark & \text { Recognizing the relevance of } \\
\text { science and engineering } \\
\text { outside of the classroom }\end{array}$ \\
\hline
\end{tabular}


Table 10

Student Outcomes Commonly Reported Across Multiple Data Sources

\begin{tabular}{ll}
\hline Data Source & Reported Student Outcomes \\
\hline Initial Interview & Scientific Literacy \\
(Goals for & Critical Reader of Information \\
Students) & Lifelong Learners \\
& Skills that Transfer \\
& Independent Thinkers \\
& Student Autonomy \\
& Sustain Student Excitement for Science \\
& Students share ideas with each other \\
Planning and & Students learn to listen to others \\
Implementation & Better at reading and following directions \\
Reflection & Greater student autonomy \\
& Skills such as finding evidence and making observations carry over to other \\
& subjects \\
& Students learning about real-world constraints in problem solving \\
& Students collaborated and kept each other on task \\
& Communicated scientific findings- cited evidence in conclusions \\
& Could identify independent and dependent variables \\
& Student recognize importance of documenting observations \\
& Retention of information (sticking power) \\
& Students discussed NOS by referencing a personal experience \\
& Learned skills to be successful in science learning all year long
\end{tabular}

T-1 Reflections

Students had fun

They were excited to do science

Recognized importance of recording observations

Learned how to follow procedures carefully to keep work consistent.

Quality of hypothesis writing better this year

Students stayed on task, met constraints

Were challenged and engaged by real-world engineering scenario.

Students learn data collection strategies on their own (applied to a new situation- TRANSFER!)

Student understanding of the NOS improved and stuck!

T-2 Reflections Students situated as scientists

Excited to do science

Collaborated to accomplish goals

Provided detailed observations

Used evidence to support findings

table continues 


\section{Data Source Reported Student Outcomes}

\begin{tabular}{ll}
\hline Coach & Students enjoy science, it engages and challenges them \\
Reflections & Students are excited to do science \\
Student learn how to collaborate successfully to share ideas and listen and \\
consider other ideas \\
Students learn appropriate terms and correct NOS misconceptions \\
Students take careful, detailed observations. \\
Experience gives concepts sticking power- independent versus dependent, \\
qualitative versus quantitative. \\
Students present their work to the class, citing evidence in their findings. \\
Final Interview \\
$\begin{array}{l}\text { Students cited experiences in conceptual understanding } \\
\text { Students stayed on task }\end{array}$ \\
$\begin{array}{l}\text { Student achieved constraints posed by engineering problem } \\
\text { Students had fun } \\
\text { Students learned skills that carried over to other subjects: making } \\
\text { observations and citing evidence } \\
\text { Conceptual growth with NOS standards } \\
\text { Better problem solvers } \\
\text { Students collaborated successfully, valued each other's contributions and } \\
\text { ideas } \\
\text { Greater self-autonomy (reading and following directions, making } \\
\text { decisions) }\end{array}$ \\
\end{tabular}




\section{Figure 6. Progression of Student Knowledge and Skill over the 5E Phases of Instruction}

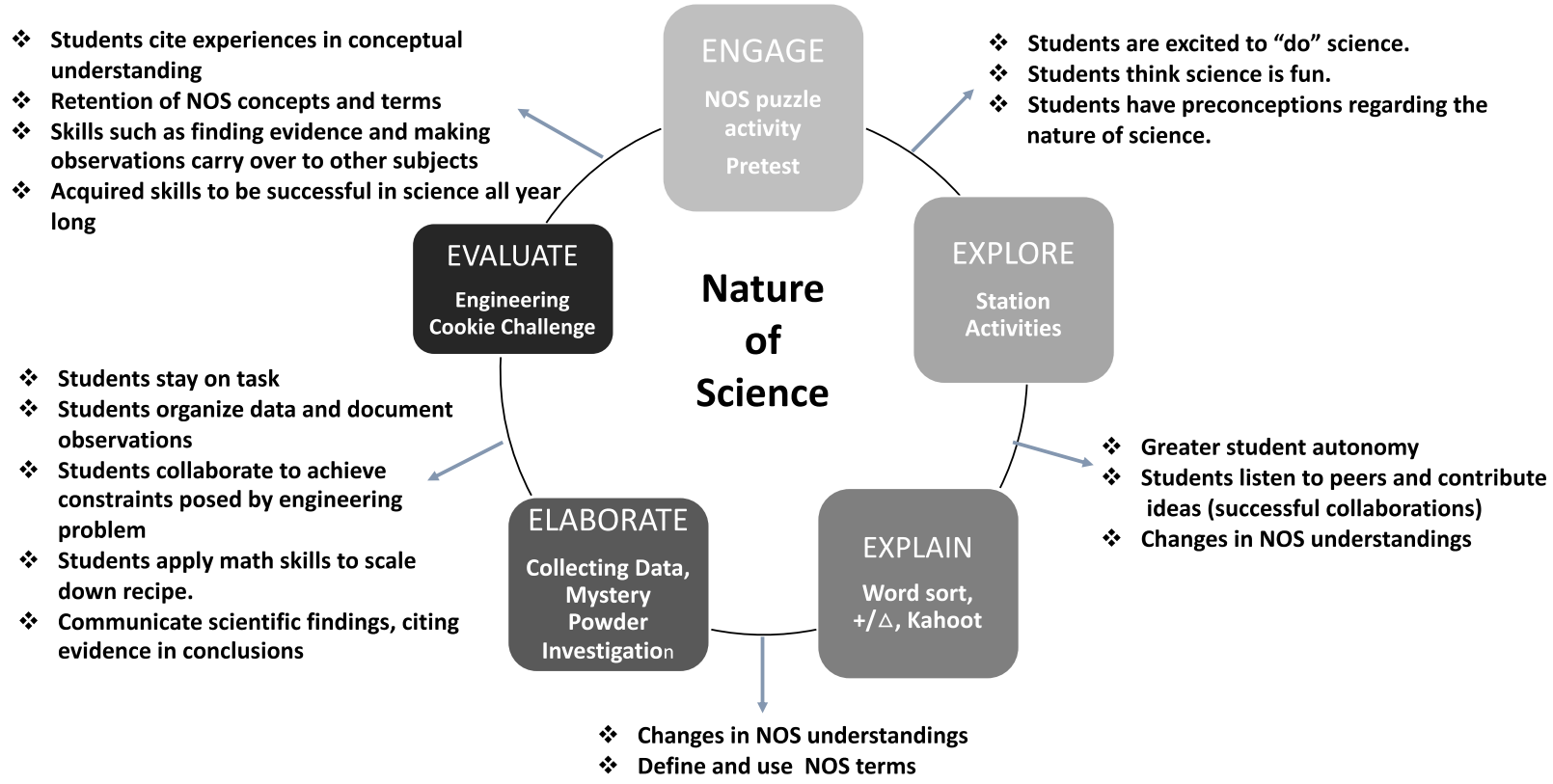

Figure 6 shows the progression of student outcomes as a function of time, beginning with the engage phase and ending with the evaluate phase. 


\section{CHAPTER IX: CONCLUSIONS AND IMPLICATIONS}

\section{Conclusions and Implications by Research Question}

The goal of this study was to shed light on the type of support practitioners need in the classroom to implement reform-based science teaching. The NGSS represent the newest version of science education standards. They advocate for engaging students in experiences that reflect the work of scientists and engineers. This approach to science teaching aims to prepare young minds to build and apply the scientific knowledge and skills necessary to address real-world problems throughout the future. The research questions explored how coaching, as described in the literature, as a form of on-going, embedded teacher support can facilitate teachers' use of the NGSS framework to structure their science teaching.

\section{Coaching as High-Quality PD}

Research question \#1 asks, "How can a coaching approach to teacher collaboration be used to offer high-quality professional development for NGSS implementation at the elementary level?" Based on the findings of this study, the coaching collaboration displayed most of the features of effective PD cited across the literature. As high-quality PD, our collaboration impacted teacher practice and student outcomes. Although the experience was intense, on-going, and of a sufficient duration to affect teacher understanding, identity, and skill, there remain challenges in the school environment that will influence the teachers' ability to sustain reformbased science teaching. Our collaboration was an isolated case of PD in science in their district, so the teachers will be on their own to plan and/or modify additional science units to reflect the NGSS. The teachers remain confident in their ability to implement the NOS science unit again, and they were able to support colleagues' implementation of the unit. The following conversation reveals the teachers' self-efficacy for teaching the NOS unit and supporting other 
sixth grade teachers' implementation of the unit, but it also reveals how obstacles such as limited time, resources, and PD in science make planning additional units difficult.

Ruth- I think if it was this one, I would be very confident. Yeah, I am really happy with the end product. I am really comfortable with it. I don't know if we could do as good of a job as when we had Elisha helping us. She was definitely a powerful resource for us.

But, I do know where to look now. I know what it is supposed to look like. I would feel comfortable taking a stab at it. I make no promises.

Elizabeth- Yes.

PI- Does the learning cycle help?

T1- Absolutely. That is what I was just thinking about. Like the whole framework of how we started like investigating with the stations and looking at all of the standards we were attacking with at the beginning. And then could kind of embed those into the different activities and then the qualitative and quantitative tools and stuff like that in there. Now, I kind of wish that I can get a redo on the water cycle because that just came so quick.

Ruth- yes, it did.

Me- I definitely think they could handle it without me. I feel they could handle it.

Would they have the time and resources?... I feel like those limiting factors are still there.

In the concluding interview, we reflected together upon the difficulty of finding time to teach science in a manner consistent with the NGSS when planning and instructional time is divided among multiple subjects.

Elizabeth- And I think it is like what we have said for years, the way the standards are written, even in language arts. We shouldn't be in a 4-6 building, we should be 
departmentalized for science. There is so much, and if we could just focus on science, it would be easier to be able to go that in depth. Because we do have to do all subjects, it is hard.

Me- We just scraped the surface. We pulled in some math, which was really cool, and I relied on you guys to tell me what was appropriate, so we were able to integrate that, but it took a lot. It is a lot of thought to put that together. Where there is a will, there is a way, but it would be a long process. I think you guys could independently do what we did together, but like you said add a new unit each year and then you become the teacher leaders like you already have with people.

Our collaboration provides an example of a partnership between university and intermediate school educators. We discussed the possibility of universities assuming a more active role in supporting K-12 practitioners' teaching of science moving forward. During the concluding interview, the PI asked, "What role should post-secondary institutions play in assisting K-12 educators in implementing the NGSS in their classrooms?"

Me- Yeah, well, I think anytime...I think sometimes at the post-secondary institution, it is very research-based and it is easy to lose touch with things at the practitioner-level, so I think it is important to keep your eyes open to what is really going on in the schools. And if you can be a support, reach out and be that support. Whether it is professional development or helping to write grants like, I think they can play an important role. Elizabeth- I don't think it is a resource that is often tapped either that should be more often. It would obviously be beneficial for us because we would have this extra resource, this knowledgeable person coming in. But then it gives you something to take back to 
these future teachers, like this what is what it looks like in there now. Trust me, I was just there. I think it would benefit all of the way around.

As teachers look to higher institutions for classroom support, higher institutions can look at K-12 collaborations as opportunities to show pre-service teachers what reform-based science teaching looks like in practice.

\section{The Coaching Process}

Research Question \#2 asks, "Based on the characteristics and needs of the teacherparticipants, how does the coaching model develop throughout the implementation of the NGSS unit?" The coach-teacher relationship was based on mutual trust and respect and rooted in a common goal. As a team, we were able to successfully address limiting factors present in the research setting by dividing up the work required to create instructional resources, gather and prepare lesson materials, and support students' investigations in the classroom. Our partnership also served to alleviate the fear and stress of trying out new instructional strategies. Our use of modeling and continuous cycle of group planning, teaching, and reflection supported teachers' development of new understandings regarding the NOS and instructional skills. Although this paper emphasized changes in the teachers' understandings, skills, and identity, the potential for the coach's professional growth is tremendous. The notion of a coach entering a collaboration to solely affect teacher practice should be revised to include outcomes possible for coaches. For example, my ability to share insight on the NGSS framework with pre-service teachers was greatly enhanced through this experience. In the initial interview, I discussed my lack of experience with the NGSS in K-12 setting.

I feel like my familiarity of them has been progressing. It's one of those things where I thought I knew them, and then I looked further and then I am like oh, I didn't know them 
as well as I thought I did. The more you look at them, the more you learn. Honestly, until I wrote my proposal for this, I don't feel like I knew them all that well. Writing the proposal, I really had to dig in. So now I feel like my level of understanding is...I have an appreciation as to how they were designed, how the framework works, and how the pieces come together, but what I do not have a good understanding of is how it works in the classroom over K-12. I know the goals, I know the intent, but I don't feel like until we start doing this type of work that I appreciate what they are about. You know what I mean? That piece is still missing for me. I feel like on paper there are practices, and there are these other pieces and how they fit together, but it has not come to life yet. Prior to this work, I had not enjoyed the opportunity to so comprehensively and experientially plan and teach science using the NGSS as the primary framework. Getting back into a K-12 classroom with these two teachers by my side was an amazing learning experience, and I will be a better educator because of it.

\section{Changes in Teacher Practice}

Research question \#3 asks, "How can a coaching model as PD for NGSS implementation be used to catalyze changes in elementary teachers' science teaching practice?" The on-going, embedded support the collaboration provided the teachers as they implemented the NGSSaligned unit was critical in affecting teacher practice. The collaboration was specific to the learning environment and to the changing needs of the teachers as we planned, taught, and reflected upon our unit. I asked the teachers in our unstructured interview how the features and effectiveness of coaching as PD compared to other forms of PD.

Me- So, do you think if you would have had, if we would of done something like this more as a workshop thing over the summer where you spent three to four days and we 
did some of these activities and then you could or could not take back some of these activities back to your school. How do you think, do you think that would have worked as well? Or do you think there is something to having people to collaborate with...like for example, if was another teacher, and they were like, hey, can you help me? ...having you to say hey these are the ins and outs. What do you think is the best model, kind of using your reference of different types of professional development, you've worked with coaches in the past, you probably have had workshops, you probably have had in-service things, what do you... comparing this experience with those types of things, what do you think is the most beneficial?

Elizabeth- I think this is so much more beneficial.

Ruth- I think so, too.

Elizabeth- Because like going to those, especially when they are in the summer you've got like this perfect vision of how it is going to go. But then the kids come, life happens, and then that is kind of like where, well, I need to control this because I want us to have this experience...

Ruth- Or, I have questions, and there is nobody there to ask. And I feel good about what we did. I feel like it is quality. Sometimes when you plan, especially when you have such a time crunch that I am not, sometimes I walk away, and I am not happy with it...it still needs tweaked, it still needs work. But I really think we did a really good job.

The findings of this study validate the literature's universally reported features of effective PD (Desimone, 2009, Borko, Jacobs, \& Koellner, 2010). Those components were essential in impacting teacher and student outcomes. 


\section{Impacting Student Outcomes}

Research Question \#4 asks, "How can coaching as a model for professional development for NGSS implementation impact student outcomes?" Speaking as a participant in the field, the reason why this experience was so positive and rewarding for me was the excitement, joy, and growth I observed in the students from day to day. They loved actively participating in the lesson activities, and their curiosity lead to growth in understandings about the nature of science. They developed skills essential for collaborating, planning and carrying out investigations, supporting conclusions with empirical evidence, and effectively communicating findings to an audience. However, the same concern with teachers' sustainment of reform-based science instruction applies to students' progression in scientific knowledge over time. The teachers shared their frustration with the lack of collaboration between sixth grade teachers and the junior-high educators in the district to align units in science with the NGSS. The seventh and eighth grade teachers provided a list of topics to the teachers to implement without a rationale for their inclusion or insight into how the units fit into a grander scheme of science learning progressions proposed by the NGSS framework. In our unstructured interview, we recognized the importance of supporting students' growth and depth of understanding science concepts over their K-12 education.

Me- But the in terms of content and that stuff, it might be good to go those learning progressions. And maybe communicate with fifth grade and seventh and eighth grade and say we are trying to hit where we are supposed to hit.

Elizabeth- The assistant principal literally just brought that up to me in my goal meeting. Yep, about how the district, how his dream would be to sit down and do that for science and social studies. But I feel like for a science curriculum to be successful, that is what 
they need. Like the example we were talking about... When I was a kid, we had the solar system every year, every year. They would say, well, every year we go more in depth with it. But it's like no, not really. Every year we name the planets, we sing the songs, we do the model of the solar system. Every year from second grade to eighth grade, so it wasn't that building...

Me- Yeah, building and progressing

A lack of collaboration and coherence across grade levels and a lack of PD in science within the district combine to create a significant barrier to the sustainability and transferability of reformbases science teaching.

\section{Limitations of the Study}

This study provides one reference point for using coaching as a model of science PD. The nature of this study situated a microscope on a small, yet very detailed instance of coaching as support for teachers' implementation of the NGSS. This approach yielded rich amounts of data, but these findings describe only one educational setting. As a researcher and a participant in the study, I was afforded a first-hand view of the coaching process, and this vantage point offered incredible insight into the coach-teacher relationship and a glimpse into reform-based science teaching in action. However, my role as a participant while giving me the status of an insider influenced my interpretation of the data as a researcher. Also, my role as an active instructor in the classroom did not allow me to make as many written, detailed observations during the implementation of the unit as a passive observer. I did not focus my generation and analysis of the data to differentiate between Elizabeth and Ruth's teaching backgrounds, personalities, perspectives, and practices. All interviews and planning sessions were conducted as one group, not with Ruth and Elizabeth individually. It is possible that individual interviews may have 
yielded less consensus between the teachers and provided more authentic and personal responses.

\section{Recommendations for Further Research}

These findings shed light on some questions critical to supporting teachers' implementation of the NGSS but also raise new questions to consider. For example, if the coaching collaboration employed in this one specific case of PD in science effectively impacted both student and teacher outcomes, how does this model apply to other educational settings with a different set of teachers and students? The success of the collaboration was directly linked to its specificity and on-going responsiveness to the unique factors present in the research setting. Through a meta-analysis of empirical literature on coaching as PD, Kraft, Blazar, and Hogan (2016) concluded that increasing the quantity of coaching experiences can affect the quality; in other words, scaling up a coaching model affects its effectiveness. Perhaps a better model is to initiate teacher change in practice through coaching collaborations and sustain and extend teachers' change in practice through the use of teachers as leaders in their own schools.

A key finding in this study was the way in which the nature of the collaboration, a partnership based on mutuality, positively influenced the participants' ability to implement an NGSS-aligned unit with students. Another important finding was a recognition of the potential outcomes possible for coach-participants. Based on these findings, does a coaching analogy for this approach to PD fit a symbiotic relationship with an equal distribution of power, and potential professional and personal outcomes for all participants? For example, consider an athletic coach-athlete relationship. Is there an equal sense of power between the coach and athlete? Can the player improve the athleticism of the coach, or is it always a matter of the coach's actions affecting the player's athleticism? This study suggests that the collaboration flourished from the 
unique, yet equally significant contributions of all participants and impacted both teacher and "coach" outcomes. These findings suggest that the collaborative work between the classroom teachers and myself might be better described as co-teaching, not coaching. Analogies can help our understanding of concepts by making something foreign familiar and relatable. However, in this case, using coaching to describe our collaboration seems misleading and may suggest a power imbalance and limit the potential effectiveness of partnerships among different educational professionals. 


\section{REFERENCES}

Achieve. (2013). How to read the Next Generation Science Standards. Retrieved from http://www.nextgenscience.org/sites/default/files/How\%20to\%20Read\%20NGSS\%20\%20Final\%2008.19.13.pdf

Achieve. (2013) Search the Standards, Retrieved from http://www.nextgenscience.org/pe/5-ps11-matter-and-its-interactions.

American Association for the Advancement of Science (AAAS). (1993). Benchmarks for Science Literacy. Washington DC: AAAS.

Appleton, K. (2007). Elementary Science Teaching. In. S.K. Abel \& N. G. Lederman (Eds.) Handbook of research on science education (pp. 493-535). Mahwah, NJ: Lawrence NerBaulm.

Appleton, K. (2008). Developing science pedagogical content knowledge through mentoring elementary teachers. Journal of Science Teacher Education, 19, 523-545.

Archambault, R. D. (Ed.). (1964). John Dewey on Education: Selected readings. New York, NY: Random House.

Ashbacher, P., Ing. M., \& Tsai, S. (2013). Boosting student interest in science. Phi Delta Kappan, 95(2), 47-52.

Atkin, J.M. \& Karplus, R. (1962). Discovery or Invention? The Science Teacher, 29(5), 45-51.

Banilower, E. R., Smith, P. S., Weiss, I. R., Malzahn, K. A., Campbell, K. M., \& Weis, A. M. (2013). Report of the 2012 National Survey of Science and Mathematics Education. Chapel Hill, NC: Horizon Research, Inc.

Barkley, S. G. (2010). Quality teaching in a culture of coaching. Lanham, MD: Rowman and Littlefield Publishers. 
Borko, H., Jacobs, J. \& Koellner, K. (2009). Contemporary Approaches to Teacher Professional Development. In International Encyclopedia of Education, Vol 7. (p. 548-556). Oxford, Elsevier.

Brinkmann, S. \& Kvale, S. (2015). Interviews: Learning the craft of qualitative research interviewing. Thousand Oaks, CA: Sage.

Brown, P. L \& Abell, S. K. (2007). Examining the learning cycle. Science and Children, 44(5), 58-59.

Bruning, R. H., Schraw, G. J., Norby, M. M., \& Ronning, R. R. (2004). Cognitive Psychology and instruction, $4^{\text {th }}$ ed. Columbus, $\mathrm{OH}$ : Pearson.

Bybee, R. W. (2013). Translating the NGSS for classroom instruction. Arlington, VA: NSTA Press.

Bybee, R. W. (2014). The BSCS 5E Instructional Model: Personal reflections and contemporary implications. Science and Children, 51(8), 10-13.

Campbell, P. \& Malkus, N. (2013). Elementary mathematics specialists: Influencing student achievement. Teaching Children Mathematics, 20(3), 198-204.

Charmez, K. (2010). Grounded theory: Objectivist and constructivist methods. Luttrell, W. (Ed.) in Qualitative educational research: readings in reflexive methodology and transformative practice, (pp. 183-207). New, York, NY: Routledge.

Chin, C. \& Chia, L. (2008) Problem-Based Learning Tools. The Science Teacher, 75 (8): pp. 4449.

Choi, J. (2004). Summer research program for science. Retrieved from http://www.scienceteacherprogram.org/genscience/Choi04.html. 
Choi, S. \& Ramsey, J. (2010) Constructing elementary teachers' beliefs, attitudes, and practical knowledge through an inquiry-based elementary science course. School Science and Mathematics, 109(6), 313-324.

Corbin, J. \& Strauss, A. (2015). Basics of qualitative research. Thousand oaks, CA: Sage Creswell, J. W. (2009). Research design: qualitative, quantitative, and mixed methods approaches. Thousand oaks, CA: Sage.

Dailey, D. \& Robinson, A. (2016). Elementary Teachers: Concerns about implementing a science program. School Science and Mathematics, 116(3), 139-147.

Darling-Hammond, L. (2000). Teacher quality and student achievement: A review of state policy evidence. Educational Policy Analysis Archives, 8(1), 1-42.

Darling- Hammond, L. \& Bransford, J. (2005). Preparing teachers for a changing world. San Francisco, CA: Jossey-Bass.

Darling-Hammond, L. \& McLaughlin, M. W. (2011). Policies that support professional development in an era of reform. Kappan, 92(6), p. 81-92.

DeChenne, S., Nugent, G., Kunz, G., Luo, L., Berry, B., Craven, K., \& Riggs, A. (2014). Coaching in a science, technology, engineering, and math professional development experience: A case study (R2Ed Working Paper No. 2014-7). Retrieved from the National Center for Research on Rural Education: r2ed.unl.edu

Desimone, L. M. (2009). Improving impact studies of Teachers' professional development: Toward better conceptualizations and measures. Educational Researcher, 38(3), 181- 192.

Desimone, L. M. \& Pak, K. (2017). Instructional coaching as high-quality professional development. Theory into Practice, 56(1), 3-12. 
Dewey, J. (1929). My pedagogic creed. Journal of the National Education Association, 19(9), 291-295.

Dixon, J. (2015). Literacy Coaching: Increasing teacher confidence and implementation of new practices. Illinois Reading Council Journal, 44(1), 15-22.

Duschl, R. (2012). The second dimension-crosscutting concepts: Understanding a Framework for K-12 Science Education. The Science Teacher, 79(2), 34-38.

Duschl, R., H. Schweingruber, H., \& Shouse, A., eds. (2007). Taking science to school: Learning and teaching science in grades K-8. Washington DC: National Academies Press.

Edmonson, S, \& Irby, B. (2008). Ten tips for producing a top qualitative research study. Boston, MA: Pearson.

Edwards, H. (2016). Leaving tests behind. Time, 185(5), 28-31.

Glaser, B. G., \& Strauss, A. (1967). The discovery of grounded theory. Chicago, IL: Aldine.

Green, J. (1990). Knowledge accumulation: Three views on the nature and role of knowledge in social science. In E. Guba (ed), The Paradigm Dialogue (pp. 227-245). Newbury Park, CA: Sage Publications.

Griffith, G., and Scharmann, K. (2008). Initial impacts of no child left behind on elementary science education. Journal of Elementary Science Education, 20(3), 35-48.

Grossman, P, Compton C., Igra, D., Ronfeldt, M., Shahan, E. and Williamson, P. D. (2009). Teaching practice: A cross-professional perspective. Teachers College Record. 111(9), 2055-2100.

Goldhaber, D. D. \& Brewer, D. J. (2000). Does teacher certification matter? High school teacher certification status and student achievement. Educational Evaluation and Policy Analysis, 22(2), 129-145. 
Hattie, J. (2009). Visible learning: A synthesis of over 800 meta-analyses relating to achievement. New York, NY: Routledge.

Hawley, W. D, \& Valli, L. (2000). Learner-centered professional development. Phi Delta Kappa Center for Evaluation, Development, and Research. Research Bulletin Number 27

Herron, D. (1996). The chemistry classroom: Formulas for successful teaching. Washington DC: American Chemical Society.

Howes, E., Lim, M., Campos, J. (2008). Journeys into inquiry-based elementary science: Literacy practices, questioning, and empirical study. Science Education, 93(2), 189-217.

Hudson, S.B., McMahon, K.C., \& Overstreet, C. M. (2002). The 2000 national survey of science and mathematics education: Compendium of tables. Chapel Hill, NC: Horizon Research.

Janusszyk, R. Miller, E. C., \& Lee, O. (2014) Addressing Student Diversity and Equity. Science Scope, 39(8), 16-19.

Joseph, P. B. (2011). Conceptualizing Curriculum. In Joseph, J. B. (Ed.) Cultures of Curriculum. (p. 3-22). New York, NY: Routledge.

Joyce, B. \& Showers, B. (1982). The Coaching of Teaching. Educational Leadership, 40(1), 4-10.

Kahoot!. (2018). Kahoot! [Trivia game platform]. Retrieved 7 September 2017 from https://kahoot.com.

Karplus, R. \& Their, H. D. (1967). A new look at elementary school science. Chicago, IL: Rand McNally.

Knight, J. (2011) What good coaches do. Educational Leadership, 69(2), 18-22.

Knight, J. ed. (2009). Coaching: Approaches and perspectives. Thousand Oaks, CA: Corwin Press. 
Knight, J. (2009). Coaching. National Staff Development Council, 30(1), 18-22.

Kraft, M. A., Blazar, D., \& Hogan, D. (2016). The effects of coaching on instruction and achievement: A meta-analysis of the causal evidence. Review of Educational Research

Kovalik, S. J. \& Olsen, K. (2010). Kid's eye view of science: A conceptual, integrated approach to teaching science, $K-6$. Thousand Oaks, CA: Corwin Press.

Krajcik, J., Codere, S., Dahsah, C., Bayer, R., \& Mun, K. (2014). Planning instruction to meet the intent of the Next Generation Science Standards. Journal of Science Teacher Education, 25, 157-175.

Kraus, R. (2008) Overcoming the difficulties of inquiry-based teaching through coaching. Retrieved from Pro-Quest Digital Dissertations (3338026).

Larmer, J. \& Mergendollar, J. R. (2012) 8 essentials for project-based learning. Novato, CA: Buck Institute for Education.

Lave, J., \& Wenger, E. (1991). Situated learning: Legitimate peripheral participation. Cambridge, England, UK: Cambridge University Press.

Lawson, A., Abraham, M. R., \& Renner, J. (1989). A theory of instruction: Using the learning cycle to teach science concepts and thinking skills. Cincinatti, OH: National Association for Research in Science Teaching.

Le Couteur, P. \& Burreson, J. (2004). Napoleon's buttons: How 17 molecules changed history. New York, NY: Penguin Group

Luft, J. A. \& Hewson, P. W. (2014). Research on teacher PD programs in science. In Abel, S. K. \& Lederman, N. G. (Eds.) Handbook of research on science education, Volume 2 (pp. 889-910). New York, NY: Routledge. 
Luttrell, W. (2010). The promise of qualitative research in education. Luttrell, W. (Ed.) in Qualitative educational research: readings in reflexive methodology and transformative Practice (pp. 1-17). New York, NY: Routledge.

Maxwell, J. A. (1992). Understanding and validity in qualitative research. Harvard Educational Review, 62 (3), 1-20.

Maxwell, J. A. (2013). Qualitative Research Design: An interactive approach. Thousand Oaks, CA: Sage.

Maxwell, L. A. (2013). Diversity goal set tone for science standards. Education Week, 32(36), 126.

McComas, W. (1996). Ten myths of scienc: Reexamining what we think we know about the nature of science. School Science and Mathematics. 96(1), 10-16.

McFadden, J. (2015). Teachers as designers: the iterative process of curriculum designed focused on STEM integration. Retrieved from Pro-Quest Digital Dissertations (3727780).

McMurrer, J. (2008). Instructional time in elementary schools: A closer look at changes for specific subjects. From the capitol to the classroom: year 5 of the No Child Left Behind Act. Washington, DC: Center on Educational Policy.

Merriam, S. B. (1998). Qualitative research and case study applications in education. San Francisco, CA: Jossey-Bass.

Merriam, S. B. (2009) Qualitative research: A guide to design and implementation. San Francisco, CA: Jossey-Bass

Michaels, S., Shouse, A. \& Schweingruber, H. (2008). Ready, set, science! Putting research to work in K-8 science education standards. Washington DC: National Academies Press. 
Milano, M. (2013). The Next Generation Science Standards and Engineering for Young Learners: Beyond Bridges and Egg Drops. Science and Children, 51(2), 10-16.

Miller, R. G., Curwen, M. S., White-Smith, K. A., \& Calfee, R. C. (2015). Cultivating Primary Students' Scientific Thinking through Sustained Teacher Professional Development. Early Childhood Education Journal, 43, 317-326.

Moll, L., Amanti, C., Neff, D. and Gonzalez, N. (1992). Funds of knowledge for teaching: Using a qualitative approach to connect homes and classrooms. Theory into Practice, XXXI, 2, $132-141$

Montessori, M. (2009). A Critical consideration of the new pedagogy in its relation to modern science. In Flinders, D. \& Thorton, S. (Eds.) The Curriculum Studies Reader (pp. 22-33). New York, NY: Routledge.

Nariman, N. , \& Chrispeels, J. (2016). PBL in the Era of Reform Standards: Challenges and Benefits Perceived by Teachers in One Elementary School. Interdisciplinary Journal of Problem-Based Learning, 10(1).

National Research Council (NRC). (2000). Inquiry and the National Education Standards. Washington DC: National Academy Press.

National Research Council. (2011). A framework for K-12 science education: Practices, crosscutting concepts, and core ideas. Washington DC: National Academies

National Research Council (NRC). (2014). Developing assessments for the Next Generation Science Standards. Washington DC: National Academies Press.

National Science Foundation. (2013). Women, Minorities, and Persons with disabilities in Science and Engineering. Retrieved from https://www.nsf.gov/statistics/wmpd/2013/pdf/nsf13304_digest.pdf. 
NGSS Lead States. (2013). Next Generation Science Standards: For states, by states. Washington DC: National Academies Press.

Passmore, C. (2015) Shifting to NGSS aligned classrooms. Leadership, 44(4), 24-27.

Penuel, W. R. Harris, C. J, \& DeBarger, A. H. (2015). Implementing the next generation science standards. Kappan, 96 (5), 45-49.

Peshkin, A. (1988). In search of subjectivity-One's own. Educational Researcher, 17, 17-21.

Peshkin, A. (2000). The nature of interpretation in qualitative research. Educational Researcher, $29(9), 5-9)$.

Ram, P. (1999) Problem-Based Learning in Undergraduate Education. Journal of Chemical Education, 76(8): pp.1122-1126.

Rivet, A. \& Ktajcik, J. (2004). Achieving standards in urban systemic reform: An example of a sixth grade project-based science curriculum. Journal of Research in Science Teaching, 41 (7), 669-692.

Rodriguez, A. J., \& Berryman, C. (2002). Using sociotransformative constructivism to teach for understanding in diverse classrooms: A beginning teacher's journey. American Educational Research Journal, 39, 1017-1045.

Roth, K. (2014). Elementary Science Teaching. In Abel, S. K. \& Lederman, N. G. (Eds.) Handbook of research on science education, Volume 2 (pp. 361-394). New York, NY: Routledge.

Shabani, K. (2010). Vygotsky's Zone of Proximal Development: Instructional Implications and Teachers' Professional Development. English Language Teaching, 3(4), 237-248.

Shulman, L. S. (1986). Those who understand: Knowledge growth in teaching. Educational Researcher, 15(2), 4-14. 
Sykes, D. (1996). Reform of and as professional development. Phi Delta Kappan, 77(7), 465489.

The Teaching Channel. (2016). NGSS EQuIP rubric overview [Video file]. Retrieved from https://www.teachingchannel.org/videos/ngss-rubric-intro-achieve).

Tobin, K. \& Tippins, D. (1993). Constructivism as a referent for teaching and learning. In K. Tobin (Ed.) The practice of constructivism in science education (p. 3-21). Hillsdale, NJ: Erlbaum.

Ulcihny, P. \& Schoener, W. (2010). Teacher-researcher collaboration from two perspectives. Luttrell, W. (Ed.) in Qualitative educational research: Readings in reflexive methodology and transformative practice (pp. 221-247). New York, NY: Routledge.

Valencia, R. R. (2010). Dismantling contemporary deficit thinking: Educational thought and practice. New York, NY: Routledge.

Villegas, A. M. \& Lucas, T. (2002). Preparing culturally responsive teachers: Rethinking the curriculum. Journal of Teacher Education, 53(1), 20-32.

Vogt, F. \& Rogalla, M. (2009). Developing Adaptive Teaching Competency through Coaching. Teaching and Teacher Education, 25, 1051-1060.

Vygotsky, L. S. (1978). Mind in society: The development of higher psychological processes. Cambridge, MA: Harvard University Press.

Weiss, I.R., Pasley, J.D., Smith, P.S., Banilower, E.R.,\&Heck, D.J. (2003). Looking inside the classroom: A study of K-12 mathematics and science education in the U.S. Chapel Hill, NC: Horizon Research.

Wenger, E. C. \& Snyder, W. M. (2000). Communities of practice: The organizational frontier. Harvard Business Review, 78, 139-145. 
Whitworth, B. A. \& Chiu, J. L. (2015). Professional development and teacher change: The missing leadership link. Journal of Science Teacher Education, 26, 121-137.

Wilson, C. D., Taylor, J. T., Kowalski, S. M., \& Carlson, J. (2010). The relative effects and equity of inquiry-based and commonplace science teaching on students' knowledge, reasoning, and argumentation. Journal of Research in Science Teaching, 47(3), 276301,

Wren, S. \& Reed, D. (2005). Literacy coaches: Roles and responsibilities. SEDL Letter, 17 (1).

Wysession, M. (2015). Kids are scientists, too. Scientific American, 313 (2).

Zedem Media (Producer). (n. d.). What's the difference between a scientific law and theory? Video retrieved from https://ed.ted.com/lessons/what-s-the-difference-between-ascientific-law-and-theory-matt-anticole.

Zollman, A., Tahemezhadi, M., \& Billman, P. (2012). Science, technology, engineering and mathematics education in the United States: Area if current successes and future needs. The International Journal of Science in Society, 3(2), p. 103-108. 


\section{APPENDIX A: INTERVIEW PROTOCOLS}

\section{Semi-Structured Interview Protocol}

Introductory Interview Questions- Teacher Participant

TEACHING EXPERIENCES

1. How long have you been teaching at the elementary level?

2. Do you have time to collaborate with other teachers when planning and implementing units of instruction?

3. What factors influence the time and resources you spend on teaching science each week?

4. How comfortable are you with working with educational professionals outside of your district?

5. Is there a particular science unit or project you have implemented in the past that you are particularly proud of?

\section{PERCEPTIONS OF THE NGSS}

1. How would you describe your familiarity with the Next Generation Science Standards $(N G S S)$ ?

The NGSS advocate for learning experiences to engage students in the practices of scientists and engineers.

2. Is there a particular science unit or project you have implemented in the past that situated your students as scientists?

Considering your students, learning environment, and community...

3. How feasible do you think this approach to teaching science is?

4. What risks are associated with this type of teaching?

5. What benefits are possible with this type of teaching?

\section{IMPLEMENTING THE NGSS}

1. If your district required you to select and implement an NGSS-aligned science unit, how comfortable would you be with completing this task?

2. How would you feel if the district provided another educational professional to support your efforts throughout the planning and teaching phases?

3. Have you worked with literacy or math coaches in the past? If so, how did the coach influence your teaching and/or your students' learning?

4. What qualities should a science coach have?

5. What roles could a science coach fulfill that would assist you in teaching science in a manner consistent with the NGSS?

6. What type of relationship is required between a coach and a teacher in order for the collaboration to be successful? 


\section{Semi-Structured Interview Protocol}

Introductory Interview Questions-Coach Participant

\section{TEACHING EXPERIENCES}

1. Describe your past experiences as an educator teaching science courses.

2. Describe your past experiences as a teacher-educator at the university level.

3. How comfortable are you with working with elementary level students?

4. How comfortable are you with working with elementary teachers?

5. Is there a particular university/K-12 collaboration you have participated in the past that you are particularly proud of?

\section{PERCEPTIONS OF THE NGSS}

1. How would you describe your familiarity with the Next Generation Science Standards $(N G S S)$ ?

The NGSS advocate for learning experiences to engage students in the practices of scientists and engineers.

2. Is there a particular science unit or project you have implemented in the past that situated your students as scientists?

Considering the challenges present at the elementary level...

3. How feasible do you think this approach to teaching science is?

4. What risks are associated with this type of teaching?

5. What benefits are possible with this type of teaching?

\section{IMPLEMENTING THE NGSS}

1. If you had to enter an elementary classroom and teach an NGSS-aligned science unit, how comfortable would you be with completing this task?

2. How would you feel if you could collaborate with experienced elementary educators throughout the planning and teaching phases?

3. How familiar are you with coaching as a method of teacher and student support?

4. What qualities should a science coach have?

5. What roles could a science coach fulfill that would assist elementary educators in teaching science in a manner consistent with the NGSS?

6. What type of relationship is required between a coach and a teacher in order for the collaboration to be successful? 


\section{Semi-Structured Interview Protocol}

Concluding Interview Questions- Teacher Participant

PERCEPTIONS OF THE NGSS

After implementing an NGSS-aligned unit with your students ...

1. What have you learned about the NGSS framework and its vision for K-12 science education?

Considering your students, learning environment, and community...

2. How feasible do you think this approach to teaching science is?

3. What risks are associated with this type of teaching?

4. What benefits are possible with this type of teaching?

\section{IMPLEMENTING THE NGSS}

1. If your district required you to select and implement an NGSS-aligned science unit, how comfortable would you be with completing this task?

2. If your district asked you to support a colleague with NGSS implementation, how comfortable would you be with completing this task?

3. What qualities should a science coach have?

4. What roles should a science coach fulfill to assist elementary educators who are teaching science in a manner consistent with the NGSS?

5. What type of relationship is required between a coach and a teacher in order for the collaboration to be successful?

\section{FUTURE TEACHING EXPERIENCES}

1. Do you plan to incorporate more reform-based science teaching in the future?

2. What changes do you think need to occur at the elementary level to make this approach to teaching science possible?

3. What professional development opportunities should be offered to teachers?

4. What role should post-secondary institutions play in assisting K-12 educators in implementing the NGSS in their classrooms? 


\section{Semi-Structured Interview Protocol}

Concluding Interview Questions- Coach Participant

PERCEPTIONS OF THE NGSS

After working with elementary teachers to implement an NGSS-aligned unit...

1. What have you learned about the NGSS framework and its vision for K-12 science education?

Considering the elementary level...

2. How feasible do you think this approach to teaching science is?

3. What risks are associated with this type of teaching?

4. What benefits are possible with this type of teaching?

\section{IMPLEMENTING THE NGSS}

1. If you had to enter an elementary classroom and teach an NGSS-aligned science unit, how comfortable would you be with completing this task?

2. If you had the opportunity to provide coaching support to assist other elementary educators with NGSS implementation, how comfortable would you be with completing this task?

3. What qualities should a science coach have?

4. What roles should a science coach fulfill to assist elementary educators who are teaching science in a manner consistent with the NGSS?

5. What type of relationship is required between a coach and a teacher in order for the collaboration to be successful?

\section{FUTURE TEACHING EXPERIENCES}

1. What has this experience taught you about how to educate pre-service teachers and inservice teachers about the NGSS framework?

2. What changes do you think need to occur at the elementary level to make this approach to teaching science possible?

3. What professional development opportunities should be offered to teachers?

4. What role should post-secondary institutions play in assisting K-12 educators in implementing the NGSS in their classrooms? 


\section{APPENDIX B: NATURE OF SCIENCE PRE-QUIZ}

Name:

Date:

1. True False Scientific ideas that are described in theories have been proven true and will never change.

2. True False Creativity is very important in science.

3. True False Any question can be answered through careful research.

4. True False Scientists do not rely on previous experiences to draw conclusions.

5. True False Scientific evidence can only come from experiments.

6. True $\quad$ False $\quad$ Models are used in science to help us understand concepts but are limited.

7. True False Scientists use observations to describe the world around them.

8. True False Science knowledge is limited by human ability, technology, and materials.

9. True False With enough evidence a theory can become a law.

10. True False Anyone can be a scientist.

** Share your responses with each other. You may not all agree, but that's ok! We will be investigating these ideas together in the next few days. **

***As a group add any words that you are unclear of or that you think are important science words to the chart in the front of the room.** 


\section{APPENDIX C: STATION ACTIVITY EXAMPLE}

\section{Station 4- Making Predictions and Identifying Patterns in Science}

Did you know that chocolate chip cookies were invented through an experiment that did not go as planned? So were medicines like penicillin! Many important discoveries were made because people were questioning the world around them. How much do you know about scientific investigations?

Everyone is a scientist! Through our ability to observe and question the world around us, scientific inquiry begins! Look at the cube in front of you...are you curious what's on the bottom? This is where our scientific investigation begins...

Materials:

- 1 cube for each group

- 10 small probes (pencils)

- 10 small pocket mirrors

\section{Objective 1:}

As scientists, your objective (goal) in this station is to determine what is on the bottom of the cube. Be prepared to defend your prediction with evidence if questioned by others. Evidence is the observations that your group can make about the what you can see of the cube without lifting it off of the table. (This means you can NOT touch, turn, lift, or open the cube).

Observations:

Proposed Answer:

Explanation:

I bet you are really curious if you are right!? Well guess what, many times scientists are unsure if their answer is correct. A great example of this is how did the dinosaurs become extinct? That is why it is important to take good notes of your observations and record your thinking properly. You never know when you may have to defend your investigation!!

Life is much more complex now than it was a hundred years ago. However, the basic ideas of questioning, observing, and forming hypotheses is still the root of scientific investigation. 


\section{Objective 2:}

Your group will be exploring a second cube. This cube is more complex than the first. Your group will again need to make a prediction on what you think is on the bottom of the cube. You may not all agree this time, that's ok! But be prepared to support your thinking.

\section{Observations:}

Proposed Answer:

Explanation:

Tricky isn't it!?! Scientists use patterns to make predictions and design future experiments. This helps them to determine if their prediction is on target. Which patterns did your group identify?

Good news! A new technological discovery has been made! Your group will be allowed to use this new technology (mirror) to look at just one corner of the bottom of the cube.

\section{Observations:}

Proposed Answer:

Explanation:

\section{THE BIG IDEAS}

In your notebook, answer the following questions. Be sure to discuss these questions with your group members first.

1. How were you able to predict what was on the bottom of the cube?

2. How did the advancements in technology support your original prediction, or did you have to modify your prediction?

3. If a science theory is supported now, does that mean it will never change? Why or why not? 
APPENDIX D: ELIZABETH'S ANCHOR CHART

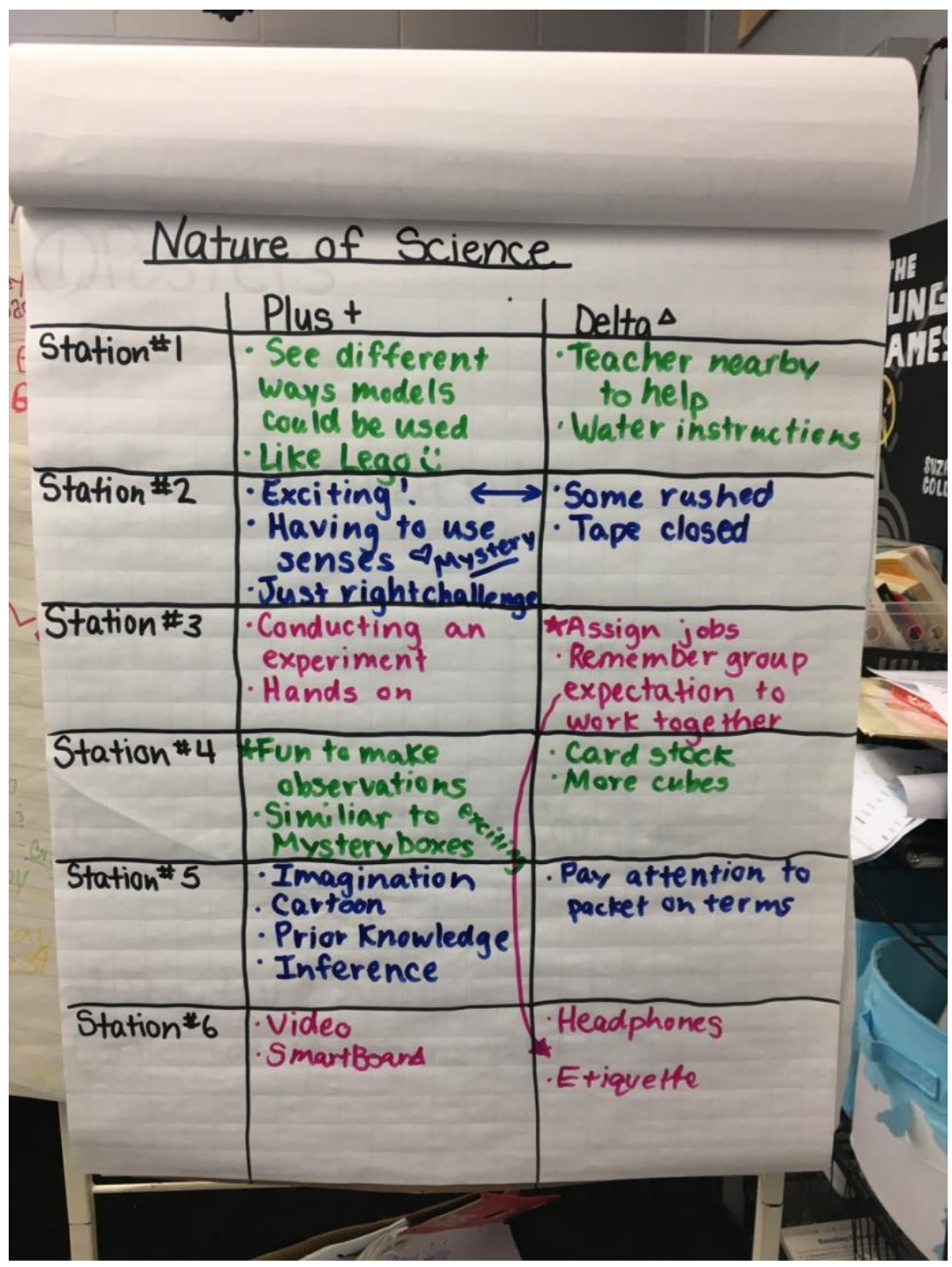




\section{APPENDIX E: EXPLAIN ACTIVITY \\ Qualitative and Quantitative Data}

Think back to our Mystery Box Station...there were a lot of observations to keep straight! A DATA TABLE would have been a great tool to use! Some of you created your own and probably didn't realize it!!

Data Tables can be organized in lots of different ways for different purposes. Two ways to organize data are qualitative and quantitative.

Qualitative data is focused on the description. This data can be observed but not measured. Colors, textures, smells, tastes, appearance, beauty, etc.

Mystery Box Example

$$
\text { Qualitative }=\text { Quality }
$$

\begin{tabular}{|l|l|l|l|}
\hline & Smell & Sound & Feel \\
\hline Box 1 & & & \\
\hline Box 2 & & & \\
\hline Box 3 & & & \\
& & & \\
\hline
\end{tabular}

Quantitative data deals with numbers. This data can be measured. Length, height, area, volume, weight, speed, time, temperature, humidity, sound levels, cost, members, ages, etc.

$$
\text { Quantitative }=\text { Quantity }
$$

In your groups you are going to collect data on two different blocks. You will need to measure the length, width, and height of each box. Use this table to organize your data.

\begin{tabular}{|l|l|l|l|}
\hline & & & \\
\hline & & & \\
\hline & & & \\
\hline & & & \\
\hline
\end{tabular}




\begin{tabular}{|c|}
\hline Quantitative Data \\
\hline Qualitative Data \\
\hline Data Collection \\
\hline Data Analysis \\
\hline Measure \\
\hline Procedure \\
\hline Question/Problem \\
\hline
\end{tabular}

\begin{tabular}{|l|l|}
\hline $\begin{array}{l}\text { A description of qualities using words... } \\
\text { Examples include noting the color, shape, } \\
\text { texture, taste, etc. }\end{array}$ & $\begin{array}{l}\text { A description of quantity using numbers... } \\
\text { Examples include height, volume, mass, } \\
\text { time, etc. }\end{array}$ \\
\hline $\begin{array}{l}\text { To determine the dimensions, quantity, or } \\
\text { capacity of an object }\end{array}$ & The purpose for conducting an investigation \\
\hline $\begin{array}{l}\text { Studying the data from an investigation for } \\
\text { patterns, trends, or a cause and effect } \\
\text { relationship between variables }\end{array}$ & $\begin{array}{l}\text { The gathering of qualitative observations } \\
\text { and/or quantitative measurements during an } \\
\text { investigation. }\end{array}$ \\
\hline $\begin{array}{l}\text { A plan of steps or an outline of the work to } \\
\text { be done during an investigation }\end{array}$ & \\
\hline
\end{tabular}




\section{APPENDIX G: ELABORATE ACTIVITY}

\section{The Mystery Powder}

\section{THE SCENARIO}

Mrs. Keebler just loves to bake cookies. She keeps all of her baking ingredients tightly sealed in plastic containers to keep them fresh. She likes to keep these containers neatly organized on labeled shelves in her pantry. However, after one day of baking with her grandkids, her pantry is completely disordered. All of the ingredients are white powders so it is difficult to identify each powder just by sight. Also, she is allergic to one of the white powders, so tasting them is not an option.

\section{THE CHALLENGE}

Using household reagents (testing liquids), you will perform a series of qualitative tests on five labeled baking ingredients- sugar, flour, baking soda, baking powder, and cream of tartar- and an unidentified mystery powder. Based on the observations of these tests, you may accumulate enough evidence to identify which of the five known ingredients the mystery powder is.

\section{THE PROCEDURE}

1. Inspect each powder closely using a magnifying glass. Record these observations in your data table.

2. Place a pea size amount of each powder in the ice cube tray. You will have enough spaces to perform two tests on all of the powders at once. Follow the diagram below to fill the tray.

\begin{tabular}{|c|c|c|c|c|c|c|}
\hline $\begin{array}{c}\text { Baking } \\
\text { Powder }\end{array}$ & $\begin{array}{c}\text { Baking } \\
\text { Soda }\end{array}$ & $\begin{array}{c}\text { Cream of } \\
\text { Tartar }\end{array}$ & Empty & $\begin{array}{c}\text { Baking } \\
\text { Powder }\end{array}$ & $\begin{array}{c}\text { Baking } \\
\text { Soda }\end{array}$ & $\begin{array}{c}\text { Cream of } \\
\text { Tartar }\end{array}$ \\
\hline Flour & Sugar & $\begin{array}{c}\text { Mystery } \\
\text { Powder }\end{array}$ & Empty & Flour & Sugar & $\begin{array}{c}\text { Mystery } \\
\text { Powder }\end{array}$ \\
\hline
\end{tabular}

3. You will be using four different liquid reagents- water, vinegar, cabbage juice, and iodine- to characterize and differentiate the white powders. After filling the tray with the powders, add one reagent to the first set of six powders, and add a different reagent to the other set of six powders. Be sure to follow the directions on each reagent bottle.

4. Make careful observations and record this data in your data table. After performing two tests, carefully dump out your tray contents into the sink or bucket. Rinse well with water and dry.

5. Repeat steps 2-4, adding the other two reagents to your powders. 
DATA COLLECTION

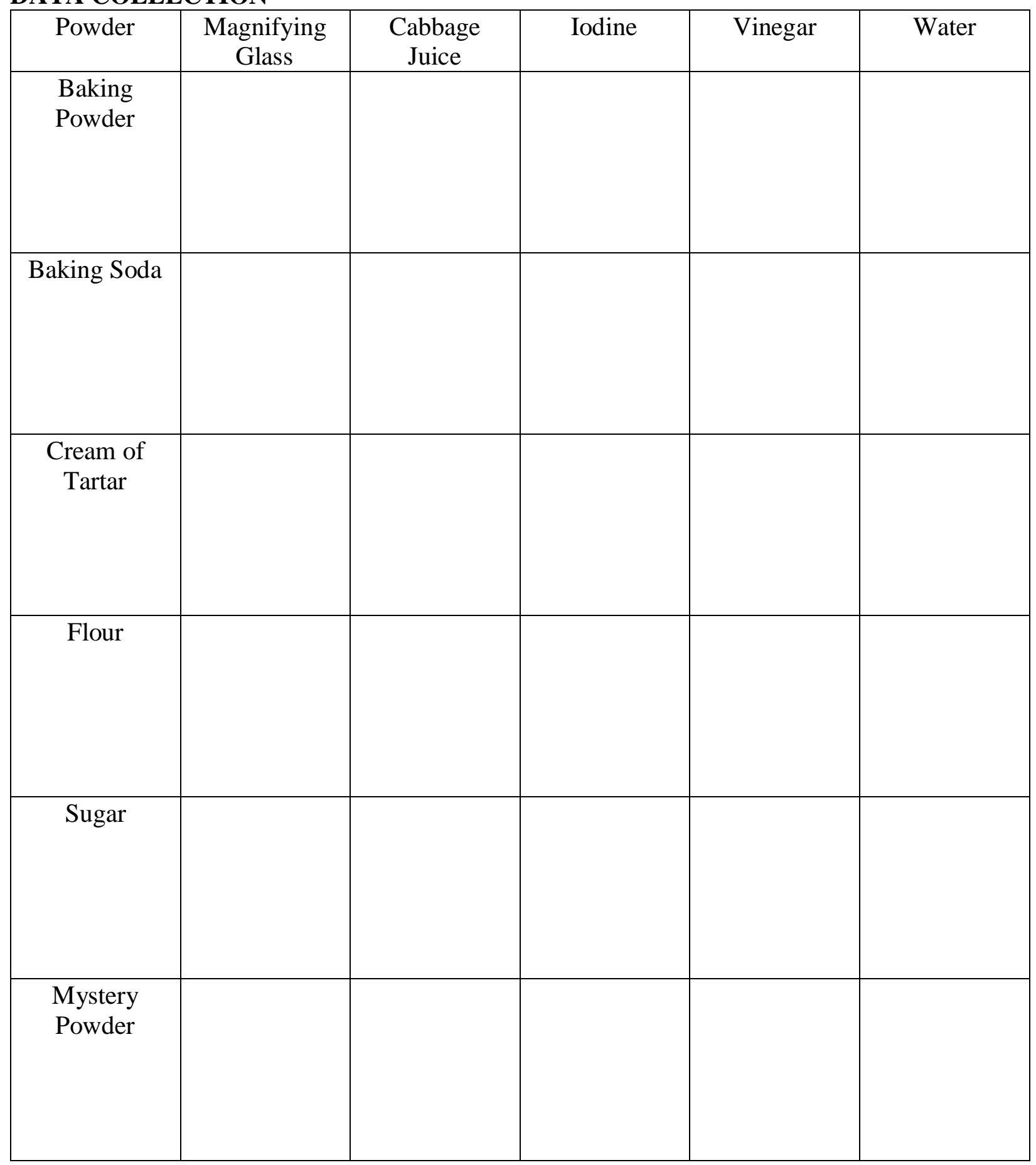




\section{RESULTS}

Based on the observations organized in your data table, can you confidently label the mystery powder?

Identify the mystery powder by comparing your observations of the mystery powder to your observations of the five known ingredients. Use this comparison of observations as evidence to support your claim. Be sure to review and reference (or cite) as much evidence as possible.

\section{COMMUNICATE}

You must share your findings with the class. Your job is to convince your classmates that you have accumulated enough evidence to confidently identify and label the mystery powder as one of the five possible baking ingredients.

\section{CLASS DISCUSSION QUESTIONS}

Scientists keep a notebook or journal to record and organize all observations and data collected during the research process.

Based on your experience with investigating the mystery powder...

1. Why is it important to make careful and detailed observations throughout an investigation?

2. Why is it important to keep observations neatly organized throughout an investigation?

3. Why is it important to use observations as evidence to support your conclusions when you share your findings with your classmates? 


\section{APPENDIX H: PROJECT-BASED SCIENCE ENGINEERING CHALLENGE}

\section{Engineering Deliciousness- The Cookie Challenge}

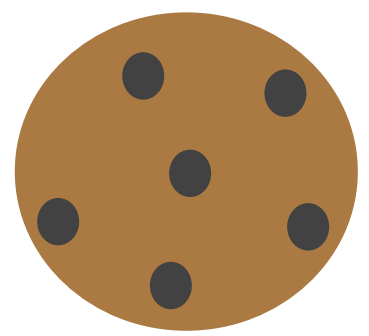

THE PROBLEM

In your own words, describe the problem you and your group members are trying to solve.

\section{THE CONSTRAINTS}

How was the perfect cookie described by the baker?

What product characteristics or qualities are you trying to produce?

How much time do you have to work on solving this challenge?

What materials do you have available to you?

Do you have a budget to purchase supplies?

Are there any safety concerns to think about throughout your investigation? 


\section{THE RESEARCH}

To meet this challenge, you will have to identify the type of ingredients that go into making chocolate chip cookies AND research the role of each ingredient. For example, why do you add baking soda to cookie batter? Also, you will need to be familiar with how to add these ingredients together and how to properly bake the cookie dough.

Let's review a couple of online videos to get you started.

\section{Cookie Science}

\section{Baking Cookies 101}

One person from each group should collect a folder of resources labeled "Research." Use these resources to complete the table and answer the questions.

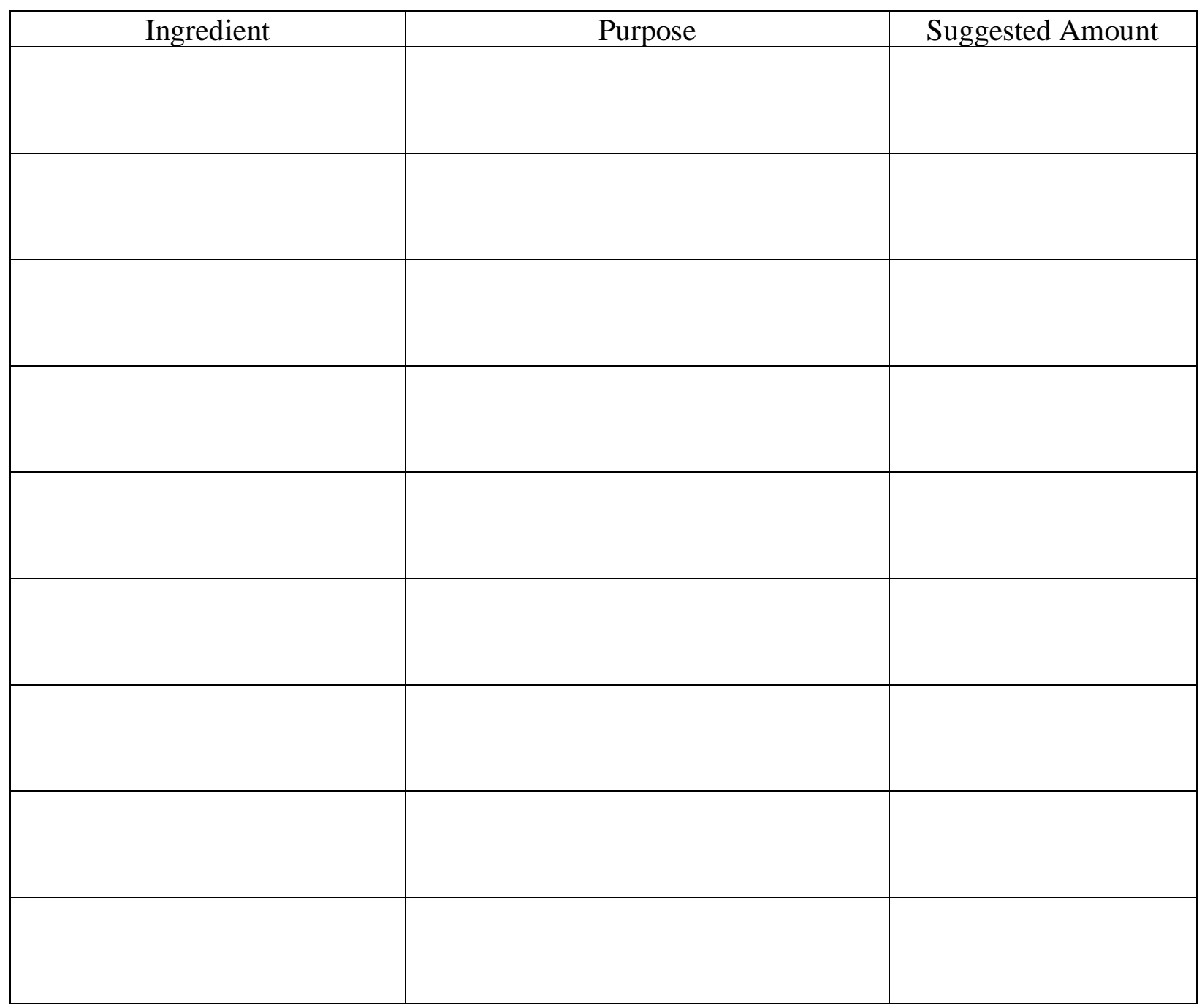


1. How does the temperature of the cookie dough affect the qualities of the baked cookie?

2. How does changing the temperature of the oven affect the qualities of the baked cookie?

\section{Notes}

Record any other interesting and/or helpful information you find out through your research. 
THE EXPERIMENT- an example

Look back at your vocabulary list and provide a definition for the following scientific terms:

Experiment-

Hypothesis-

Independent Variable

Dependent Variable

Watch the video and answer the following questions.

$\underline{\text { A Cookie Experiment }}$

1. How does the work presented in the video fit the description of a scientific experiment?

2. What was the scientist's hypothesis?

3. What was the independent variable?

4. What was the dependent variable?

5. What observations and/or measurements did the scientist make to form conclusions from the experiment? 
The Cookie Challenge project requires many scientists to work together to develop a recipe that produces a cookie with the desired qualities while working under the specified constraints. To do your part, your group must design and conduct an experiment, choosing one independent and one dependent variable. All groups will use the original Nestle Toll House chocolate chip cookie recipe as a control recipe. Your job is to change one variable to determine its effect on a cookie characteristic (just like the scientist did in the video). You will share the findings of your investigation with the class.

You must complete the following tasks in sequence in order to complete the project requirements and successfully contribute knowledge to the scientific and engineering community.

Task 1- Design an experiment. Share your design with the class.

Task 2- Develop a list of materials and a procedure in consideration of the problem constraints. Task 3- Create the prototype (in this case, your cookies).

Task 4- Collect and analyze data on your product.

Task 5- Report your findings in a shared online document.

\section{Group Members}

TASK 1- The Experiment

Complete the following information.

1. State your hypothesis.

2. What is your independent variable?

3. What is your dependent variable?

4. What observations/measurements do you plan to collect to gain information about your hypothesis?

*Once your experimental design is approved by one of the project supervisors, please add your information to the class data table. You will also be given the instructions for Task 2. 


\section{TASK 2-Creating a Material List within a Budget}

In order to stay under your budget of $\$ 5.00$, you must take your experiment recipe (which is the same as the control recipe with one variable changed) and scale it down. You will use half of each ingredient in your recipe. Once you figure out how much of each ingredient you need, you will have to figure out how much each ingredient costs. Then, you will add up the cost of each ingredient to get a total cost for your recipe. Use the Ingredient Price List to assist you in calculating costs. The deadline for completing this task is Friday, September 22.

\section{Example}

Scaling down...

The control recipe requires 2 sticks of butter. To scale the recipe down to half, you would use just one stick of butter.

Calculating cost...

One stick of butter is 8 tablespoons. Each tablespoon costs $\$ 0.19$ or 19 cents. The total cost for butter in the recipe would be $\$ 1.52$ (\$0.19 x 8 tbs.).

Complete the table.

\begin{tabular}{|c|c|c|c|c|}
\hline Ingredient & $\begin{array}{c}\text { Suggested } \\
\text { Amount }\end{array}$ & $\begin{array}{c}\text { Scaled Amount } \\
\text { (half of the amount) }\end{array}$ & $\begin{array}{c}\text { Cost of } \\
\text { Ingredient } \\
\text { per c., tsp. or tbs. }\end{array}$ & $\begin{array}{c}\text { Total Cost of } \\
\text { Ingredient }\end{array}$ \\
\hline Example: Butter & 2 sticks & 1 stick (8 tbs.) & $\$ 0.19$ per 1 tbs. & $\$ 1.52$ \\
\hline & & & & \\
\hline & & & & \\
\hline & & & & \\
\hline & & & & \\
\hline & & & & \\
\hline & & & & \\
\hline & & & & \\
\hline & & & & \\
\hline & & & & \\
\hline
\end{tabular}

Once your Material List and Budget have been given a stamp of approval by the project supervisors, you may move on to TASK 3-Creating the Prototype. 


\section{Cookie Ingredient Price List}

\begin{tabular}{|c|c|}
\hline Ingredient & Price/Unit \\
\hline All Purpose Flour & $\$ 0.14$ per 1 cup \\
\hline Cake flour & $\$ 0.36$ per 1 cup \\
\hline Cornstarch & $\$ 0.19$ per 1 tbs. \\
\hline Brown Sugar & $\$ 0.42$ per 1 cup \\
\hline White Sugar & $\$ 0.20$ per 1 cup \\
\hline Eggs & $\$ 0.05$ per egg \\
\hline Salt, fine & $\$ 0.02$ per $1 \mathrm{tsp}$. \\
\hline Salt, course & $\$ 0.03$ per $1 \mathrm{tsp}$ \\
\hline Butter & $\$ 0.19$ per 1 tbs. \\
\hline Margarine & $\$ 0.03$ per 1 tbs. \\
\hline Crisco & $\$ 0.06$ per 1 tbs. \\
\hline Vegetable Oil & $\$ 0.50$ per 1 cup \\
\hline Chocolate Chips (any variety) & $\$ 1.34$ per 1 cup \\
\hline Vanilla Extract & $\$ 0.41$ per $1 \mathrm{tsp}$ \\
\hline Imitation Vanilla & $\$ 0.16$ per $1 \mathrm{tsp}$ \\
\hline Baking Soda & $\$ 0.01$ per $1 \mathrm{tsp}$ \\
\hline Baking Powder & $\$ 0.05$ per $1 \mathrm{tsp}$ \\
\hline
\end{tabular}




\section{TASK 3- Creating a Prototype}

In engineering design, a prototype is an early model or sample of the product you are working to develop. For our cookie project, each group will bake a cookie that will serve as a prototype. Each group will study the qualitative and quantitative characteristics of their prototype (cookie). The information your group learns about your prototype will help the entire class create the final product.

For research purposes, you must document the process of making the prototype. Be sure to write out the procedure (directions) you followed to make your cookie dough and bake the cookies. The deadline for completing this task in Monday, September 25.

PROCEDURE- Preparing the dough

PROCEDURE- Baking the cookies 


\section{TASK 4- Collecting Data}

Now that you have created your cookie prototype, you must use observations and make measurements to describe its qualitative and quantitative characteristics.

You will need a ruler and your five senses to complete this task!

\begin{tabular}{|c|c|c|c|c|c|c|c|c|}
\hline & $\begin{array}{c}\text { Thickness } \\
\text { (Height) } \\
\text { cm }\end{array}$ & $\begin{array}{c}\text { Spread } \\
\text { (Diameter) } \\
\text { cm }\end{array}$ & Color & Smell & $\begin{array}{c}\text { Texture } \\
\text { Outside }\end{array}$ & $\begin{array}{c}\text { Texture } \\
\text { Inside }\end{array}$ & Crispness & Taste \\
\hline $\begin{array}{c}\text { Control } \\
\text { Cookie }\end{array}$ & & & & & & & & \\
\hline Prototype & & & & & & & & \\
\hline
\end{tabular}

Conclusion-Based on the data you collected, which cookie is a better product, the control cookie or your prototype? Be sure to review the statement of the problem and the cookie qualities you were trying to achieve. Support your answer using your data as evidence. The deadline for completing this task is Tuesday, September 26. 


\section{APPENDIX I: STUDENT SHARING OF DESIGN AND RESULTS}

TASK 1- Sharing Experimental Designs

\begin{tabular}{|c|c|c|c|}
\hline Mrs. $\overline{\text { Class }}$ & Hypothesis & $\begin{array}{l}\text { Independent } \\
\text { Variable }\end{array}$ & $\begin{array}{l}\text { Dependent } \\
\text { Variable }\end{array}$ \\
\hline Group 1 & $\begin{array}{l}\text { If we add an extra egg, it will make } \\
\text { the cookies softer. }\end{array}$ & \# of eggs & $\begin{array}{l}\text { Texture and } \\
\text { structure }\end{array}$ \\
\hline Group 2 & $\begin{array}{l}\text { If we increase the amount of brown } \\
\text { sugar and decrease the amount of } \\
\text { granulated sugar, then the cookie will } \\
\text { be chewier }\end{array}$ & Brown sugar & Texture \\
\hline Group 3 & $\begin{array}{l}\text { If we add more baking powder (and } \\
\text { take out baking soda), then the } \\
\text { cookies will rise more. }\end{array}$ & Baking powder & $\begin{array}{l}\text { Fluffiness and } \\
\text { texture }\end{array}$ \\
\hline Group 4 & $\begin{array}{l}\text { If we put less granulated sugar } \\
\text { (change } 3 / 4 \text { to } 1 / 2 \text { ), then it will create a } \\
\text { softer cookie }\end{array}$ & $\begin{array}{l}\text { Granulated } \\
\text { sugar }\end{array}$ & $\begin{array}{l}\text { Texture and } \\
\text { size }\end{array}$ \\
\hline Group 5 & $\begin{array}{l}\text { If we add } 1 / 2 \text { tsp of salt, then the } \\
\text { cookies will be sweeter. }\end{array}$ & Salt & Taste \\
\hline Group 6 & $\begin{array}{l}\text { If we add cornstarch, then the cookies } \\
\text { will get thicker and softer }\end{array}$ & Cornstarch & Texture \\
\hline
\end{tabular}




\begin{tabular}{|c|c|c|c|}
\hline Mrs. & Hypothesis & $\begin{array}{c}\text { Independent } \\
\text { Variable }\end{array}$ & Dependent Variable \\
\hline Group 1 & $\begin{array}{l}\text { If we add three cups } \\
\text { of flour, then the } \\
\text { cookies will get soft } \\
\text { and chewier. }\end{array}$ & Flour & Texture \\
\hline Group 2 & $\begin{array}{l}\text { If we use one cup of } \\
\text { brown sugar, then the } \\
\text { cookies will have } \\
\text { more flavor and will } \\
\text { be chewier. }\end{array}$ & Brown Sugar & $\begin{array}{l}\text { Texture } \\
\text { Flavor }\end{array}$ \\
\hline Group 3 & $\begin{array}{l}\text { If we use baking } \\
\text { powder instead of } \\
\text { baking soda, it will } \\
\text { make the cookies } \\
\text { fluffier. }\end{array}$ & Baking powder & Fluffier cookies \\
\hline Group 4 & $\begin{array}{l}\text { If we use milk } \\
\text { chocolate chunks } \\
\text { instead of semi-sweet } \\
\text { chocolate chips, the } \\
\text { cookie will have } \\
\text { more chocolate } \\
\text { flavor. }\end{array}$ & $\begin{array}{l}\text { Milk chocolate } \\
\text { chunks }\end{array}$ & Taste \\
\hline Group 5 & $\begin{array}{l}\text { If we use cake flour } \\
\text { instead of regular } \\
\text { flour, then our cookie } \\
\text { will be softer and } \\
\text { chewier. }\end{array}$ & Flour & Texture of the cookie. \\
\hline
\end{tabular}




\section{TASK 5- Sharing Results}

This project is based on the collaborative work of many scientists and engineers. You have been working alongside your peers to help solve Mrs. problem. It is very important that you share your findings with the entire community. Your results will help the project supervisors create a product that customers love and a cookie that meets Mr. approval.

\begin{tabular}{|c|c|}
\hline $\begin{array}{l}\text { Mrs. } \\
\text { Class }\end{array}$ & Evidence-based Conclusion \\
\hline Group 1 & \\
\hline Group 2 & $\begin{array}{l}\text { When we tasted are cookie we all came to an agreement that we thought are } \\
\text { cookie was better than the control. For are experiment we added more brown } \\
\text { sugar and less granulated sugar. We thought this would make are cookie more } \\
\text { chewy and spread out more and after baking the cookie it did more than just } \\
\text { spread and was chewy it was grunchy also had holes but it did get more hard } \\
\text { than we thought it would have. This makes me think that if you are going for a } \\
\text { good but different cookie you should try this }\end{array}$ \\
\hline Group 3 & $\begin{array}{l}\text { In conclusion putting baking powder instead of baking soda makes a fluffy and } \\
\text { chewy especially tasty cookie. When you make the cookies I totally suggest you } \\
\text { add lots of chocolate chips because it is a really good mixture with the } \\
\text { chewiness. It is just a plus to have a thick cookie for an extra yum factor. }\end{array}$ \\
\hline Group 4 & $\begin{array}{l}\text { In result we took out most of the granulated sugar and we put only } 1 / 4 \text {. so that } \\
\text { the caramelization process wouldn't make it crunchy.we found out that this was } \\
\text { a good move because they rose a lot and were chewy. We recommend this } \\
\text { cookie recipe because they were soft and more chewy than the nestle toll house } \\
\text { recipe. }\end{array}$ \\
\hline Group 5 & $\begin{array}{l}\text { We tested adding more salt because our hypothesis was it would give it more } \\
\text { flavor. But it just made it more salty it did add more flavor. Our suggestion is if } \\
\text { you add more salt you add more sugar to. }\end{array}$ \\
\hline Group 6 & $\begin{array}{l}\text { We added to make it more chewy and taller but it came out to be dry. The } \\
\text { cookie needed more chocolate chips. We should add about } 1 / 2 \text { more cups of } \\
\text { chocolate }\end{array}$ \\
\hline
\end{tabular}




\begin{tabular}{|c|c|}
\hline Mrs. & Evidence-based Conclusion \\
\hline Class & \\
\hline Group 1 & $\begin{array}{l}\text { According to our results, using three cups of flour created a taller cookie but it } \\
\text { was very floury. It did not spread. We would not recommend adding } \\
\text { additional flour. }\end{array}$ \\
\hline Group 2 & $\begin{array}{l}\text { According to our test, we would recommend using more brown } \\
\text { sugar. However, the protocol cookie was too moist and could not hold its } \\
\text { shape. We would recommend not using } 13 / 4 \text { cup but possibly a smaller } \\
\text { portion. The overall taste of the cookie was great:) }\end{array}$ \\
\hline Group 3 & $\begin{array}{l}\text { According to our test, we would recommend using baking powder to make the } \\
\text { perfect cookie. Our protocol cookie was fluffier and had less spread. They } \\
\text { were chewy with no crunchy edges. }\end{array}$ \\
\hline Group 4 & $\begin{array}{l}\text { According to our test, we would recommend using milk chocolate chips } \\
\text { instead of semi-sweet chips. The milk chocolate chips created a much sweeter } \\
\text { taste. However, the cookies had trouble holding their shape so we would } \\
\text { recommend not using a full cup. }\end{array}$ \\
\hline Group 5 & $\begin{array}{l}\text { According to our test, the cake flour did not hold the cookie's shape. We } \\
\text { would not suggest using cake flour for the perfect cookie. }\end{array}$ \\
\hline
\end{tabular}




\section{APPENDIX J: INSTITUTIONAL REVIEW BOARD (IRB) APPROVAL}

Research Ethics and Compliance

Campus Box 3330

Normal, IL 61790-3330

Phone: (309) 438-2529

rec@IllinoisState.edu

DATE: April 25, 2017

TO: Anthony Lorsbach

FROM: Illinois State University IRB

PROJECT TITLE: [1023509-2] NGSS Implementation at the Elementary School Level:

Supporting Practitioners in the Classroom

REERENCE \#:

SUBMISSION TYPE: Revision

ACTION: APPROVED

APPROVAL DATE: April 24, 2017

EXPIRATION DATE: April 24, 2018

REVIEW TYPE: Expedited Review

Thank you for your submission of Revision materials for this project. The Illinois State University IRB has APPROVED your submission. This approval is based on an appropriate risk/benefit ratio and a project design wherein the risks have been minimized. All research must be conducted in accordance with this approved submission.

This submission has received Expedited Review based on applicable federal regulations. Please remember that informed consent is a process beginning with a description of the project and insurance of participant understanding followed by a signed consent form. Informed consent must continue throughout the project via a dialogue between the researcher and research participant. Federal regulations require that each participant receives a copy of the consent document. Please note that any modification to previously approved materials must be approved by this committee prior to initiation. Please use the appropriate modification forms for this procedure. All UNANTICIPATED PROBLEMS involving risks to subjects or others (UPIRSOs) and SERIOUS and UNEXPECTED adverse events must be reported promptly to this office.

Please use the appropriate reporting forms for this procedure. All sponsor reporting requirements should also be followed. All NON-COMPLIANCE issues or COMPLAINTS regarding this project must be reported promptly to this office.

You must submit a continuation request and receive approval prior to continuing your research beyond this expiration date. Please use the appropriate forms for this procedure. The forms provide instructions and timelines according to review type. Your documentation for continuing review must be received within the designated time for review and continued approval before the expiration date of April 24, 2018. Please note that all research records must be retained for a minimum of three years after the completion of the project.

If you have any questions, please contact Research Ethics and Compliance at 309-438-2529 or rec@ilstu.edu. Please include your project title and reference number in all correspondence with this committee. 